

\section{Arts and Cultural Participation Among 17-Year-Olds}

Emer Smyth

November 2020

Research Series

Number 103

Available to download from ww.esri.ie and ww.artscouncil.ie

The Economic and Social Research Institute

Whitaker Square, Sir John Rogerson's Quay, Dublin 2

ISBN 978-0-7070-0517-1

https://doi.org/10.26504/rs103

(9) $\left(\begin{array}{c}0 \\ \text { in }\end{array}\right.$

This Open Access work is licensed under a Creative Commons Attribution 4.0 International License (https://creativecommons.org/licenses/by/4.0/), which permits unrestricted use, distribution, and reproduction in any medium, provided the original work is properly credited.

Cover photographs courtesy of Dublin Youth Theatre and Dublin Youth Dance Company. 
About the Arts Council

The Arts Council of Ireland is the Irish government agency for developing the arts. The Arts Council works in partnership with artists, arts organisations, public policymakers and others to build a central place for the arts in Irish life. 


\section{Foreword}

We are grateful to the ESRI and to Dr. Emer Smyth for her work on this report, which provides us with useful insights into the arts and culture in the lives of 17-year-olds. In the time since this research and analysis were carried out, the world has been grappling with a global pandemic, the impact of which continues to unfold. As we plan for young people's engagement with the arts, the challenges we have all faced this year remind us that young people's experiences and opportunities matter at all stages in their lives, as well as potentially impacting on later patterns, experiences and opportunities.

From Smyth's earlier analysis of arts and cultural participation among children, published by the Arts Council and ESRI in 2016, we learned about the levels of engagement of this same cohort of young people at ages nine and 13. The current research confirms that earlier involvement is strongly predictive of participation at a later age. However, it is not a sufficient condition for later engagement, and overall, the research points to a significant decline in participation as young people reach 17. This mirrors the decline in young people's engagement in other activities, including sports, over this period, and is particularly acute for those in their Leaving Certificate year.

Some participation in the arts is so ubiquitous that it receives only brief mention in the report. Listening to music is a common activity amongst all groups of young people - topping the list over and above surfing the internet or hanging out with friends. On the flipside, we see significant differentiation among young people who take up Leaving Certificate music, with much lower levels among the lowest-income groups. This appears to support other research that points to the relationship between doing well in music at Leaving Certificate and in higher education, and young people's access to out-of-school musical instrument tuition, which is largely paid-for.

The research presents interesting findings in relation to the arts in school. Despite the overall context of decline in participation between the ages of 13 and 17, the data regarding Transition Year and DEIS schools provide some positive news in terms of interventions and opportunities that enable young people to ignite or rekindle engagement in the arts in their teenage years. Transition Year brings a boost to participation. However, given that young people from more disadvantaged backgrounds are less likely to complete Transition Year, this widens the gap regarding the groups of young people that benefit. The counter to this is the emphasis placed on the arts within DEIS schools, where extracurricular arts provision is on a par with non-DEIS schools, and where young people report being more positive about the role their school has played in their appreciation of art and culture than 17-year-olds from similar backgrounds attending other schools. 
The research also provides some insight into young people's participation outside of school, including the time young people spend reading for pleasure, playing an instrument, and participating in structured cultural activities such as dance and drama. There is a decline in participation among young people in all of these activities in their teenage years, and participation is stratified socially and by gender. However, involvement in structured cultural activities does not vary significantly according to additional needs, family structure, migrant status or location. A similar profile of engagement emerges with reading for pleasure. This is useful information as the Arts Council implements our Equality, Human Rights and Diversity policy and seeks to ensure that the full diversity of Irish life is represented across our artistic and cultural community.

Following earlier patterns, girls remain more likely to participate in the arts than boys. This is also reflected in the perception of arts and culture among 17-year-olds. Overall, arts and culture were viewed by 17-year-olds as more important than religion and politics - though unsurprisingly, less important than some other areas such as family and friends. Girls - from the highest and lowest social class groups - placed more importance on the arts and culture than boys. Young people from more highly educated families also placed more importance on arts and culture; though less so among the highest income group.

A range of positive outcomes for children participating in the arts were noted in the earlier research among the infant and child cohorts from ages 3 to 5 and 9 to 13 . By age 17 , some similar benefits remain evident, but the findings become more nuanced. The longitudinal analysis from age nine to 17 shows that children who had read for pleasure more regularly when they were younger had a greater improvement in their vocabulary levels and academic performance over time. Involvement in music, drama lessons or clubs was also associated with higher Junior Certificate grades. However, no significant relationship was found with regard to non-cognitive outcomes, such as self-esteem or socio-emotional wellbeing, when the profile of those involved was taken into account. For 17-year-olds, the research shows that life satisfaction levels are higher where young people regularly make music, go to the cinema and are involved in music/drama clubs or lessons. Similar to the findings of earlier research, both life satisfaction and self-esteem are lower where young people play computer games regularly. 
All of these findings give us pause. How does the provision and perception of arts and cultural education and activities, at a time when young people are making pivotal choices in terms of their careers and further education, influence young people's participation in these activities? At the time of writing, after a disruption in young people's education and activities earlier in the year, young people's education and services are being prioritised in the Plan for Living with Covid 19. This priority extends to areas such as youth work and sport. However, young people who rely on arts education outside of school or youth work settings have found some of these activities curtailed. This has highlighted gaps in public provision in the area of arts education and services. For young people who find their voice and their safe space in the arts, and for those who wish to develop a career in this area, and who rely on classes outside of school for training and education, this has presented difficulties.

What impact can we expect from the increase in online engagement for young people's activities during Covid 19? Do young people continue to reap the benefits of structured cultural activities in terms of their wellbeing as well as cognitive development, when those activities move online? On the other hand, has the current year provided opportunities for young people to rediscover reading, or time to learn to play an instrument?

The research answers some questions and raises others. We must all seek to answer these pressing questions with young people, who are impacted by how we plan and provide for the arts - in both good times and bad.

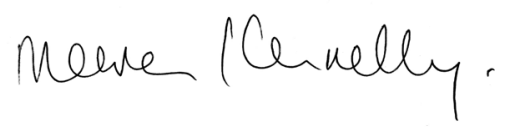

Maureen Kennelly,

Director, The Arts Council

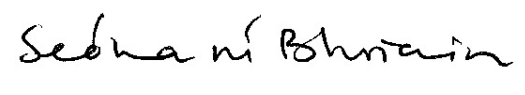

Seóna Ní Bhriain Head of Young People, Children and Education The Arts Council 


\section{About The ESRI}

The mission of the Economic and Social Research Institute is to advance evidencebased policymaking that supports economic sustainability and social progress in Ireland. ESRI researchers apply the highest standards of academic excellence to challenges facing policymakers, focusing on 12 areas of critical importance to $21 \mathrm{st}$ Century Ireland.

The Institute was founded in 1960 by a group of senior civil servants led by Dr T.K. Whitaker, who identified the need for independent and in-depth research analysis to provide a robust evidence base for policymaking in Ireland.

Since then, the Institute has remained committed to independent research and its work is free of any expressed ideology or political position. The Institute publishes all research reaching the appropriate academic standard, irrespective of its findings or who funds the research.

The quality of its research output is guaranteed by a rigorous peer review process. ESRI researchers are experts in their fields and are committed to producing work that meets the highest academic standards and practices.

The work of the Institute is disseminated widely in books, journal articles and reports. ESRI publications are available to download, free of charge, from its website. Additionally, ESRI staff communicate research findings at regular conferences and seminars.

The ESRI is a company limited by guarantee, answerable to its members and governed by a Council, comprising 14 members who represent a cross-section of ESRI members from academia, civil services, state agencies, businesses and civil society. The Institute receives an annual grant-in-aid from the Department of Public Expenditure and Reform to support the scientific and public interest elements of the Institute's activities; the grant accounted for an average of 30 per cent of the Institute's income over the lifetime of the last Research Strategy. The remaining funding comes from research programmes supported by government departments and agencies, public bodies and competitive research programmes.

Further information is available at www.esri.ie 


\section{The Author}

\section{Emer Smyth is a Research \\ Professor at the Economic and \\ Social Research Institute (ESRI) \\ and an Adjunct Professor at \\ Trinity College Dublin (TCD).}

\section{Acknowledgements}

This study has been commissioned by the Arts Council.

I am grateful for very helpful comments and suggestions from Seóna Ní Bhriain, Monica Corcoran and Toby Dennett. I would also like to thank an external reviewer and two ESRI reviewers as well as Helen Russell and Alan Barrett for their useful comments on the report.

The data for this report come from Waves 1 to 3 of Cohort '98 of the Growing Up in Ireland (GUI) survey. GUI has been funded by the Government of Ireland through the Department of Children and Youth Affairs (DCYA) in association with the Central Statistics Office (CSO) and the Department of Employment Affairs and Social Protection (DEASP). These data have been collected in accordance with the Statistics Act, 1993. The DCYA, CSO and DEASP take no responsibility for the views expressed or the outputs generated from the research undertaken on the GUI data. 


\section{Table Of Contents}

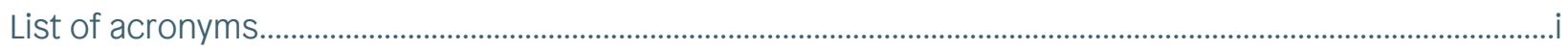

Executive summary............................................................................................................................................ii

Chapter 1: Introduction .....................................................................................................................................

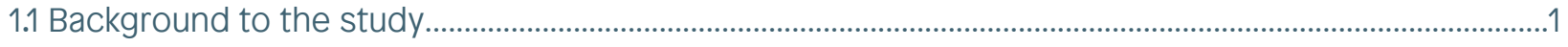

1.2 Previous research on cultural participation among young people

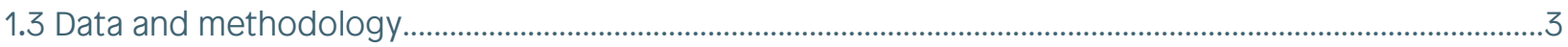

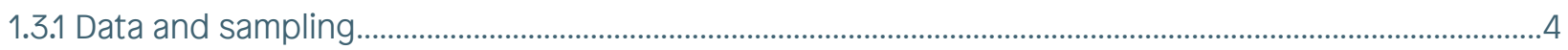

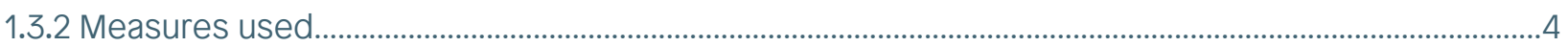

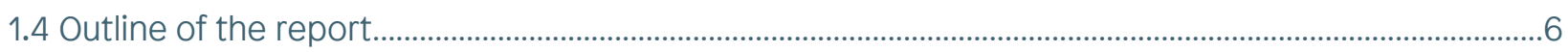

Chapter 2: Arts and cultural participation among 17-Year-Olds................................................................

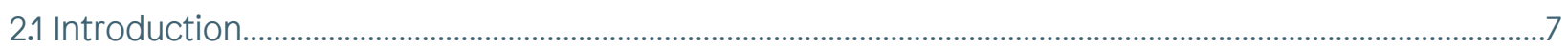

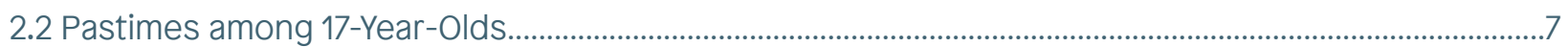

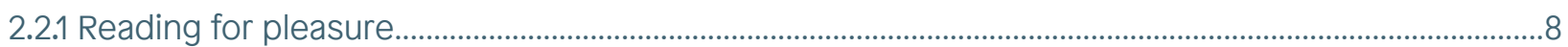

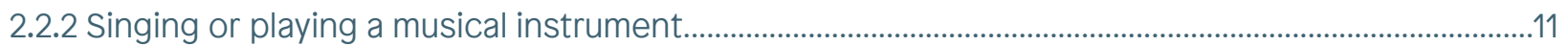

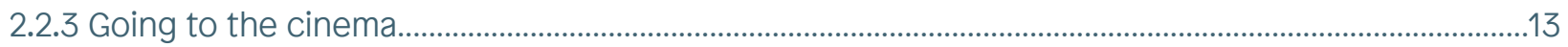

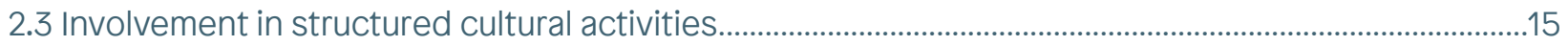

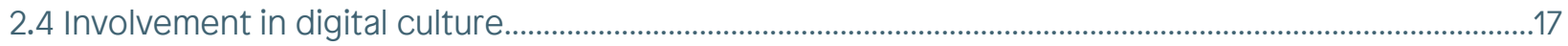

2.5 Perceived importance of art and culture

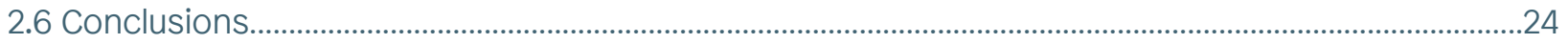

Chapter 3: Arts and cultural participation from nine to 17 years.............................................................25

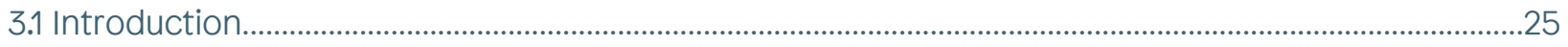

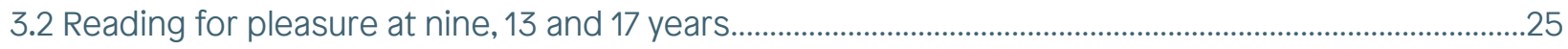

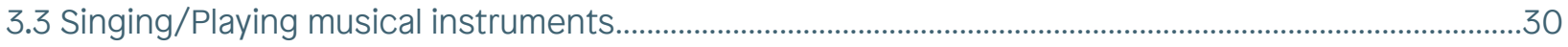




\section{Table Of Contents}

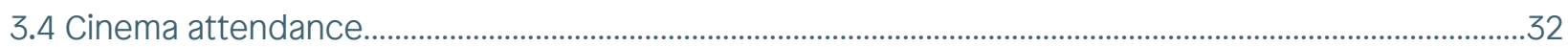

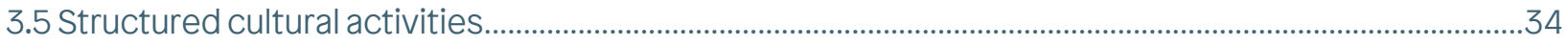

3.6 Involvement in digital culture

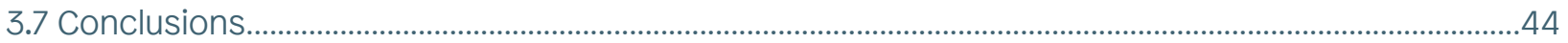

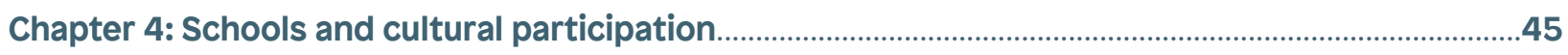

4.1 Introduction

4.2 School provision of curricular and extracurricular art and culture...........................................................45

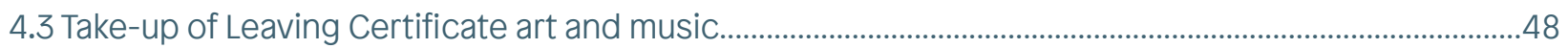

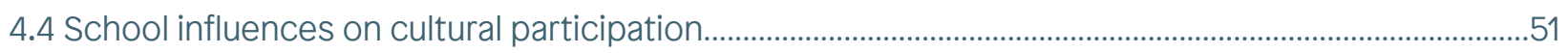

4.5 Conclusions

Chapter 5: Cultural participation and outcomes among young people

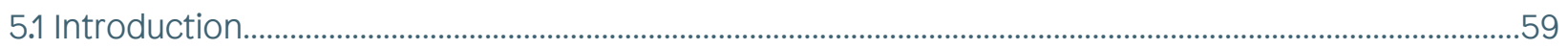

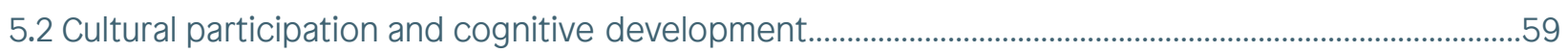

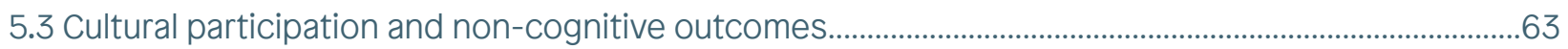

5.4 Conclusions.

Chapter 6: Conclusions

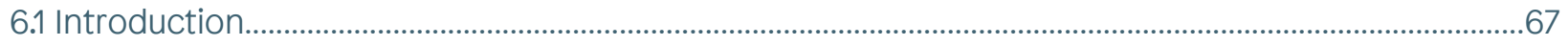

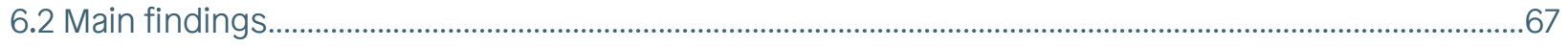

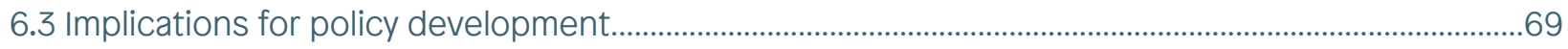

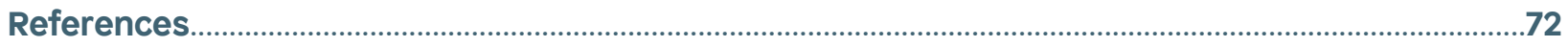




\section{List of Figures}

Figure 2.1 Frequency of involvement in cultural and social activities among 17-Year-Olds.

Figure 2.2 Frequency of reading for pleasure at least weekly at 17 years, by gender and social class.....9

Figure 2.3 Frequency of singing/playing an instrument at least weekly at 17 years, by gender and social class.

Figure 2.4 Frequency of going to the cinema at least monthly at 17 years, by gender and social class.

Figure 2.5 Proportion of 17-Year-Olds who engaged in structured cultural activities in the past year, by gender and social class.

Figure 2.6 Time spent per day on TV/films and computer games on a weekday and at the weekend among 17-Year-Olds.

Figure 2.7 Perceived importance of art and culture among 17-Year-Olds.

Figure 3.1 Proportion reporting 'never' reading for pleasure and average time spent reading at nine, 13 and 17 years..

Figure 3.2 Proportion reporting involvement in structured cultural activities and average time spent on these activities at nine, 13 and 17 years.

Figure 3.3 Proportion reporting 'never' watching TV/video/film and average time spent watching TV at nine, 13 and 17 years (weekday during term-time).

Figure 3.4 Proportion reporting 'never' playing computer games and average time spent playing at nine, 13 and 17 years (weekday during term-time)...

Figure 4.1 Proportion of young people attending a school that offers Leaving Certificate art or music, by school social mix, gender mix and size.

Figure 4.2 Proportion of young people attending a school that offers extracurricular choir, musical instrument tuition, drama or dance, by school social mix, gender mix and size.

Figure 4.3 Perceived benefits of second-level education among 17-Year-Olds 


\section{List of Tables}

Table 2.1 Logistic regression model showing the factors associated with reading for pleasure at least weekly among 17-Year-Olds (odds ratios).

Table 2.2 Logistic regression model of the factors associated with singing/playing an instrument at least weekly among 17 year olds (odds ratios).

Table 2.3 Logistic regression model of the factors associated with going to the cinema at least monthly among 17 -Year-Olds (odds ratios).

Table 2.4 Logistic regression model of the factors associated with participating in structured cultural activities among 17 year olds (odds ratios)......

Table 2.5 Logistic regression model of the factors associated with higher levels of time spent on TV/films on a week day and a weekend day among 17-Year-Olds (odds ratios).......

Table 2.6 Logistic regression model of the factors associated with higher levels of time spent on computer games on a week day and a weekend day among 17-Year-Olds (odds ratios).........20

Table 2.7 Linear regression model of the factors associated with perceived importance of art and culture among 17-year-olds.

Table 3.1 Proportion who never read for pleasure at nine, 13 and 17 years, by gender, mother's education, migrant status and SEN status......

Table 3.2 Relationship between reading for pleasure at least weekly at 17 years and involvement in cultural activities at nine and 13 years (logistic regression model showing odds ratios).....

Table 3.3 Relationship between singing/playing a musical instrument at least weekly at 17 years and involvement in cultural activities at nine and 13 years (logistic regerssion model showing odds ratios).....

Table 3.4 Relationship between going to the cinema at least monthly at 17 years and involvement in cultural activities at nine and 13 years (logistic regression model showing odds ratios)......

Table 3.5 Proportion involved in structured cultural activities at nine, 13 and 17 years by gender, mother's education, migrant status and SEN.

Table 3.6 Relationship between involvement in structured cultural activities (in the past year) at 17 years and involvement in cultural activities at nine and 13 years (logistic regression model showing odds ratios)

Table 3.7 Relationship between high levels of TV/film watching at 17 years and involvement in cultural activities at nine and 13 years (logistic regression model showing odds ratios).

Table 3.8 Relationship between high levels of computer gaming at 17 years and involvement in cultural activities at nine and 13 years (logistic regression model showing odds ratios)..... 


\section{List of Tables}

Table 4.1 Individual and school factors associated with take-up of Leaving

Certificate art and music (logistic regression models showing odds ratios)

Table 4.2 School factors associated with out-of-school cultural participation (set of logistic regression models showing odds ratios)...

Table 4.3 School factors associated with high levels of participation in digital culture (set of logistic regression models showing odd ratios)...

Table 4.4 School factors associated with 17 year olds feeling their second-level education was 'a lot' of help in appreciating reading for pleasure and art and culture (logistic regression models showing odds ratios)..

Table 4.5 School factors associated with 17 year olds' rating of the importance of art and culture for life in general (OLS regression model)

Table 5.1 Relationship between cultural activities at nine and 13 years of age and cognitive outcomes at 17 years of age (OLS regression models)

Table 5.2 Relationship between cultural activities and cognitive outcomes at 17 years of age (OLS regression models).

Table 5.3 Relationship between cultural activities at nine and 13 years of age and non-cognitive outcomes at 17 years of age (OLS regression models).

Table 5.4 Relationship between cultural activities and non-cognitive outcomes at 17 years of age (OLS regression models). 


\section{List of Acronyms}

\begin{tabular}{|c|c|}
\hline AMFs & Anonymised microdata files \\
\hline CSO & Central Statistics Office \\
\hline DCYA & $\begin{array}{l}\text { Department of Children and } \\
\text { Youth Affairs }\end{array}$ \\
\hline DEIS & $\begin{array}{l}\text { Delivering Equality of } \\
\text { Opportunity in Schools } \\
\text { programme }\end{array}$ \\
\hline GUI & Growing Up in Ireland \\
\hline ISSDA & $\begin{array}{l}\text { Irish Social Science Data } \\
\text { Archive }\end{array}$ \\
\hline LGBTI & $\begin{array}{l}\text { Lesbian, gay, bisexual, } \\
\text { transgender and intersex }\end{array}$ \\
\hline NCCA & $\begin{array}{l}\text { National Council for Curriculum } \\
\text { and Assessment }\end{array}$ \\
\hline OLS & Ordinary least Square \\
\hline SDQ & $\begin{array}{l}\text { Strengths and Difficulties } \\
\text { Questionnaire }\end{array}$ \\
\hline SEN & special educational need \\
\hline TY & Transition Year \\
\hline
\end{tabular}




\section{Executive Summary}

This report draws on information on the 6,216 17-year-olds who took part in the Growing Up in Ireland (GUI) longitudinal study to document their involvement in a range of cultural activities. The study adopts a broad definition of cultural participation, including: reading for pleasure; singing/playing a musical instrument; taking music/drama/dance lessons; going to the cinema; and involvement in digital culture (as measured by watching TV and playing computer games). ${ }^{1}$ Building upon previous research on these young people when they were nine and 13 years of age (Smyth, 2016), the study addresses three broad research questions:

1. How does cultural participation at 17 years of age vary by gender, family background, migrant status and having a special educational need (SEN)?

2. How do young people access the arts at school (on a curricular or extracurricular basis) and does this vary by type of school?

3. Does cultural participation have an impact on cognitive skills (such as vocabulary development and academic performance) and non-cognitive outcomes (such as self-esteem and socio-emotional wellbeing)?

The findings provide an important evidence base for arts and cultural policy relating to children and young people.

\section{Activities at 17 years of age}

The most common cultural activities in which young people engaged for fun or relaxation several times a week were listening to music (87\%), surfing the internet $(86 \%)$ and singing/playing a musical instrument (23\%). Less than one in six (14\%) of young people read for pleasure several times a week. Cinema attendance tended to be occasional rather than regular, although only one-fifth of these 17-year-olds said they never went to the cinema. In addition, almost one-quarter (23\%) had taken part in art, drama, dance or music clubs/groups/rehearsals in the year prior to the survey.

The vast majority of young people spent at least some time watching TV/films, with the proportion watching TV for two or more hours a day increasing from 19 per cent on weekdays to 37 per cent at the weekend. Less than half of young people played computer games regularly, with time spent on gaming also increasing from the weekday to the weekend ( $9 \%$ to $18 \%$ spending two or more hours per day).

1 Some aspects of cultural participation, such as drawing/painting or going to 


\section{Gender and social background differences in participation}

Marked gender differences were evident in relation to the type and level of arts and cultural participation, with young women much more likely than young men to read for pleasure, to make music (singing/playing an instrument) and to take part in structured cultural activities (such as music/drama clubs). They were much less likely than young men to spend time playing computer games. Participation was also highly differentiated by family socio-economic background, with those from professional/managerial or graduate families more likely to read, make music and participate in structured cultural activities, and less likely to be involved in digital culture (at least on weekdays). Cinema attendance emerged as the only cultural activity that was common across all social groups. In contrast to the situation at younger ages, no marked differences in participation were evident by migrant status or having a SEN.

\section{Pathways of participation}

The longitudinal nature of the GUI study allows for an analysis of the extent to which cultural participation changes between the ages of nine and 17 years. This can be captured on the basis of self-reports in the survey component as well as more specific reports of the time spent on various activities in the time-use diaries completed by the young people at nine, 13 and 17 years. The findings highlight a decline in all types of cultural participation as young people become older. There is a particularly large decline in reading for pleasure, with the proportion reporting not doing so increasing from 19 per cent at 13 years to 53 per cent at 17 years. The decline in some activities (such as music/drama clubs) was greater for those in their exam year and those who had already left school. Despite this decline, earlier involvement in cultural activities is strongly predictive of participation at 17. It therefore seems that involvement in middle childhood and adolescence is a necessary but not sufficient condition for cultural engagement as a young adult.

\section{Schools and cultural participation}

Most (83\%) of the 17-year-olds were still in second-level education, so school represented an important domain for accessing cultural activities on a curricular or extracurricular basis. Larger schools, fee-paying schools and single-sex girls' schools were more likely to offer art and music as subjects at Leaving Certificate level, as well as a broader range of extracurricular cultural activities (such as choir and musical instrument tuition). Young people's access to school-based cultural pursuits was therefore found to depend on the type of school they attended. Take-up of Leaving Certificate art and music was much higher among young women, with music being more frequently studied by those from more advantaged backgrounds. 
Those who had taken part in the Transition Year programme were much more likely to take art or music for their Leaving Certificate and to engage in making music or other structural cultural activities outside school, even taking account of their social background. Schools in the Delivering Equality of Opportunity in Schools (DEIS) programme were as likely as non-DEIS schools to provide extracurricular cultural activities; this appeared to reduce the gap in participation in structured activities. Young people who had attended DEIS schools were also more likely to place a strong emphasis on the importance of art and culture in their lives, all else being equal.

\section{Cultural participation and young people's outcomes}

The study looked at the relationship between earlier cultural participation (at nine and 13 years of age) and later cognitive development (vocabulary and Junior Certificate performance) and non-cognitive outcomes (such as self-esteem, selfefficacy and life satisfaction). Those who had read for pleasure more regularly when they were younger had a greater improvement in their vocabulary levels and academic performance over time. Involvement in music/drama lessons/clubs was also associated with higher Junior Certificate grades. These kinds of activities had little relationship with non-cognitive outcomes, such as self-esteem or socioemotional well-being, when the profile of those involved was taken into account. However, young people who spent three or more hours playing computer games (at age 13) had consistently poorer outcomes at 17; they had lower grades, poorer life satisfaction, lower self-esteem and greater socio-emotional difficulties, even taking account of a broad range of individual characteristics.

\section{Implications for policy development}

Arts and cultural participation among children and young people has been given increasing policy attention through initiatives like the Arts in Education Charter and the Creative Ireland programme. These findings therefore provide an important evidence base to inform the development and implementation of such policies. Perhaps the greatest challenge arising from the study findings is ensuring that all children and young people, regardless of their gender and social background, access arts and cultural activities. This is important in order to provide all children and young people with a variety of developmental and learning experiences. Furthermore, given the benefits of reading and involvement in structured cultural activities for cognitive development, there is a risk that existing patterns of cultural engagement will contribute to social inequalities in educational outcomes.

As participation patterns are established in middle childhood (or even younger), early intervention to support children's involvement in the arts and culture would appear crucial. In addition, the significant decline in arts involvement between 13 and 17 years suggests a need to focus attention on bolstering engagement at this crucial phase. 
Schools represent an important domain for access and exposure to the arts and culture. However, there is a risk that the pattern of curricular and extracurricular provision across different types of school will serve to reinforce gender and social variation in terms of access. Smaller schools face particular challenges in offering the full range of curricular and extracurricular cultural experiences, suggesting the potential for cross-school cooperation in provision and/or for an enhanced role for community-based provision in some contexts. DEIS schools appear to have made an active effort to provide their students with access to extracurricular cultural activities and have bridged some of the gap with non-DEIS schools in arts and cultural participation. Funding for such activities, through the School Completion Programme, for example, is crucial in achieving further progress in inclusive arts provision.

The TY programme emerges as a key vehicle in promoting cultural engagement and recognising the value of art and culture among participants. However, given lower levels of participation in TY among more disadvantaged groups, there is potential that take-up will further reinforce social differentiation in engagement. $A$ review of senior cycle is ongoing at the time of writing (NCCA, 2019; Smyth et al., 2019). Suggested options, such as short courses at senior cycle, could provide the flexibility to facilitate greater exposure to culture and creativity for a wider range of young people. Other suggestions around reducing the content of subject areas and/or moving away from an emphasis on exam-based assessment could lead to an improved balance between formal and informal learning opportunities.

The young people in this study were on the brink of the transition to further/higher education and the labour market. The pattern established by 17 years of age may set the tone for cultural engagement in adult life, making interventions to support this age group all the more important. The cohort described in this study have since been followed up at 20 years of age and are likely to be surveyed again in their twenties, offering the potential to examine the way in which cultural engagement in childhood, adolescence and early adulthood influences later adult outcomes. 


\section{Chapter 1 \\ Introduction}

\subsection{Background to the Study}

The subject of arts and cultural participation among children and young people has been receiving increasing policy attention in recent years through policy documents such as Better outcomes, brighter futures, the Arts in education charter and the Creative Ireland programme. The LGBTI+ national youth strategy (DCYA, 2018) also emphasises the importance of positive representation and participation in culture. However, until recently, there has been little evidence on the kinds of cultural activities engaged in by children and young people. Previous research using Growing Up in Ireland (GUI) data has pointed to the way in which cultural engagement among nine and 13 -year-olds varies by gender, family background and school experience (Smyth, 2016). This study builds upon this research to document the experiences of this cohort of 6,216 young people at 17 years of age. ${ }^{2}$

Much previous research on arts and cultural participation has focused on 'high culture' activities, including theatre, classical music and ballet attendance, going to visual arts exhibitions and reading for pleasure (see, for example, Chan and Goldthorpe, 2005; Lunn and Kelly, 2008). In contrast, several studies that focus on children and young people have adopted a more inclusive definition of cultural activities, encompassing not only attendance at performances but painting and drawing, watching TV and videos, and listening to (all kinds of) music (Harland et al., 1995; Robinson, 1999). From this perspective, digital technology has been increasingly recognised as an important aspect of cultural participation (Marsh et al., 2005; Edwards, 2014). This study adopts a similarly broad definition of arts and cultural participation, taking account of involvement in popular culture, including TV viewing and engagement in computer games, singing/playing a musical instrument, participation in music, dance and drama lessons, cinema attendance and reading for pleasure. While not designed as a specific survey of arts and cultural participation, GUI nonetheless provides rich insights into young people's engagement in a range of cultural activities. The study addresses three broad research questions:

1. How does cultural participation at 17 years of age vary by gender, family background and having a special educational need (SEN)?

2. How do young people access the arts at school (either on a curricular or extracurricular basis) and does this vary by type of school?

3. Does cultural participation impact on young people's cognitive skills (such as vocabulary development and academic performance) and non-cognitive outcomes (such as self-esteem and socio-emotional wellbeing)?

\footnotetext{
2 Because of timing of fieldwork, one-fifth of the sample were actually 18 years 
Section 1.2 contextualises the current research study in relation to previous literature on the topic. Section 1.3 describes the GUI data and measures used in greater detail, while Section 1.4 presents an outline of the report.

\subsection{Previous Research on Cultural Participation Among Young People}

Much of the research on cultural participation has focused on involvement in 'highbrow' culture among adults. Attendance at theatre, drama and visual arts exhibitions is typically found to be higher among those with higher levels of education and income and who are from a higher social class (see, for example, Chan and Goldthorpe, 2005). Chan and Goldthorpe (2005) used data from England, but similar patterns are evident in Ireland, with more highly educated groups attending arts events more frequently (Lunn and Kelly, 2008; Arts Council, 2018). Gender differences are evident among adults, with women more likely to go to plays, opera, ballet and art exhibitions and having somewhat higher levels of active participation (singing, dancing or playing a musical instrument). Younger people (those aged under 24) have higher rates of going to the cinema and rock/pop concerts than other age groups; rates of active engagement in making music are also somewhat higher among those aged under 34 years of age (Lunn and Kelly, 2008; Arts Council, 2018).

International research points to similar socio-economic differences in cultural participation among children and young people, patterns that have variously been attributed to parents encouraging (and paying for) their children to engage in highbrow cultural pursuits, regularly reading to their children, attending cultural events as a family and modelling particular activities or tastes (Bodovski and Farkas, 2008; Kloosterman et al., 2011; Kraykamp and Van Eijck, 2010; Nagel, 2010). Differences in cultural participation by social class and parental education have also been documented in the Irish context (Smyth, 2016). This 'concerted cultivation' (Lareau, 2003) is a way of enhancing children's academic and social development, promoting the kinds of skills and dispositions that are rewarded in the educational system and thus contributing to academic success. There is some evidence that parents' use of concerted cultivation is more pronounced among daughters than sons (Cheadle and Amato, 2010; Warner and Milkie, 2015; Smyth, 2016). The social and gender gap in cultural participation among adults is therefore, at least partly, related to differences in engagement in childhood and adolescence (Christin, 2012; Dumais, 2019). One study points to the way in which certain aspects of cultural participation become closely linked to gender identity and conforming to gendered norms during adolescence (Lagaert et al., 2017), although the size of the gender gap in participation has been found to vary across schools (Schmutz et al., 2016). As a result, males who take part in organised cultural activities are more likely to be bullied by their peers (Lehman and Dumais, 2017). 
Fewer studies look at how cultural participation changes over the early life course. Small-scale studies in Sweden and the Netherlands show a decline in the time spent reading over the teenage years (Johnsson-Smaragdi and Annelis Jönsson, 2006; van Schooten et al., 2005). However, a Dutch study shows relative stability in attendance at cultural performances between the ages of 14 and 25 years (Nagel, 2010), although a decline in reading for pleasure was observed between 14 and 19 years (Nagel and Verboord, 2012).

Participation in a range of different structured out-of-school activities, including organised sports, art or music classes, and school clubs, is found to be associated with improved cognitive development and higher academic achievement (Broh, 2002; Covay and Carbonaro, 2010; Fredericks and Eccles, 1996; Hallam, 2010). A large body of work indicates that parents reading to their children and older children reading themselves both have long-term benefits for cognitive development (see, for example, Kloosterman et al., 2011; Sullivan and Brown, 2013). Similar relationships between reading, involvement in structured cultural activities and cognitive development have been found among young children and adolescents in Ireland (Smyth, 2016). The evidence on the impact on non-cognitive skills is more mixed. Some studies report improved socio-emotional wellbeing (Mak and Fancourt, 2019a; Metsäpelto and Pulkkinnen, 2012) or self-esteem and life satisfaction (Mak and Fancourt, 2019b; Martin et al., 2013). However, other reviews of research (See and Kokotsaki, 2015) have pointed to the lack of a strong evidence base on the impact of arts education on non-cognitive development.

\subsection{Data and Methodology}

The GUI study was commissioned by the Department of Health and Children through the (then) Office of the Minister for Children, in association with the Department of Social Protection and the Central Statistics Office (CSO). The study has been carried out by a consortium of researchers led by the Economic and Social Research Institute (ESRI) and Trinity College Dublin (TCD). It focuses on two cohorts of children: a nine-month (infant) cohort (now called Cohort '08) and a nine-year-old (child) cohort (now called Cohort '98). While previous research focused on both cohorts (Smyth, 2016), this report documents the experiences of Cohort '98 at 17 years of age, using both survey and time-use data, placing these patterns in the context of their earlier participation at nine and 13 years. 


\subsubsection{Data and sampling}

Cohort '98 was first sampled through the primary school system in 2007 and early 2008. This sample was followed up in 2011-2012 when the young people were 13 years of age and again at 17 years of age (2015-2016). In this third wave, 6,216 young people completed the survey, representing 83 per cent of those who had participated at age 13 and 73 per cent of those who had participated at age nine. At each wave, detailed interviews were conducted with the primary and secondary caregivers. The child/young person completed questionnaires at Wave 1 and 2 but at 17 years of age, the focus shifted towards the young person as the main informant. At all three waves, children/young people completed a time-use diary for a given day. In it, they were asked to record the time spent on a set of specified activities in 15-minute intervals throughout a designated day. Information was also gathered from their school principal at each wave of the study. Analyses presented in this report are based on the anonymised microdata files (AMFs), which are provided by the Irish Social Science Data Archive (ISSDA) for research purposes and designed to prevent the identification of an individual or family.

The data for all waves have been re-weighted (statistically adjusted) to ensure that the information is representative of the population of children and young people in Ireland. In each chapter of this report, descriptive analyses of the main patterns are presented, followed by multivariate models designed to look at a number of factors simultaneously.

\subsubsection{Measures used}

The study adopts a broad view of arts and cultural participation, encompassing reading, cinema attendance, taking music or dance lessons, watching TV and using digital technology. The indicators examined vary somewhat across the ages of nine to 17 and are as follows:

$\hookrightarrow$ Frequency of reading for fun/pleasure (ages nine, 13 and 17);

$\hookrightarrow$ Participation in structured cultural activities (such as music or drama lessons (ages nine, 13 and 17);

$\hookrightarrow$ Listening to music as a way of relaxing (age 17);

$\hookrightarrow$ Singing/playing a musical instrument (age 17);

$\hookrightarrow$ Time spent watching TV and playing computer games (ages nine, 13 and 17), with 17-year-olds distinguishing between weekday and weekend involvement; and

$\hookrightarrow$ Take-up of art and music subjects at Leaving Certificate level (age 17). 
The time-use diary recorded information on the time spent on:

$\hookrightarrow$ Reading (ages nine, 13 and 17);

$\hookrightarrow$ Structured cultural activities (ages 13 and 17);

$\hookrightarrow$ Watching TV/film (ages nine, 13 and 17); and

$\hookrightarrow$ Playing computer games (ages nine, 13 and 17).

Information was collected from school principals on whether the school offered the subjects of art and music at Leaving Certificate level and provided specified cultural extracurricular activities.

GUI data provide very rich background information on the socio-economic circumstances of the children and their families, allowing for an analysis of the factors influencing arts and cultural participation. The individual and family variables used for analysis throughout this report are outlined below.

$\hookrightarrow$ Family social class: A social class classification, based on the Irish Census of Population measure, was assigned to both mother and father (where the latter was resident) based on their respective occupations at Wave 1 of the survey (when the child was nine years old). In line with standard procedures, a dominance approach (see Erikson, 1984) was used, whereby in two-parent families in which both partners were economically active outside the home, the family's social class group was assigned on the basis of the higher of the two. This approach provides a more accurate picture of the social position and resources of the family as a whole. A four-fold classification of family social class is used: professional/managerial; non-manual/skilled manual; semi-skilled/unskilled manual; and non-employed. In order to explore the potential interaction of gender and social class (see above), this is disaggregated between boys and girls.

$\hookrightarrow$ Family income: Total household income at Wave 3 was adjusted for household size and composition (number of adults and children) and grouped into quintiles (fifths).

$\hookrightarrow$ Mother's education: Based on educational level at Wave 1, the categories used are: Junior Certificate or less; Leaving Certificate; post-secondary; and degree (or higher). Among the GUI sample, mother's education and father's education are found to be closely related. As a result, mother's education is used in the analyses, as including father's education would result in missing data for those in loneparent families.

$\hookrightarrow$ Family structure: A two-fold classification of family structure is used: one-parent or two-parent.

$\hookrightarrow$ Immigrant status: A family is defined as being an immigrant family if both parents were born outside Ireland (or the sole parent if in a one-parent family).

$\hookrightarrow$ Special educational need: This is based on whether a child has a SEN, as reported by the teacher when the child was nine years.

$\hookrightarrow$ Urban/rural: This concerns whether the family is living in an urban or rural area. 
As well as looking at the influence of child and family characteristics on arts and cultural participation, the report also examines the relationship between cultural engagement and cognitive and non-cognitive outcomes for children and young people. The outcomes measures used are discussed in Chapter 5.

\subsection{Outline of the Report}

Chapter 2 provides an overview of cultural participation among 17-year-olds, including how it varies by gender and family characteristics. Chapter 3 draws on information collected at earlier waves of the study (at nine and 13 years of age) to look at trends over time in cultural participation and the extent to which earlier engagement shapes later involvement. Chapter 4 looks at school as an arena for access to curricular and extracurricular culture and examines whether out-ofschool cultural involvement is shaped by the type of school attended. Chapter 5 examines the relationship between cultural participation and cognitive and noncognitive outcomes, including Junior Certificate performance, self-esteem and socio-emotional difficulties. Chapter 6 provides a summary of the main findings and discusses the implications for policy development. 


\section{Chapter 2}

\section{Arts and Cultural Participation among 17-Year-Olds}

\subsection{Introduction}

This chapter provides an overview of the arts and cultural activities in which 17-yearolds engage. Section 2.2 looks at the frequency of involvement in different pastimes while the remainder of the section looks at the individual and family background factors associated with reading for pleasure, singing/playing a musical instrument and going to the cinema. Section 2.3 examines patterns of involvement in structured cultural activities (for example, music lessons or drama clubs) and the extent to which such participation varies by individual and family characteristics. Section 2.4 looks at involvement in digital culture, namely, watching TV/films and playing computer games, while Section 2.5 examines the perceived importance of art and culture, a question included for the first time in the survey administered at 17 years of age.

\subsection{Pastimes among 17-Year-Olds}

Young people were asked about the kinds of activities that they did 'regularly for fun or to relax' and how often they engaged in these activities. Figure 2.1 presents findings on a selection of these activities, placing arts and cultural activities against a backdrop of involvement in sports and other social activities. The most frequent activities were listening to music and surfing the internet, with almost four-fifths of young people engaging in these activities several times a week. In terms of other cultural activities, 23 per cent of young people sang or played a musical instrument several times a week, with a further 10 per cent engaging in these activities on a weekly basis. Over half (59\%) of young people never sang or played an instrument. Less than one in six (14\%) of young people read for pleasure several times a week while over half (53\%) said they never did so. Cinema attendance tended to be occasional rather than regular, though only one-fifth of the cohort never went to the cinema. The cultural activities of singing/playing an instrument and reading were somewhat less common than team sports or running/going to the gym but more frequent than going to clubs, pubs or parties. 


\section{Figure 2.1 Frequency of Involvement in Cultural and Social Activities among 17-Year-Olds}

LISTENING TO MUSIC

SURFING THE INTERNET

HANGING OUT WITH FRIENDS

TEAM SPORTS

GYM/RUNNING

SINGING/INSTRUMENT

READING FOR PLEASURE

INDIVIDUAL SPORT

CRAFTWORK/HOBBIES

PARTIES

CLUBS/PUBS

CINEMA

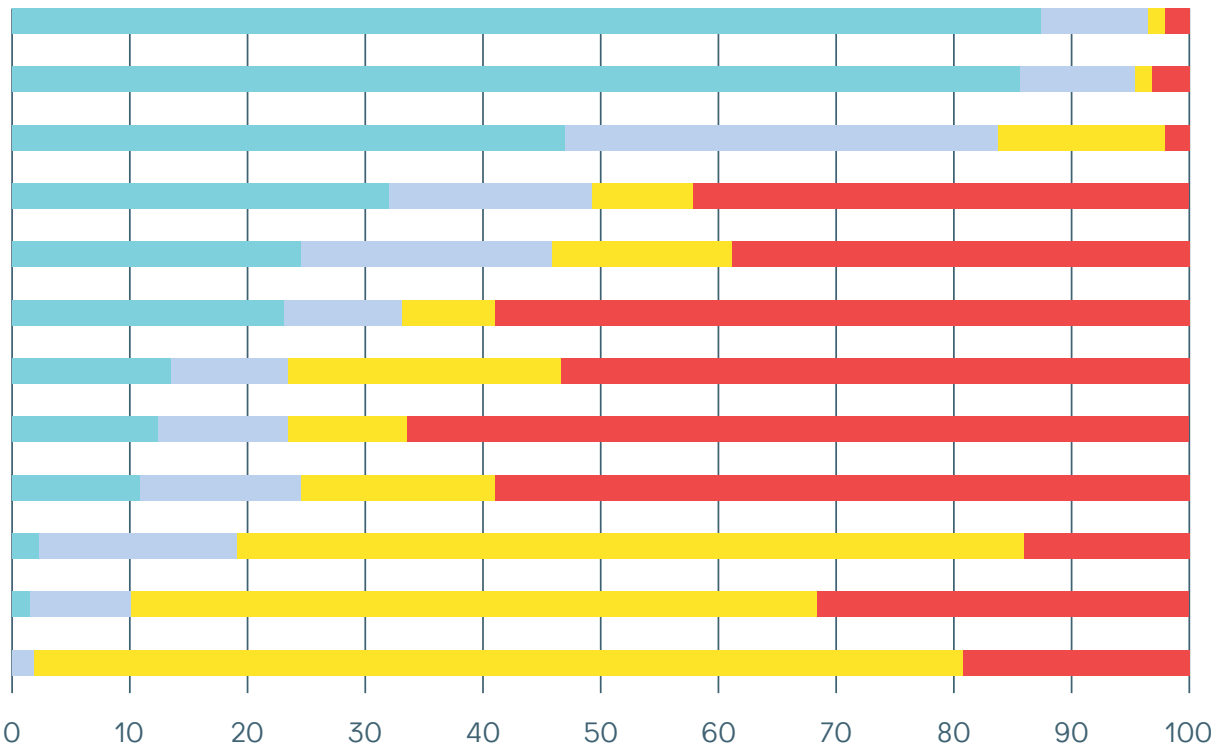

SEVERAL TIMES A WEEK

WEEKLY

LESS OFTEN

NEVER

Listening to music was a common activity among all groups of young people;

because of this lack of variation, it is not further analysed here. A significant minority of young people engaged in craftwork/hobbies on a frequent basis. However, the extent to which this category includes a broad range of activities (other than crafts) is unclear and so this is not analysed as a cultural activity in the remainder of the report. The rest of this subsection looks at the profile of young people who engaged in singing/playing an instrument, reading or going to the cinema on a regular basis. For singing/playing and reading, frequent engagement means at least weekly while for cinema, frequent engagement is taken to be at least monthly.

\subsubsection{Reading for pleasure}

Almost one-quarter of 17-year-olds read for pleasure at least weekly, but this overall pattern conceals considerable variation by gender and family background. There was a social gradient, albeit not a very pronounced one, among young women, with rates of reading for pleasure highest among those from professional/managerial families and lowest for those from non-employed families. Among young men, reading was more common for the professional/managerial group, with little systematic variation among the other class groups. ${ }^{3}$ Young women were much more likely to read frequently than young men, across all social class groups, though the difference was small for those from non-employed families. It is worth noting that, as at younger ages, reading for pleasure was almost as common among disadvantaged females as among the most advantaged males.

\footnotetext{
3 The patterns do differ across class groups but not in a linear fashion, with 


\section{Figure 2.2 Frequency of Reading for Pleasure at Least Weekly at 17 Years, by Gender and Social Class}

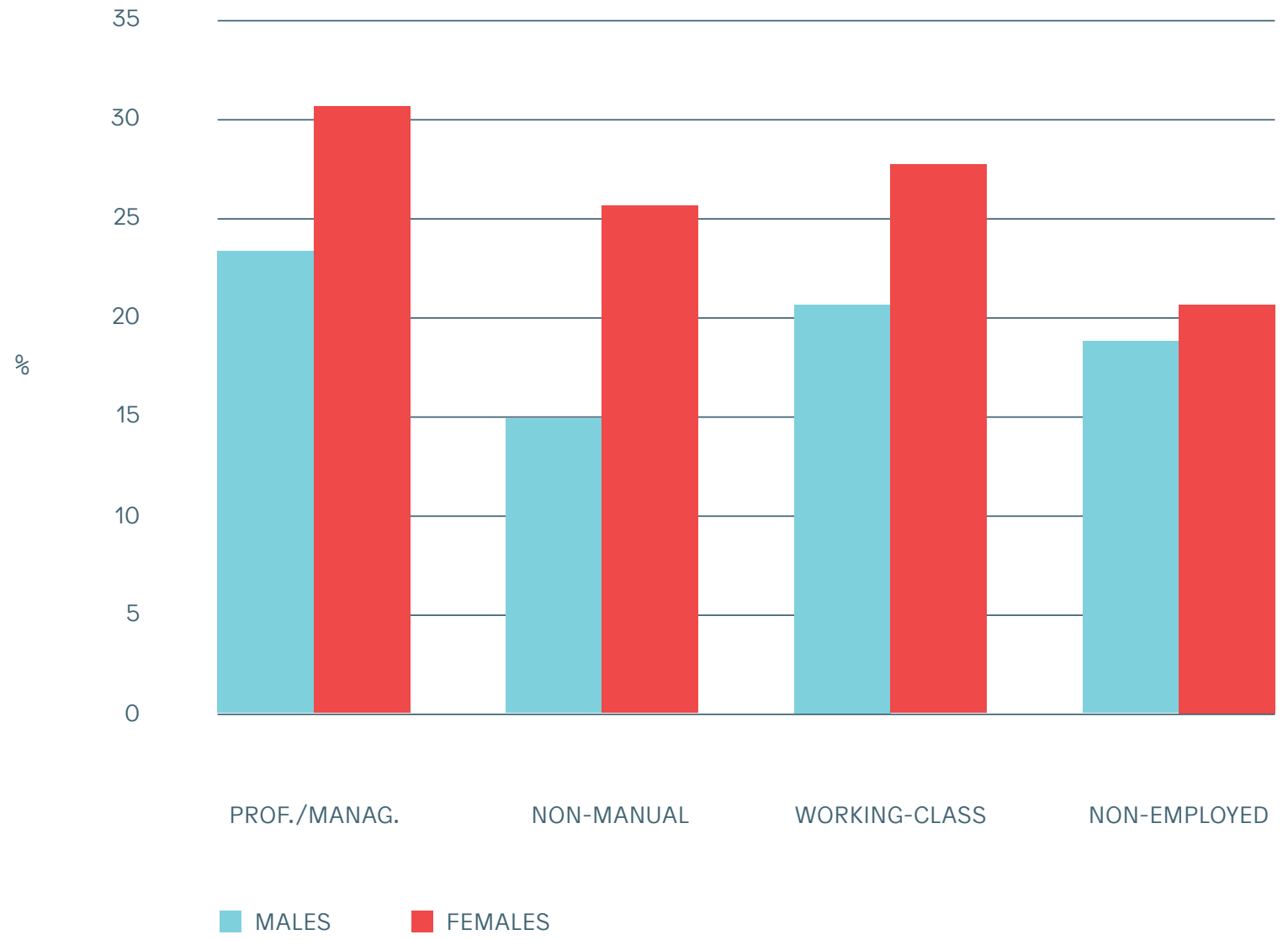

Table 2.1 shows the influence of social class and gender, as well as other family background characteristics, on reading for pleasure. Because the outcome is binary (that is, reading frequently or not), the coefficients represent odds ratios; for example, the odds of young people with graduate mothers reading regularly are 1.5 times higher than for those whose mothers have Junior Certificate or lower qualifications. Controlling for other factors, females from professional/managerial, non-manual or semi/unskilled manual backgrounds read more frequently than males from any social class and females from non-employed households. Over and above the effects of social class, those whose mothers have a post-secondary education or degree had much higher rates of reading for pleasure. There was no significant variation by migrant status, household income or whether the young person lives in an urban or rural area. The relationship between having a special educational need (SEN) and reading frequently or not was not significant. However, 17-year-olds with a SEN were more likely to report 'never' reading for pleasure (63\% compared with 52\%). Those from lone-parent families had slightly higher rates of reading than might be expected, given their profile. 
Table 2.1 Logistic Regression Model Showing the Factors associated with Reading for Pleasure at Least Weekly among 17-Year-Olds (Odds Ratios)

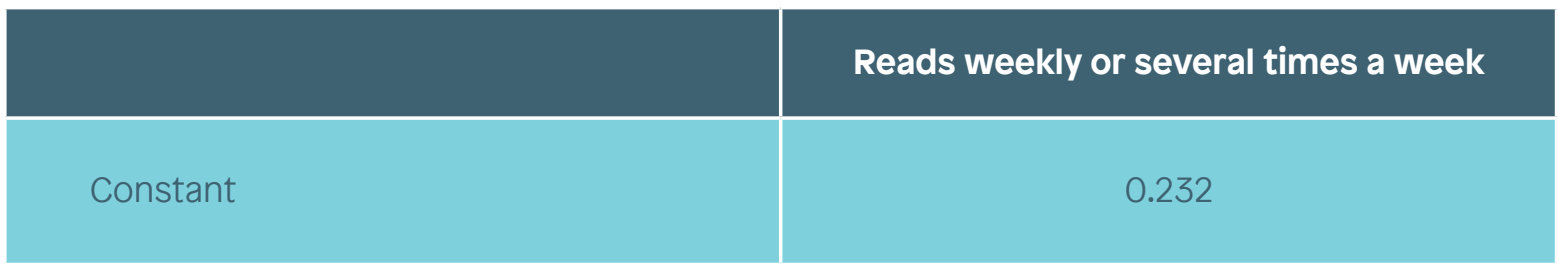

Social group:

Professional - female

Non-manual - male

Non-manual - female

Working-class - male

Working-class - female

Non-employed - male

Non-employed - female

(Ref.: Professional - male)

$1.428^{* * *}$

$0.640 * * *$

$1.312^{* * *}$

0.957

$1.454^{* *}$

0.752

0.928

Mother's education:

Leaving Certificate

Post-secondary

Degree or higher

(Ref.: Junior Certificate or less)

Income quintile:

Second

1.039

Third

1.054

Fourth

1.010

Highest

1.036

(Ref.: Lowest quintile)

Lone parent family

0.980

Immigrant background

1.205

Has special educational need

$1.195^{*}$

Lives in an urban area

1.014

N

5,972 


\subsubsection{Singing or playing a musical instrument}

As with reading for pleasure, significant gender differences are found in the frequency of singing/playing a musical instrument, with higher rates of involvement among females than males in all social groups (Figure 2.3). Among males, involvement did not vary markedly by social class, though this was slightly higher among those from professional/managerial backgrounds. For young women, involvement was highest among the professional/managerial group, with little systematic variation among the other groups. Table 2.2 shows that the scale of the gender gap is large, with the odds of young women from professional/managerial backgrounds singing/playing frequently being around twice those of their male peers from similar backgrounds. Over and above the effect of social class, those with graduate mothers were more likely to be involved in music on a frequent basis, but the other aspects of family background do not play a significant role here.

Figure 2.3 Frequency of Singing/Playing an Instrument at Least Weekly at 17 Years, by Gender and Social Class

50

45

40

35

30

$\%$

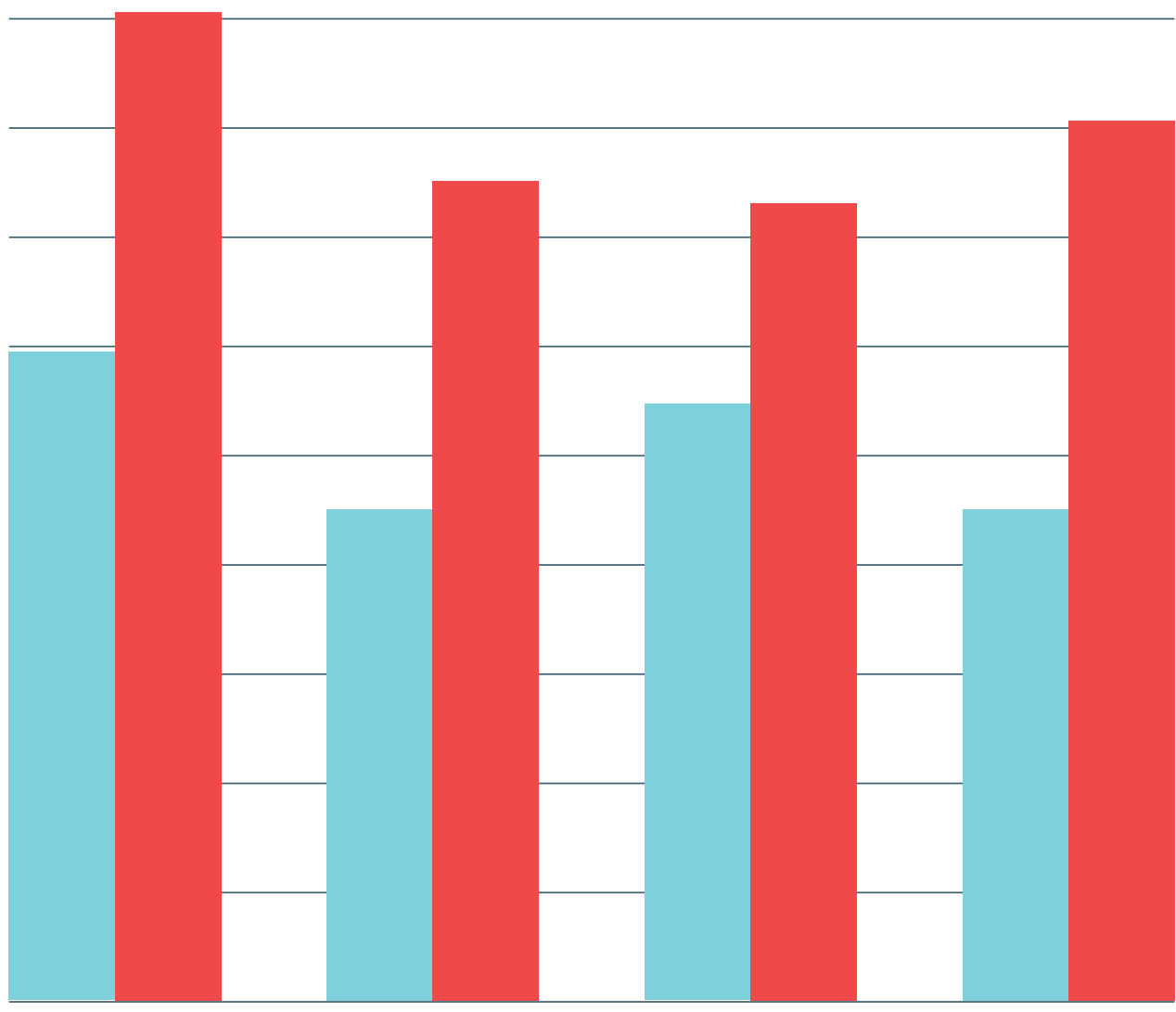


Table 2.2 Logistic Regression Model of the Factors Associated with Singing /Playing an Instrument At Least Weekly among 17-Year-Olds (Odds Ratios)

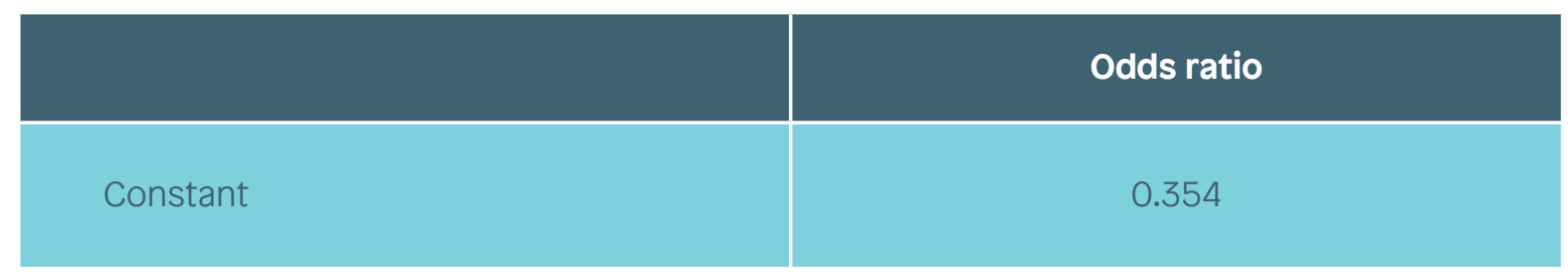

Social group:

Professional - female

Non-manual - male

Non-manual - female

Working-class - male

Working-class - female

Non-employed - male

Non-employed - female

(Ref.: Professional - male)

$1.991^{* * *}$

$0.772^{* *}$

$1.570 * * *$

1.005

$1.547^{* *}$

$0.715^{*}$

$1.732^{* * *}$

Mother's education:

Leaving Certificate $\quad 0.966$

Post-secondary $\quad 0.974$

Degree or higher $1.371^{* *}$

(Ref.: Junior Certificate or less)

Income quintile:

Second

Third

Fourth

Highest

1.112

1.084

(Ref.: Lowest quintile)

1.028

Lone parent family

0.980

Immigrant background

1.000

Has special educational need

0.921

Lives in an urban area

1.014

N

5,972 


\subsubsection{Going to the cinema}

Going to the cinema at least monthly was not as socially differentiated as reading for pleasure and singing/playing an instrument (Figure 2.4), though rates of attendance were much lower among males from non-employed households than among other groups. The gender gap was also small, except for the non-employed group where female rates of attendance were much higher than among males. Other factors play little role, though cinema attendance was higher among those from lone-parent families or whose mothers have Leaving Certificate qualifications. Not surprisingly, given variation in cinema location, rates of attendance were much higher in urban areas (Table 2.3).

Figure 2.4 Frequency of Going to the Cinema at least Monthly at 17 Years, by Gender and Social Class

60

50

40

$\%$

30

20

10

0

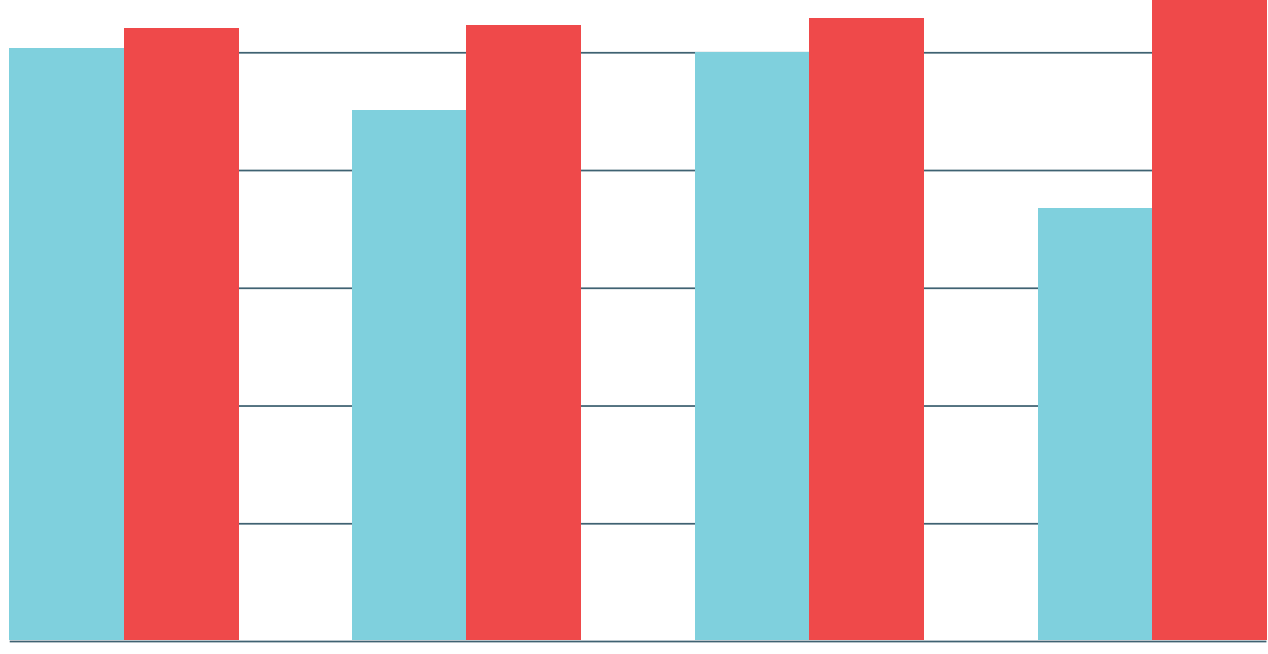

PROF./MANAG.

NON-MANUAL

WORKING-CLASS

NON-EMPLOYED 
Table 2.3 Logistic Regression Model of the Factors Associated with Going to the Cinema At Least Monthly among 17-Year-Olds (Odds Ratios)

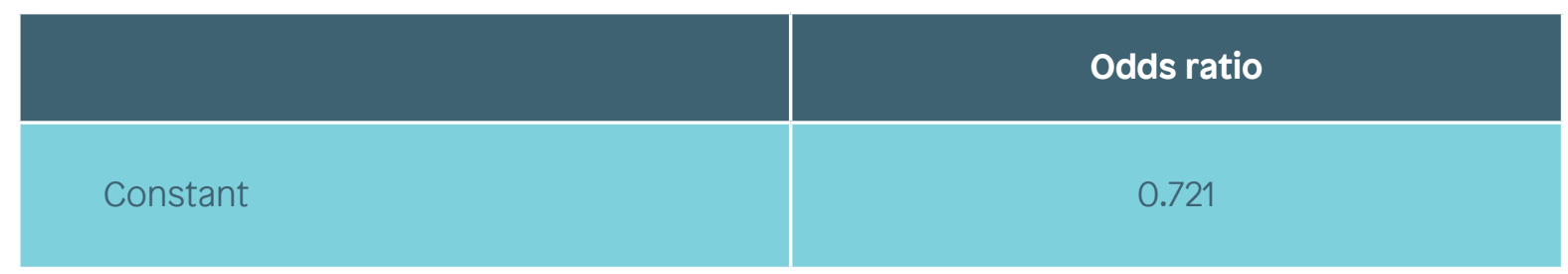

Social group:

Professional - female

1.064

Non-manual - male

0.855

Non-manual - female

1.152

Working-class - male

1.073

Working-class - female

1.143

Non-employed - male

$0.588^{* * *}$

Non-employed - female

1.202

(Ref.: Professional - male)

Degree or higher

(Ref.: Junior Certificate or less)

Income quintile:

second

Third

1.015

1.196

1.086

Fourth

1.102

Highest

(Ref.: Lowest quintile)

Lone parent family

$1.172^{*}$

Immigrant background

0.873

Has special educational need

0.925

Lives in an urban area

$1.528 * * *$

N

5,972 


\subsection{Involvement In Structured Cultural Activities}

As well as being asked about activities they engaged in to have fun or relax, 17-yearolds were asked about whether they had taken part in 'art, drama, dance or music clubs/groups/rehearsals' in the year prior to the survey. Almost one-quarter (23\%) reported such involvement, compared to the higher figure of 56 per cent for sports clubs/teams. As at nine and 13 years of age, there were marked gender differences in participation in all groups, except those from non-employed households. Among females, there was a social gradient in participation, with the highest rates found among the professional/managerial group (36\%) and the lowest among the nonemployed households (17\%). In contrast, male participation levels varied much less by social background. Over and above the effects of social class, young people with more highly educated mothers were more likely to participate, with the odds among those with graduate mothers being 2.1 times higher than for those whose mothers have Junior Certificate qualifications at most (Table 2.4). Participation was somewhat lower among the second lowest income group, but there is little systematic variation by household income. Involvement in structured cultural activities did not vary by SEN, family structure, migrant status or location.

\section{Figure 2.5 Proportion of 17-Year-Olds Who Engaged in Structured Cultural Activities in the Past Year, by Gender and Social Class}

40

35

30

$\%$

25

20

15

10

MALES

FEMALES

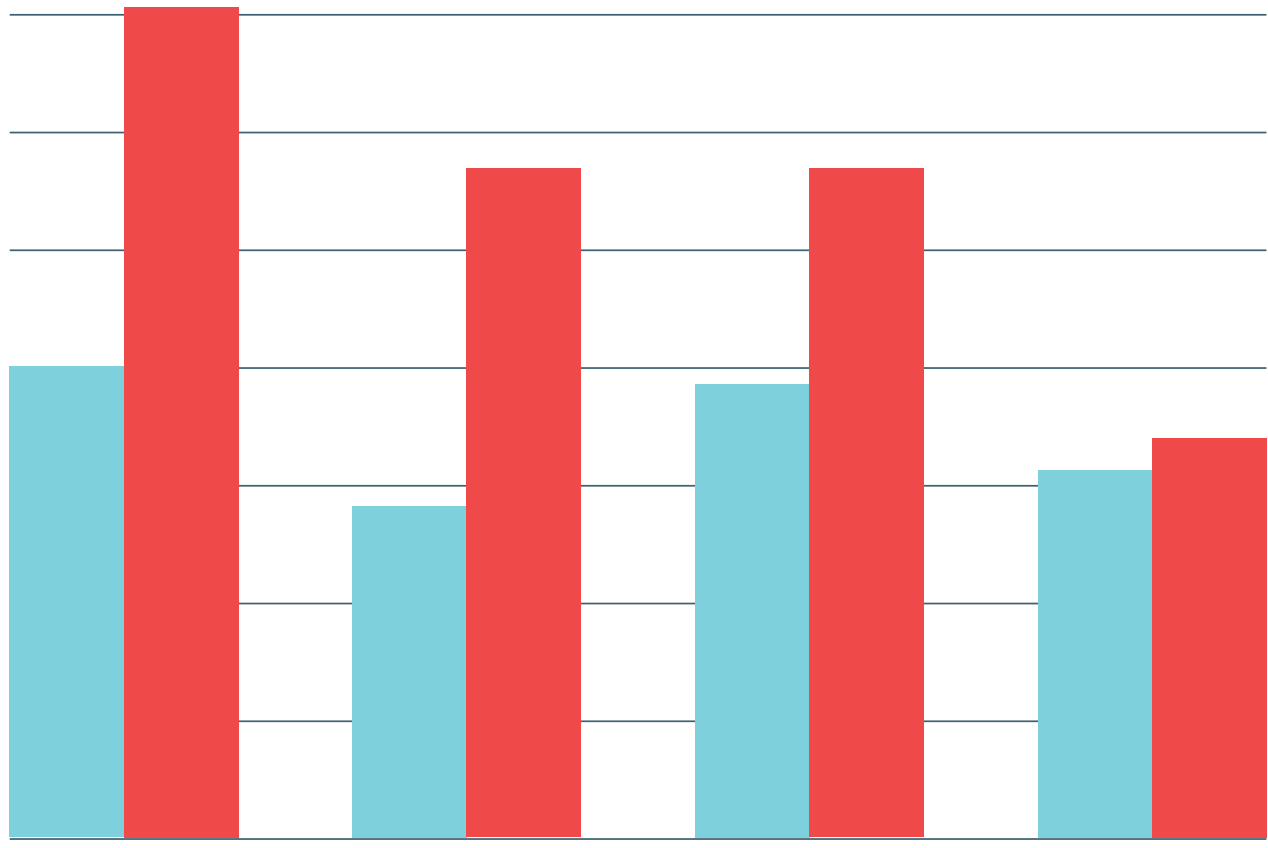

PROF./MANAG.

NON-MANUAL

WORKING-CLASS

NON-EMPLOYED 
Table 2.4 Logistic Regression Model of the Factors Associated with Participating in Structured Cultural Activities among 17-Year-Olds (Odds Ratios)

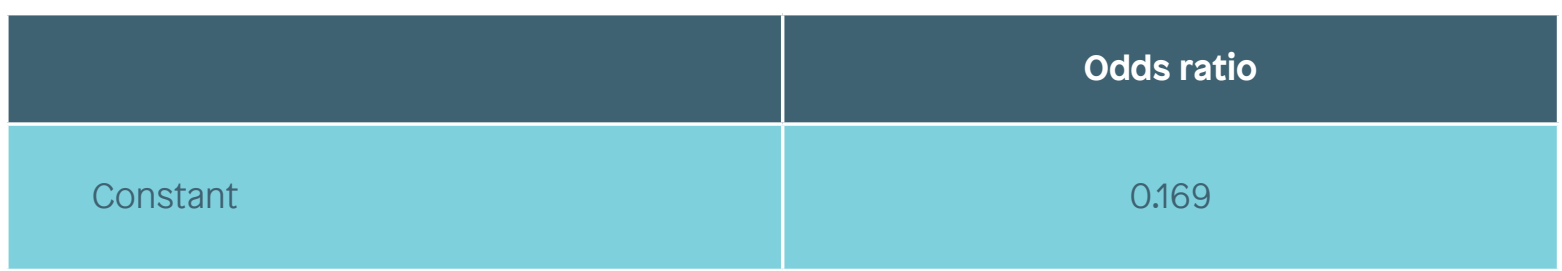

Social group:

Professional - female

Non-manual - male

Non-manual - female

Working-class - male

Working-class - female

Non-employed - male

$2.288^{* * *}$

0.843

$2.062^{* * *}$

1.266

$2.037^{* * *}$

Non-employed - female

0.937

(Ref.: Professional - male)

1.016

Mother's education:

Leaving Certificate

Post-secondary

$1.281^{* *}$

$1.589 * * *$

Degree or higher

$2.144^{* * *}$

(Ref.: Junior Certificate or less)

Income quintile:

Second

Third

$0.742 *$

1.051

Fourth

0.800

Highest

1.000

(Ref.: Lowest quintile)

Lone parent family

0.980

Immigrant background

1.113

Has special educational need

0.899

Lives in an urban area

1.007

N

5,972 


\subsection{Involvement in Digital Culture}

Analyses of young people's out-of-school activities at the ages of nine and 13 indicated the importance of digital culture in their lives. As noted in Section 2.2, surfing the internet was one of the most common pastimes among 17-year-olds. Other survey responses revealed that a good deal of internet usage related to cultural activities; 90 per cent used the internet to watch movies, 89 per cent used it to listen to music and 39 per cent used it to play games. Using the internet in general and for cultural activities is not analysed further in this report because of high levels of involvement across all groups. Instead, the analysis of digital culture in this report focuses on the amount of time spent watching TV/films and playing computer games. The vast majority of young people spent at least some time watching TV, especially at the weekend (Figure 2.6). They spent longer on this activity at the weekend, with the rates watching for two or more hours daily almost doubling (from $19 \%$ to $37 \%$ ). A significant number of young people - over half - spent no time on computer games. At the other extreme, almost one-tenth spent two or more hours during the week, with this figure rising to almost one-fifth (18\%) at weekends.

\section{Figure 2.6 Time Spent Per Day on TV/Films and Computer Games} on a Weekday and at the Weekend among 17-Year-Olds

70

60

50

40

$\%$

30

20

10

0

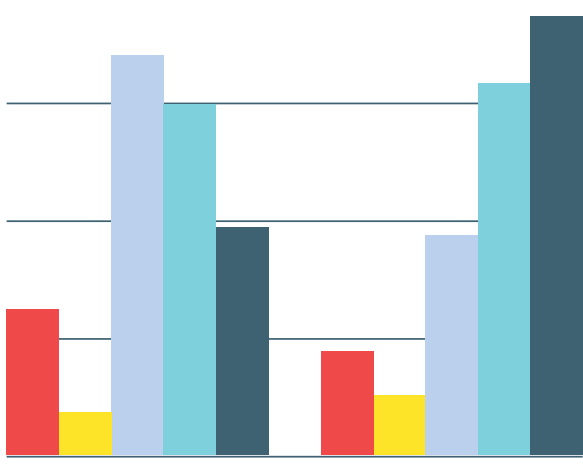

WEEKDAY

WEEKEND

TV

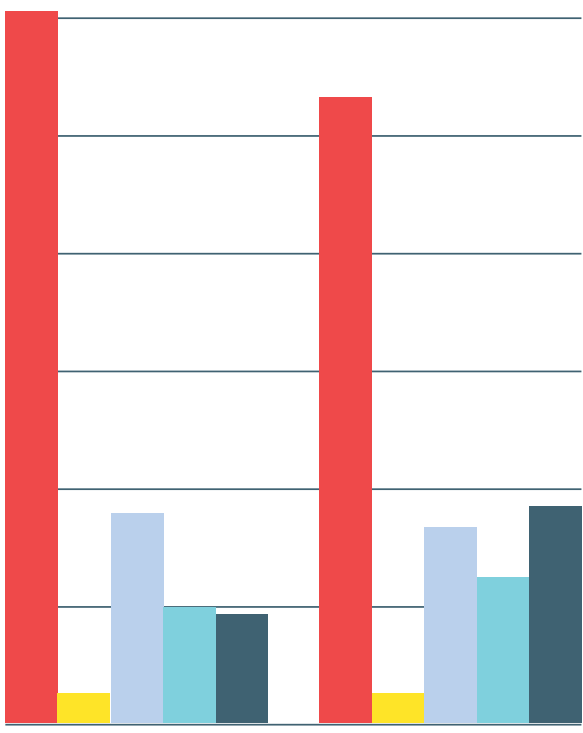

WEEKDAY

WEEKEND

COMPUTER GAMES 
Table 2.5 Logistic Regression Model of the Factors Associated with Higher Levels of Time Spent on TV/Films on a Weekday and a Weekend Day among 17-Year-Olds (Odds Ratios)

\begin{tabular}{|c|c|c|}
\hline & Weekday & Weekend \\
\hline Constant & 0.247 & 0.474
\end{tabular}

Social group:

\begin{tabular}{l|l|l} 
& & \\
Professional - female & 0.998 & $1.201^{*}$ \\
Non-manual - male & $1.262^{*}$ & 1.012 \\
Non-manual - female & $1.518^{* * *}$ & $1.305^{* *}$ \\
Working-class - male & 1.237 & 1.205 \\
Working-class - female & $1.364^{*}$ & $1.298^{*}$ \\
Non-employed - male & $1.475^{*}$ & 1.049 \\
Non-employed - female & 1.192 & 1.224 \\
(Ref.: Professional - male) & &
\end{tabular}

Mother's education:

Leaving Certificate

$\begin{array}{ll}0.927 & 1.215^{* *} \\ 0.790^{*} & 1.124 \\ 0.643^{* * *} & 0.994\end{array}$

Degree or higher

$0.643^{* * *}$

0.994

(Ref.: Junior Cert or less)

Income quintile:

Second

Third

0.936

1.123

Fourth

0.892

0.958

Highest

0.917

1.125

(Ref.: Lowest quintile)

$0.633^{* *}$

0.692

Lone parent family

Immigrant background

Has SEN

Lives in an urban area

N

$1.201^{*}$

0.966

1.164

0.869

$1.215^{*}$

0.956

0.914

0.971 
High levels of TV/film watching during the week were more prevalent among young people whose parents have lower levels of education; the patterns by social class are more complex but TV viewing was somewhat lower among the more advantaged professional/managerial group (Table 2.5). During the week, those from higherincome families watched less TV while those from lone-parent households or those with a SEN were more likely to watch TV for two or more hours per day. The pattern at the weekend was less differentiated by family background, with higher rates among young women (except for the non-employed group). The difference in the patterns of weekday and weekend screen-time may reflect more time spent on homework/study during the week among more advantaged groups. 
Table 2.6 Logistic Regression Model of the Factors Associated with Higher Levels of Time Spent on Computer Games on a Weekday and a Weekend Day among 17-Year-Olds (Odds Ratios)

\begin{tabular}{|c|c|c|}
\hline & Weekday & Weekend \\
\hline Constant & 0.743 & 1.106
\end{tabular}

Social group:

\begin{tabular}{l|l|l} 
& & \\
Professional - female & $0.116^{* * *}$ & $0.066^{* * *}$ \\
Non-manual - male & 1.190 & 0.879 \\
Non-manual - female & $0.162 * * *$ & $0.082^{* * *}$ \\
Working-class - male & $1.393^{*}$ & 0.893 \\
Working-class - female & $0.187^{* * *}$ & $0.119 * * *$ \\
Non-employed - male & $1.309 \pm$ & 0.709 \\
Non-employed - female & $0.327^{* * *}$ & $0.180 * * *$ \\
(Ref.: Professional - male) & &
\end{tabular}

Mother's education:

Leaving Certificate

$\begin{array}{ll}0.914 & 0.983 \\ 0.696^{* *} & 0.832 \\ 0.769^{*} & 0.866\end{array}$

Degree or higher

$0.769 * \quad 0.866$

(Ref.: Junior Cert or less)

Income quintile:

Second

Third

Fourth

$0.741^{*}$

0.933

Highest

$0.598 * * *$

0.872

(Ref.: Lowest quintile)

0.762 *

Lone parent family

1.020

0.915

\begin{tabular}{l|c|c} 
Immigrant background & $1.320^{*}$ & $1.508^{* * *}$ \\
Has SEN & $1.310^{* *}$ & 1.095 \\
\hline Lives in an urban area & $1.278 * *$ & $1.161^{*}$
\end{tabular}

N 
There was a striking gender difference in engagement in computer games, with particularly low levels of involvement among young women from professional/ managerial backgrounds (Figure 2.6 and Table 2.6). Among males, weekday participation was somewhat higher among semi/unskilled manual and non-employed groups than among their advantaged peers, but this difference was not evident in terms of weekend involvement. Levels of participation on a weekday were lower among more educated groups and those from higher-income families, the latter also having lower levels of weekend engagement. Young people from immigrant backgrounds and those living in urban areas were more likely to spend more than one hour per day on computer games than their peers. Young people with a SEN were more likely to do so on a weekday, but the weekend patterns for this group were similar to those for young people without a SEN.

\subsection{Perceived Importance of Art and Culture}

The 17-year-olds were asked about the perceived importance of different domains of their life, including family and friends, politics, religion and art and culture. They were asked to rate each domain from one ('not important at all') to six ('very important'). Responses in relation to art and culture were mainly around the middle of the distribution (three), with 15 per cent rating art and culture as 'not important at all' and eight per cent rating them as 'very important' (Figure 2.7). With an average rating of 3.2 (out of six), art and culture were rated as less important than parents and siblings (5.7), health, friends and acquaintances, one's own family and children, education, free time/relaxation, profession/work, partnership (4.2) and engagement in associations/organisation (4.0). However, art and culture were rated more highly by 17-year-olds than religion (2.7) and politics (2.6).

\section{Figure 2.7 Perceived Importance of Art and Culture Among 17-Year-Olds}

30

25

20

$\% \quad 15$

10

5

0

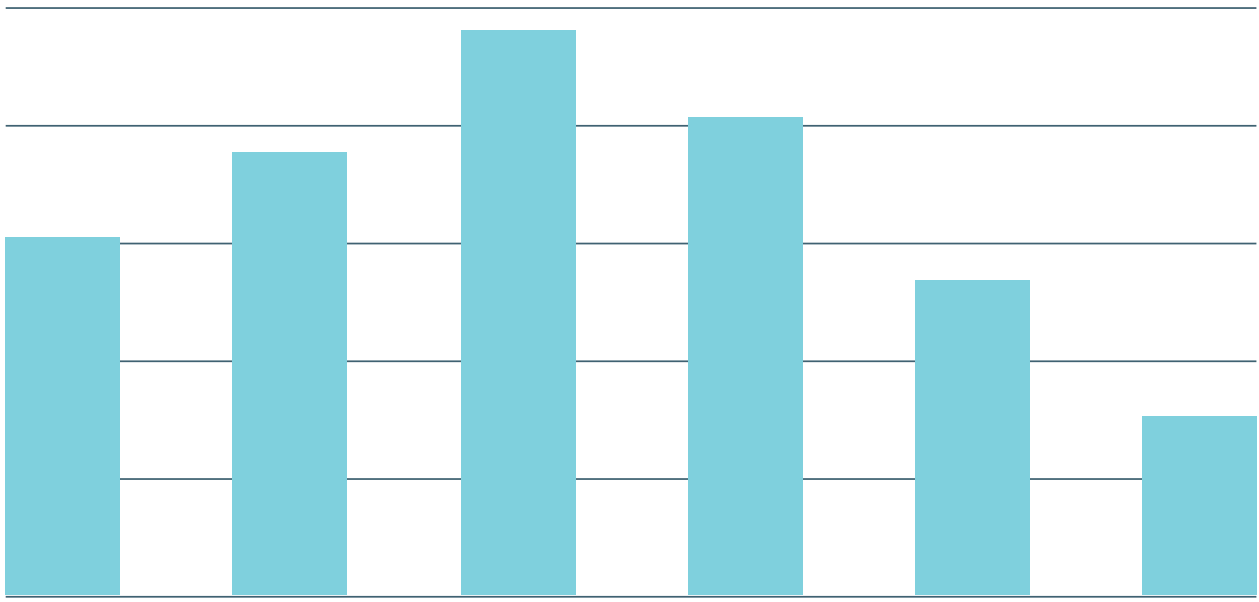


There were significant gender differences in the perceived importance of art and culture, with females from the highest and lowest social class groups rating art and culture as more important (Table 2.7). Young people from more highly educated families rated art and culture as more important; this was somewhat less likely for the highest income group. There was no significant difference in the perceived importance of art and culture by family structure, migrant status or having a SEN, though young people from urban areas placed a stronger emphasis on them. The extent to which the perceived importance of art and culture reflects school attended is explored in Chapter 4. 


\section{Table 2.7 Linear Regression Model of the Factors Associated with Perceived Importance of Art and Culture among 17-Year-Olds}

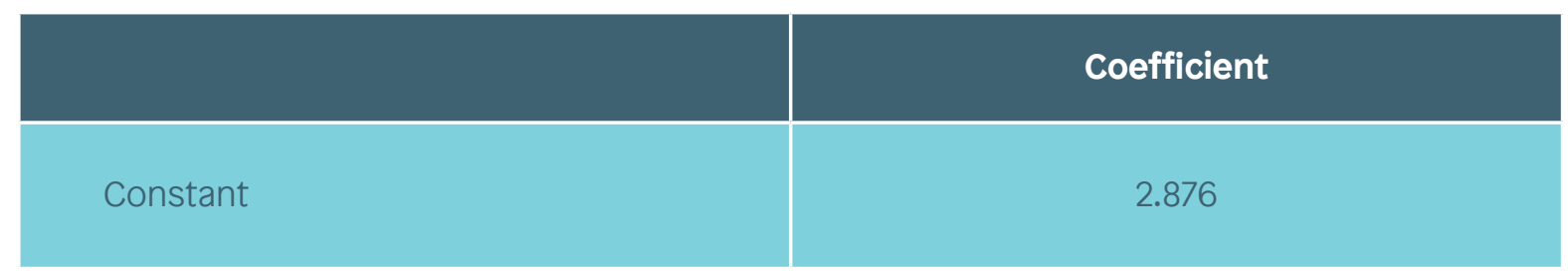

Social group:

Professional - female

Non-manual - male

Non-manual - female

Working-class - male

Working-class - female

Non-employed - male

Non-employed - female

$0.566^{* * *}$

$-0.153^{*}$

$0.410 * * *$

$0.195^{*}$

$0.250 * * *$

0.075

(Ref.: Professional - male)

$0.433^{* * *}$

Mother's education:

Leaving Certificate $\quad 0.170^{* *}$

Post-secondary $\quad 0.213^{* *}$

Degree or higher $\quad 0.359^{* * *}$

(Ref.: Junior Certificate or less)

Income quintile:

Second

Third

Fourth

Highest

(Ref.: Lowest quintile)

$-0.093$

$-0.162^{*}$

Lone parent family

0.037

Immigrant background

0.043

Has special educational need

$-0.011$

Lives in an urban area

$0.135^{* * *}$

N

5,972 


\subsection{Conclusions}

This chapter has provided an overview of arts and cultural activities among 17-yearolds. Listening to music was found to be a very common activity, while frequent engagement in reading for pleasure and singing/playing a musical instrument was common for a significant minority. Watching TV/films was very common, especially at the weekends, but playing computer games was much less prevalent. As at nine and 13 years of age (Smyth, 2016), very significant gender differences in cultural participation were evident, with young women much more likely to read for pleasure, make music and take part in structured cultural activities, and less likely to play computer games. A social gradient in involvement was also evident, with those from graduate or professional/managerial households more likely to be involved in reading, making music and taking part in structured cultural activities, and less likely to be involved in digital culture on weekdays. Cinema was the only cultural activity that was prevalent across all social groups (with the exception of young men from non-employed backgrounds). In contrast to the situation at nine and 13 years of age, there was no significant variation in cultural participation by migrant status or having a SEN. These trends are discussed further in Chapter 3. 


\section{Chapter 3}

\section{Arts and Cultural Participation from nine to 17 Years}

\subsection{Introduction}

This chapter takes advantage of the longitudinal nature of the Growing Up in Ireland (GUI) study to place cultural participation at 17 years of age in the context of earlier participation at nine and 13 years. It looks not only at trends in participation reported in the survey but also at the amount of time spent on the different activities, as captured in the time-use diaries completed at the three time-points. The sections look at trends in reading for pleasure (3.2), singing/playing an instrument (3.3), cinema attendance (3.4), taking part in structured cultural activities (3.5) and involvement in digital culture (3.6).

\subsection{Reading for Pleasure at nine, 13 and 17 Years}

The longitudinal nature of the study means that we can track the reading patterns of individual respondents, at nine, 13 and 17 years, by using findings from the earlier GUI survey waves (reported reading levels and the time-use diary data). The columns in Figure 3.1 indicate the proportion of young people who reported that they 'never' read for pleasure, at each of the survey waves. This increased from five per cent at age nine to around one-fifth of 13-year-olds, before rising dramatically to just over half of young people at 17 years. The time-use diaries provide more precise measures of the time spent (in 15-minute blocks) on reading for the day on which the diary was completed. The average amount of time spent reading more than halved between nine and 17 years of age. 
Figure 3.1 Proportion 'Never' Reading for Pleasure and Average Time Spent Reading at nine, 13 and 17 Years

60

25

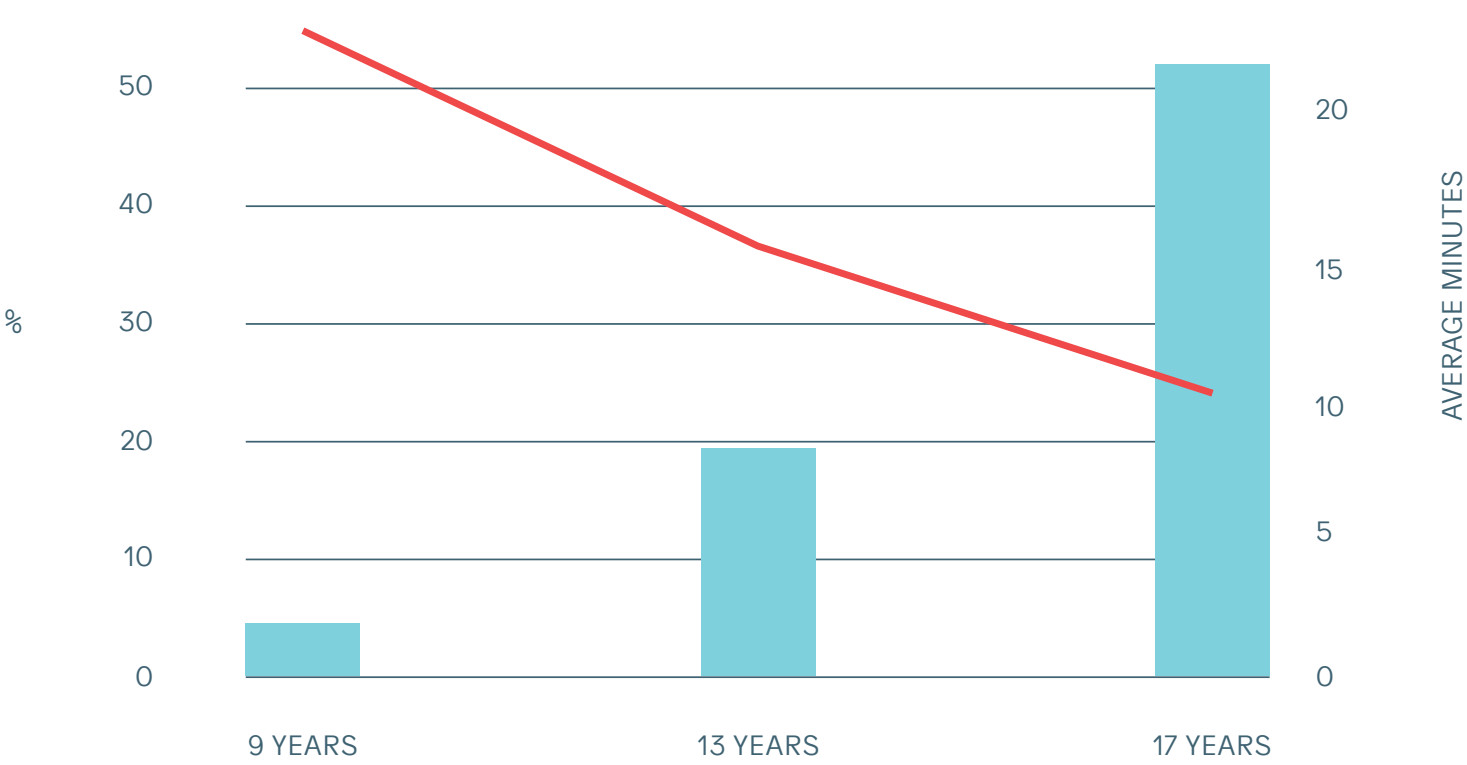

NEVER READS / NO TIME (\%) - $\quad$ AVERAGE TIME PER DAY

These figures reflect average changes, so Table 3.1 looks at trends by gender, mother's education, migrant status and special educational need (SEN). The proportion who never read for pleasure increased between 13 and 17 years of age for all groups. However, relative rates of increase were somewhat greater for those from graduate families and those without a SEN (Table 3.1). Migrant young people were more likely never to read at nine years of age, with this gap closing by 13 years of age and rates of never reading at 17 being lower for those from migrant families than for those with Irish-born parents. 
Table 3.1 Proportion who Never Read for Pleasure at nine, 13 And 17 Years, by Gender, Mother's Education, Migrant Status and SEN Status

\begin{tabular}{l|c|c|c|} 
& 9 Years & $\mathbf{1 3}$ Years & $\mathbf{1 7}$ Years \\
\hline Male & $21.4^{* * *}$ & $21.5^{* * *}$ & $60.0 * * *$ \\
Female & 9.1 & 16.9 & 45.7 \\
\hline
\end{tabular}

\section{Mother's education:}

Junior Certificate or lower education

$19.2 * * *$

$24.0 * * *$

$60.2^{* * *}$

Degree or higher education

11.2

12.5

40.5

Migrant family background

Irish family background

$20.3 *$

19.2

$48.9 * *$

15.0

19.3

53.4

Has SEN

$21.1 * * *$

$25.8 * * *$

$62.7^{* * *}$

Does not have SEN

14.5

18.3

51.6

N 
Table 3.2 looks at the relationship between cultural activities at the ages of nine and 13 years and later reading behaviour, controlling for the individual and background factors discussed in Chapter 2. The first column shows the relationship between reported reading behaviour at nine and 13 and later patterns at 17 years. Frequent reading for pleasure at 17 is found to be strongly related to earlier reading behaviour. Thus, the odds of reading at least weekly at 17 were almost seven times greater among those who read frequently at 13 than among those who spent no time reading. Even taking account of reading time at 13, those who had read on a frequent basis at the age of nine were still more likely to read later on. Engaging in structured cultural activities at age nine is associated with reading levels at 17 (analyses not shown here), but this is because it influences reading levels at 13 years; no direct effect is found when reading at 13 is taken into account. In contrast, those who spend a lot of time on TV or computer games at 13 are less likely to read for pleasure at 17 years of age.

The gender gap in reading at 17 years described in Chapter 2 is no longer significant when earlier reading behaviour is taken into account (not shown here). In other words, greater female involvement in reading at 17 years reflects a pattern established in middle childhood and adolescence. Interestingly, young women from non-employed households appear to lose some ground, having lower reading levels at 17 than might be expected given their earlier patterns. As with the gender gap, the influence of maternal education on reading at 17 is mediated through the kinds of cultural activities engaged in by children and young people from more highly educated backgrounds at nine and 13 years. 
Table 3.2 Relationship Between Reading for Pleasure at Least Weekly at 17 Years and Involvement in Cultural Activities at 9 and 13 Years (Logistic Regression Model Showing Odds Ratios)

\begin{tabular}{|l|c|c|} 
& Survey report & Time-use diary \\
\hline Reading at age nine: & \\
Once a week & 1.061 \\
Several times a week & $1.879^{* * *}$ \\
Every day & $3.375^{* * *}$ & $1.077^{* * *}$ \\
(Ref.: Less than weekly) & & \\
Time on reading & & \\
\hline
\end{tabular}

Involved in structured cultural activities at 9

1.073

TV at age nine:

$1-3$ hours

$3+$ hours

(Ref.: $<1$ hour)

Time on TV

Computer games at nine:

$1-3$ hours

$3+$ hours

1.046

(Ref.: $<1$ hour)

Reading at age 13:

$<1$ hour

$1-1.5$ hours

$>1.5$ hours

(Ref.: None)

Time on reading (time use)

Involved in structured cultural activities at 13

Time on cultural activities (time use)

1.111

Time spent listening to music (time use)

TV at age 13:

$1-2$ hours

0.837

$2-3$ hours

$3+$ hours

(Ref.: $<1$ hour)

Time on TV (time use)

Computer games at 13:

$\begin{array}{ll}1-1.5 \text { hours } & 0.999 \\ 1.5-3 \text { hours } & 0.694^{* *} \\ 3+\text { hours } & 0.738 \pm\end{array}$

(Ref.: $<1$ hour)

Time on computer games (time use)

0.999

N

** $\mathrm{p}<.001 . * * \mathrm{p}<.01 . * \mathrm{p}<0.05 ; \pm \mathrm{p}<10$. The models control for 
Column 2 of Table 3.2 shows the effects of time spent on these cultural activities, as recorded in the time-use diary at nine and 13 years of age. The model also controls for whether the time-use diary related to term-time and a weekday or the weekend. Time on structured cultural activities or computer games was not given as a separate diary item for nine-year-olds, so cannot be analysed here. As with the use of survey reports, time spent on reading at nine and 13 years is associated with being more likely to read for pleasure frequently at age 17. Time spent on structured cultural activities at 13 is also associated with later reading behaviour. The reported time spent on TV, computer games and listening to music is not significantly related to later reading. The difference between the two sets of models in the patterns for TV and computer games may reflect the fact that time spent on these activities does not have a linear effect on reading behaviour.

\subsection{Singing/Playing Musical Instruments}

In the time-use diary, young people were asked about the amount of time spent listening to music at the ages of 13 and 17 years. The average amount of time spent listening to music increased from 16.9 minutes per day to 27.2 minutes per day. It is worth noting that regarding the time-use diary, young people were asked to record the main activity they were engaged in at a particular time, which means that time spent listening to music while doing another activity (e.g. homework/study) will not be recorded. In the survey, young people had not been asked about the frequency of singing/playing a musical instrument when they were younger but it is possible to look at whether involvement in other cultural activities at an earlier stage is associated with making music at 17 years of age.

Table 3.3 shows the relationship between earlier cultural participation and involvement in making music at 17 years. As with reading, the analyses look both at self-reported frequency and the actual time recorded in the time-use diary. Those involved in singing/playing an instrument tended to read for pleasure frequently at nine and 13 years of age. Similarly, the time spent reading at nine and 13 is associated with later musical engagement. Those who spent more time watching TV, at nine and/or 13 years, are slightly less likely to be involved in music later on. There is no significant relationship between musical involvement at 17 and earlier computer game use. The question on involvement in structured cultural activities at nine and 13 includes attendance at music lessons (as well as other activities such as drama and dance), so it is not surprising that earlier involvement is associated with musical engagement at 17. Thus, those involved in structured activities at 13 are much more likely to sing or play an instrument at least weekly four years later. Interestingly, there is no significant relationship between the time spent listening to music at 13 and active musical engagement at 17. 
Table 3.3 Relationship Between Singing/Playing a Musical Instrument at Least Weekly at 17 Years and Involvement an Cultural Activities at 9 and 13 Years (Logistic Regression Model Showing Odds Ratios)

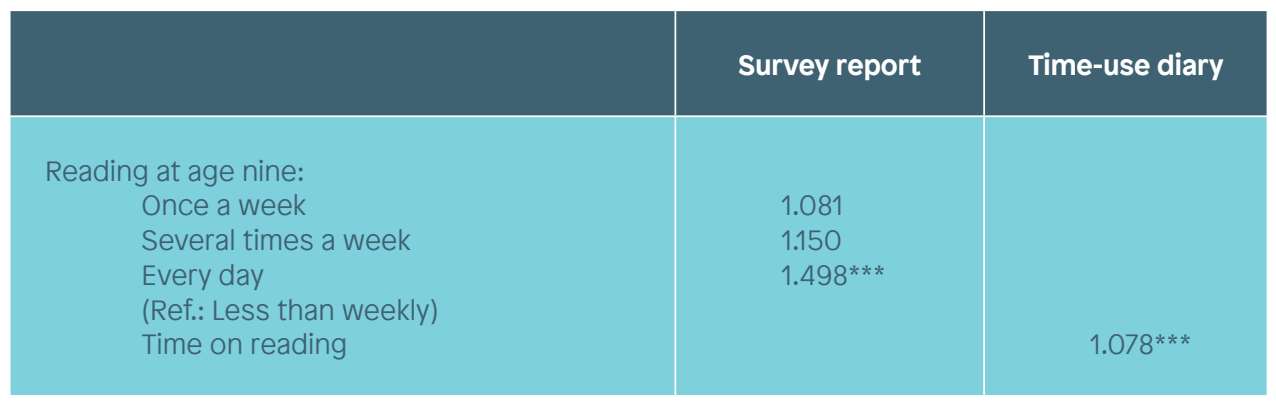

Involved in structured cultural activities at 9

$1.411 * * *$

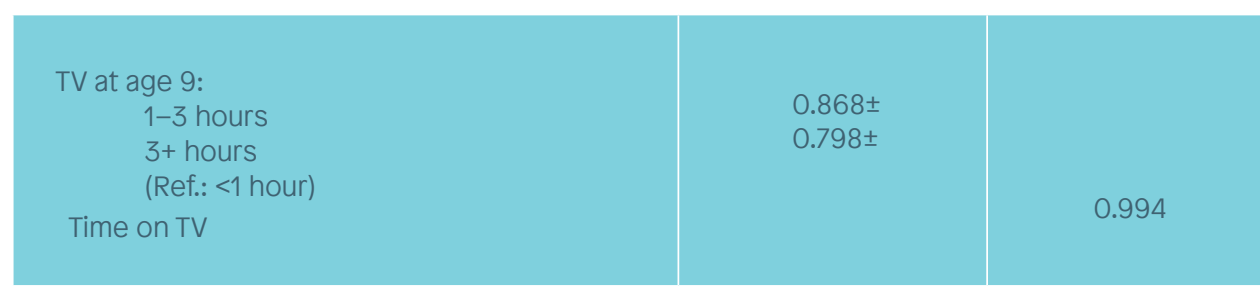

Computer games at 9:

$\begin{array}{ll}1-3 \text { hours } & 1.011 \\ 3+\text { hours } & 0.889 \\ \text { (Ref.: }<1 \text { hour) } & \end{array}$

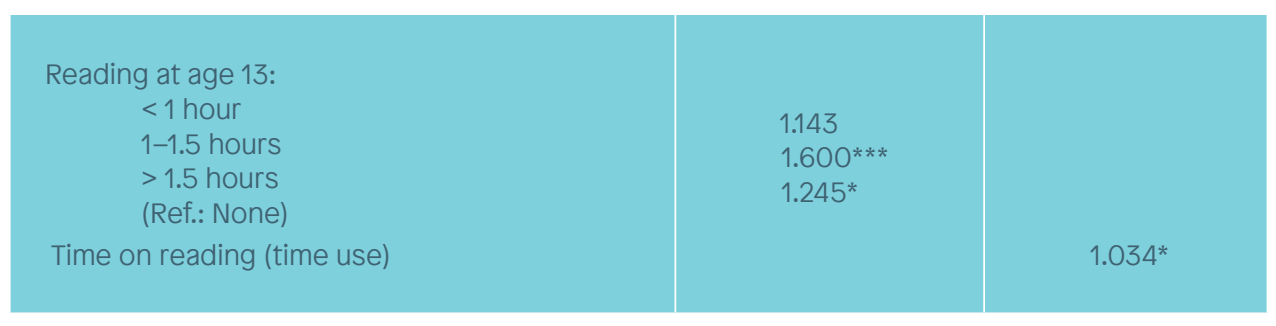

Involved in structured cultural activities at $13 \quad 3.067^{* * *}$

Time on cultural activities (time use)

$3.067^{* * *} 1.130^{* * *}$

Time spent listening to music (time use)

0.979

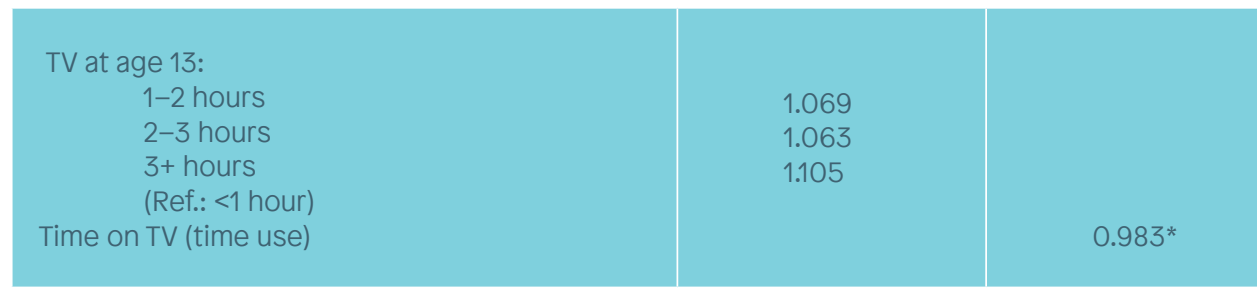

Computer games at 13 :

$\begin{array}{ll}1-1.5 \text { hours } & 1.013 \\ 1.5-3 \text { hours } & 0.892 \\ 3+\text { hours } & 0.934\end{array}$

(Ref.: $<1$ hour)

0.892
0.934

Time on computer games (time use)

1.002

N 
The strong gender differences in making music at 17 years of age are found to be mainly related to gender differences in cultural activities at nine and 13 years. Once earlier involvement is taken into account, no significant gender difference is evident.

\subsection{Cinema Attendance}

The frequency of cinema attendance was not recorded at earlier waves but, as with music, it can be related to participation in broader cultural activities in middle childhood and adolescence. Cinema attendance is more common among those who had engaged in any reading for pleasure at nine or 13 , but is not significantly related to the amount of time spent reading (Table 3.4). There is no relationship between cinema attendance and involvement in structured cultural activities. There is also no significant relationship between the frequency of watching TV at nine and 13 and later cinema going, though cinema attendance is associated with having spent more time playing computer games at nine or moderate amounts of time on such games at 13. 
Table 3.4 Relationship Between Going to the Cinema at Least Monthly at 17 Years And Involvement in Cultural Activities at 9 and 13 Years (Logistic Regression Model Showing Odds Ratios)

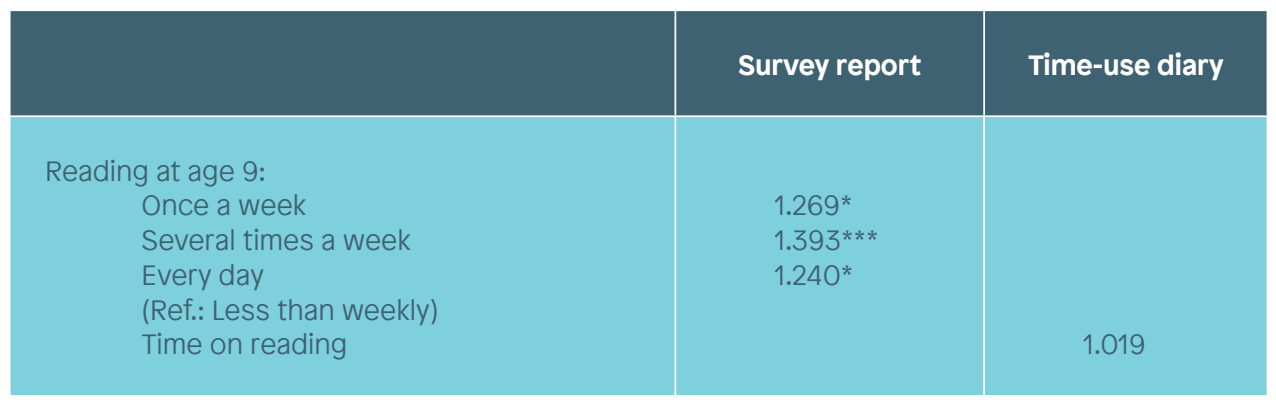

Involved in structured cultural activities at 9

0.929

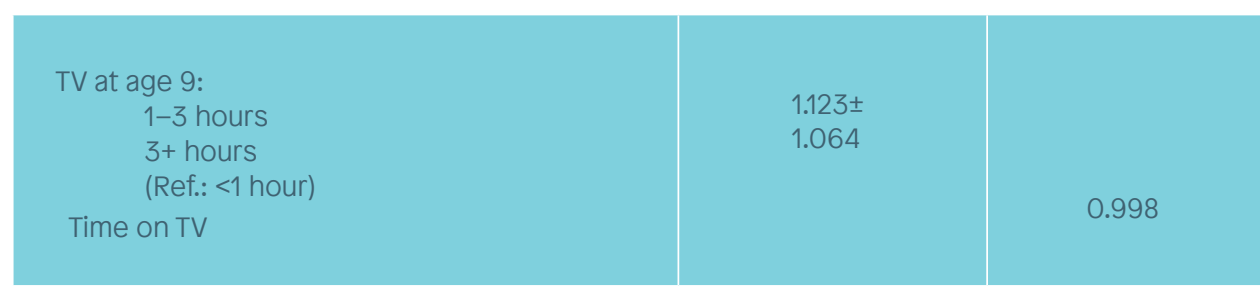

Computer games at 9:

$\begin{array}{ll}1-3 \text { hours } & 1.107 \\ 3+\text { hours } & 1.410^{* * *} \\ \text { (Ref.: }<1 \text { hour) } & \end{array}$

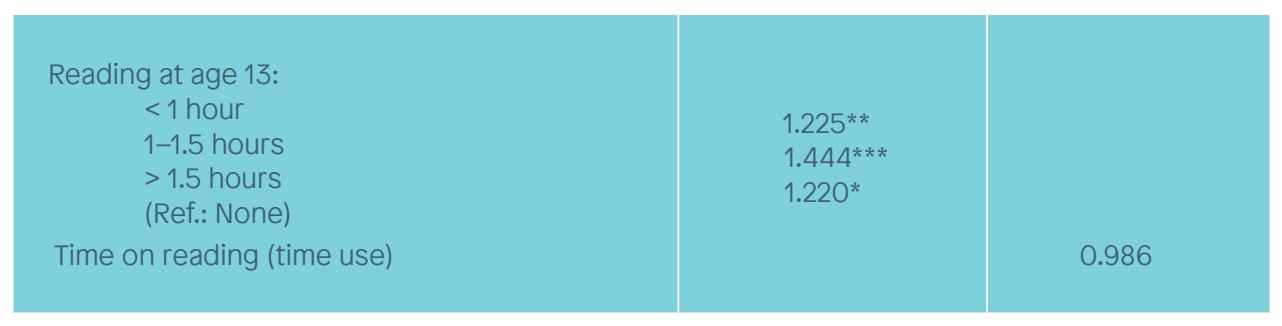

Involved in structured cultural activities at 13

Time on cultural activities (time use)

0.971

Time spent listening to music (time use)

0.994

\begin{tabular}{|c|c|c|}
\hline $\begin{array}{l}\text { TV at age 13: } \\
\qquad \begin{array}{r}1-2 \text { hours } \\
2-3 \text { hours } \\
3+\text { hours } \\
\text { (Ref.: }<1 \text { hour) }\end{array} \\
\text { Time on TV (time use) }\end{array}$ & $\begin{array}{l}1.000 \\
1.106 \\
1.102\end{array}$ & 0.999 \\
\hline
\end{tabular}

Computer games at 13:

$\begin{array}{ll}1-1.5 \text { hours } & 0.937 \\ 1.5-3 \text { hours } & 1.213^{*} \\ 3+\text { hours } & 1.117\end{array}$

(Ref.: $<1$ hour)

$1.034 * *$

Time on computer games (time use)

3,611 


\subsection{Structured Cultural Activities}

Chapter 2 described the way in which involvement in structured cultural activities (such as music lessons and drama clubs) is more prevalent among young women and those from more advantaged social backgrounds. Looking at involvement longitudinally, a significant decline in participation is found, with a decline over the transition to second-level education (from $39 \%$ to $34 \%$ ) and a much greater decline after the transition into or beyond senior cycle (from 34\% to $23 \%$ ). In keeping with this pattern, there was also a significant decline in the amount of time spent on these activities daily from 12.9 to 8.4 minutes. $^{4}$

\section{Figure 3.2 Proportion Reporting Involvement in Structured Cultural Activities and Average Time Spent on These Activities at nine, 13 and 17 Years}

50

15

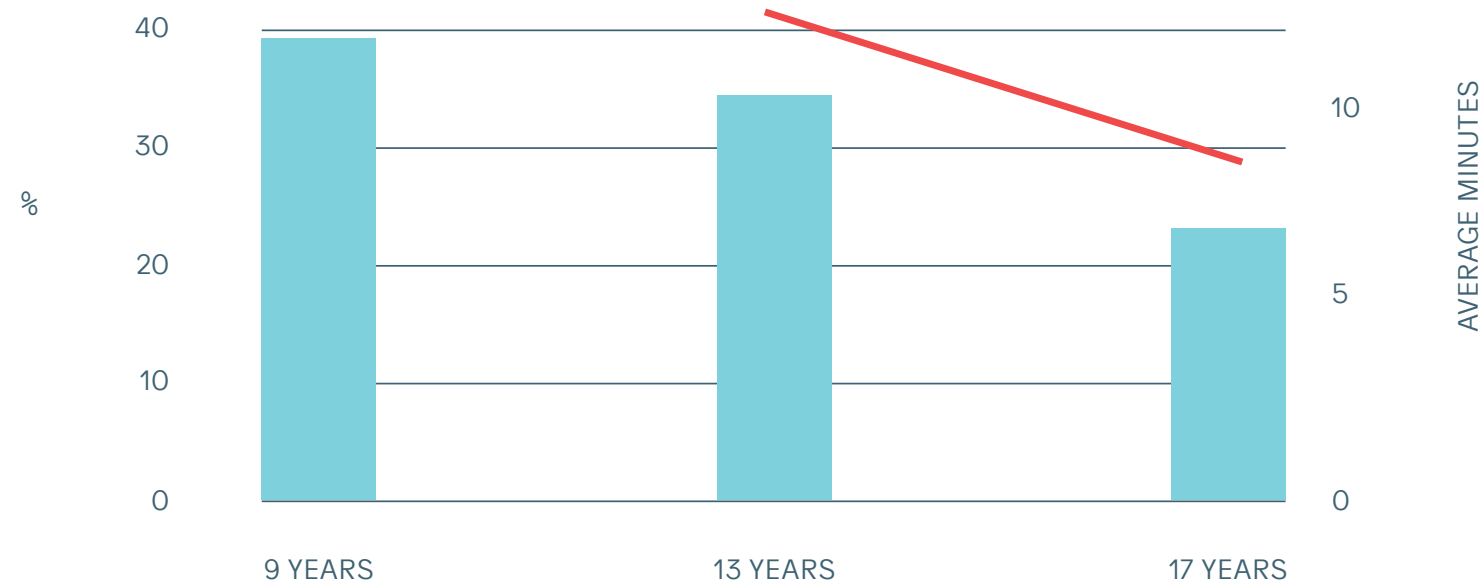

INVOLVED

- AVERAGE TIME PER DAY

Table 3.5 shows this trend broken down by different groups. Between 13 and 17 years, there is a smaller decline in structured cultural participation among males than among females. However, as males were much less likely to be involved in the first place, a significant gender difference in favour of females remains at 17. Similarly, there is a slightly smaller decline in participation over the same period for those with SEN compared to those without SEN. In terms of mother's education, levels of participation for both groups halve between nine and 17 years of age. As with reading patterns, the gap between young people from migrant families and their peers narrows between nine and 13 years; thereafter, participation remains at similar levels to those from Irish families.

${ }^{4}$ The time-use diary for nine-year-olds did not distinguish structured 
Table 3.5 Proportion Involved in Structured Cultural Activities at nine, 13 And 17 Years, by Gender, Mother's Education, Migrant Status and SEN Status

\begin{tabular}{l|c|c|c|}
\hline & 9 Years & $\mathbf{1 3}$ Years & $\mathbf{1 7}$ Years \\
\hline Male & $31.5^{* * *}$ & $19.4^{* * *}$ & $17.2^{* * *}$ \\
\hline Female & 66.9 & 50.9 & 29.7 \\
\hline
\end{tabular}

\section{Mother's education:}

Junior Certificate or lower education

$36.4^{* * *}$

$29.1^{* * *}$

$17.8^{* * *}$

Degree or higher education

65.4

43.7

32.9

\begin{tabular}{|c|c|c|c|}
\hline $\begin{array}{l}\text { Migrant family background } \\
\text { Irish family background }\end{array}$ & $\begin{array}{l}39.5^{* * *} \\
49.6\end{array}$ & $\begin{array}{l}33.1 \\
35.0\end{array}$ & $\begin{array}{l}24.7 \\
23.2\end{array}$ \\
\hline Has SEN & $37.3^{* * *}$ & $24.8^{* * *}$ & $18.7^{* * *}$ \\
\hline Does not have SEN & 50.6 & 36.3 & 24.0 \\
\hline N & 6,038 & 6,039 & 6,033 \\
\hline
\end{tabular}

Note:

$* * * p<.001 ; * * p<.01 ;{ }^{*} p<.10$.

Table 3.6 looks at the relationship between participation in music/drama/dance classes or clubs at 17 years and earlier involvement in the same. Participation is found to be much more common among those who had taken part in such activities in middle childhood or adolescence - those involved at age 13 are, all else being equal, much more likely to be involved at 17 years. Similarly, time spent on structured cultural activities at 13 is associated with later involvement. Involvement at 17 is also related to time spent reading for pleasure, especially at 13. There is little consistent variation by involvement in digital culture, though recorded time spent watching TV at 13 years is negatively related to participation in music/drama/dance classes or clubs at 17. Interestingly, those who spent more time listening to music at 13 years were less likely to be actively engaged in cultural activities at 17. 
Table 3.6 Relationship between Involvement in Structured Cultural Activities (in the Past Year) at 17 Years and Involvement in Cultural Activities at 9 and 13 Years (Logistic Regression Model Showing Odds Ratios)

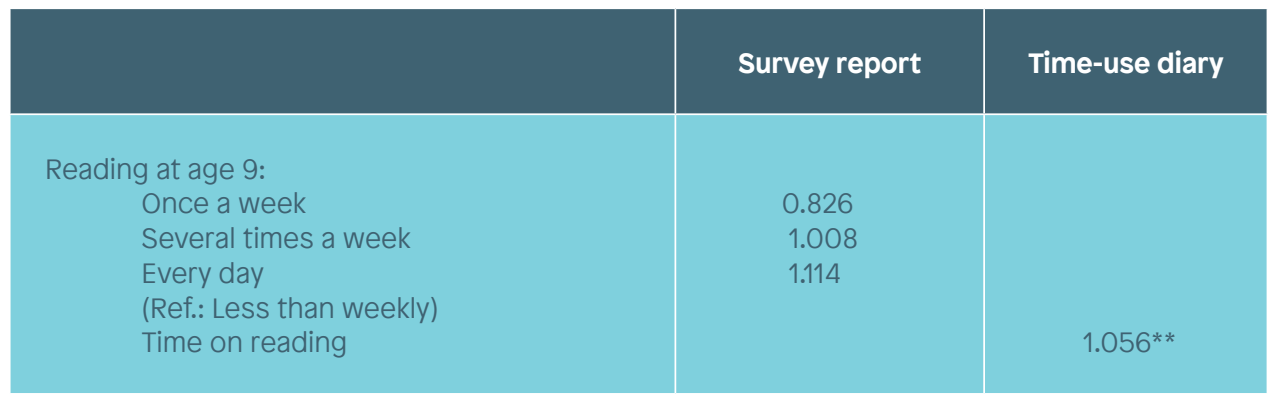

Involved in structured cultural activities at 9

$1.793^{* * *}$

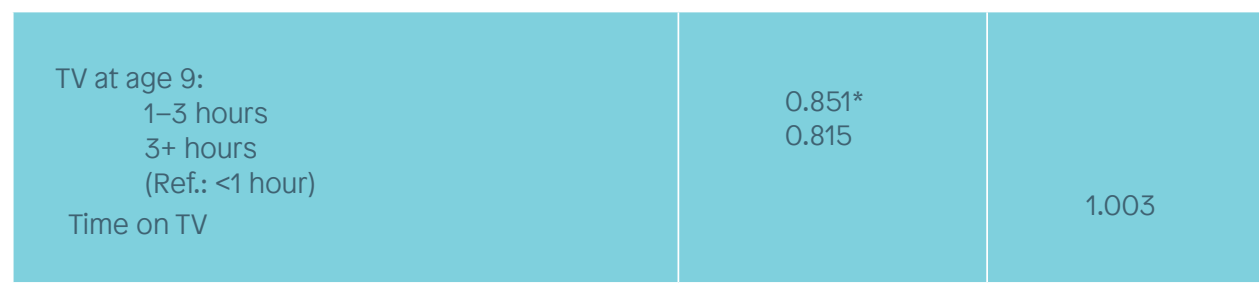

Computer games at 9:

$\begin{array}{lr}1-3 \text { hours } & 1.211^{*} \\ 3+\text { hours } & 0.936 \\ \text { (Ref.: }<1 \text { hour) } & \end{array}$

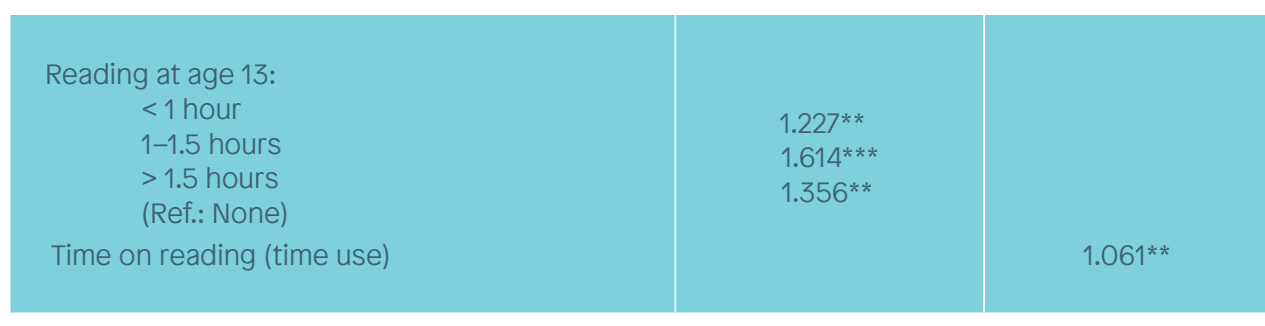

Involved in structured cultural activities at 13

Time on cultural activities (time use)

$1.126 * * *$

Time spent listening to music (time use)

$0.947 * *$

\begin{tabular}{|c|c|c|}
\hline $\begin{array}{l}\text { TV at age 13: } \\
\qquad \begin{array}{l}\text { 1-2 hours } \\
2-3 \text { hours } \\
\text { 3+ hours } \\
\text { (Ref.: }<1 \text { hour) }\end{array} \\
\text { Time on TV (time use) }\end{array}$ & $\begin{array}{l}0.943 \\
0.891 \\
1.014\end{array}$ & $0.978^{*}$ \\
\hline
\end{tabular}

Computer games at 13:

$\begin{array}{ll}1-1.5 \text { hours } & 0.998 \\ 1.5-3 \text { hours } & 0.838 \\ 3+\text { hours } & 0.811 \\ \text { (Ref.: }<1 \text { hour) } & \end{array}$

Time on computer games (time use)

N

5,911

3,611 
The gender differences in participation described in Chapter 2 are, as with reading, largely explained by involvement during middle childhood and adolescence. However, the social gradient in involvement is only partly explained by earlier activities. Thus, even taking account of involvement at nine and 13 years, those with graduate mothers are significantly more likely to take part in structured cultural activities than those whose mothers have Junior Certificate qualifications. Furthermore, involvement among young men from non-employed backgrounds is much lower than might be expected given their earlier activities. Thus, all else being equal, the decline in involvement between 13 and 17 years is less evident among more educated households and, at least for males, more evident among disadvantaged households.

\subsection{Involvement in Digital Culture}

As discussed in Chapter 1, the measures of frequency of activities like TV/video/ film watching and playing computer games changed over time. ${ }^{5}$ When the children were nine, their mothers were asked about the amount of time they spent on these activities on an average weekday evening during term-time. At 13 years, the young people themselves reported the amount of time they spent on them, again relating to a weekday evening during term-time. The 17-year-olds were asked about weekday and weekend viewing separately; to ensure longitudinal comparability, the weekday measures are used here. ${ }^{6}$ In the time-use diaries, we know whether the day of the diary completion was during the week or in term-time so can limit the analyses to weekday term-time reports to allow comparability over time and between survey and diary reports.

\footnotetext{
${ }^{5}$ Regarding TV/video/film watching, there were also some changes in question wording between waves with 'TV/video' used in earlier waves and 'TV/film' used at 17 years.

${ }^{6}$ For differences between weekday and weekend patterns, see Chapter 2.
} 
Figure 3.3 Proportion Reporting 'Never' Watching TV/Video/Film and TV at 9, 13 and 17 Years (Weekday during Term-Time)

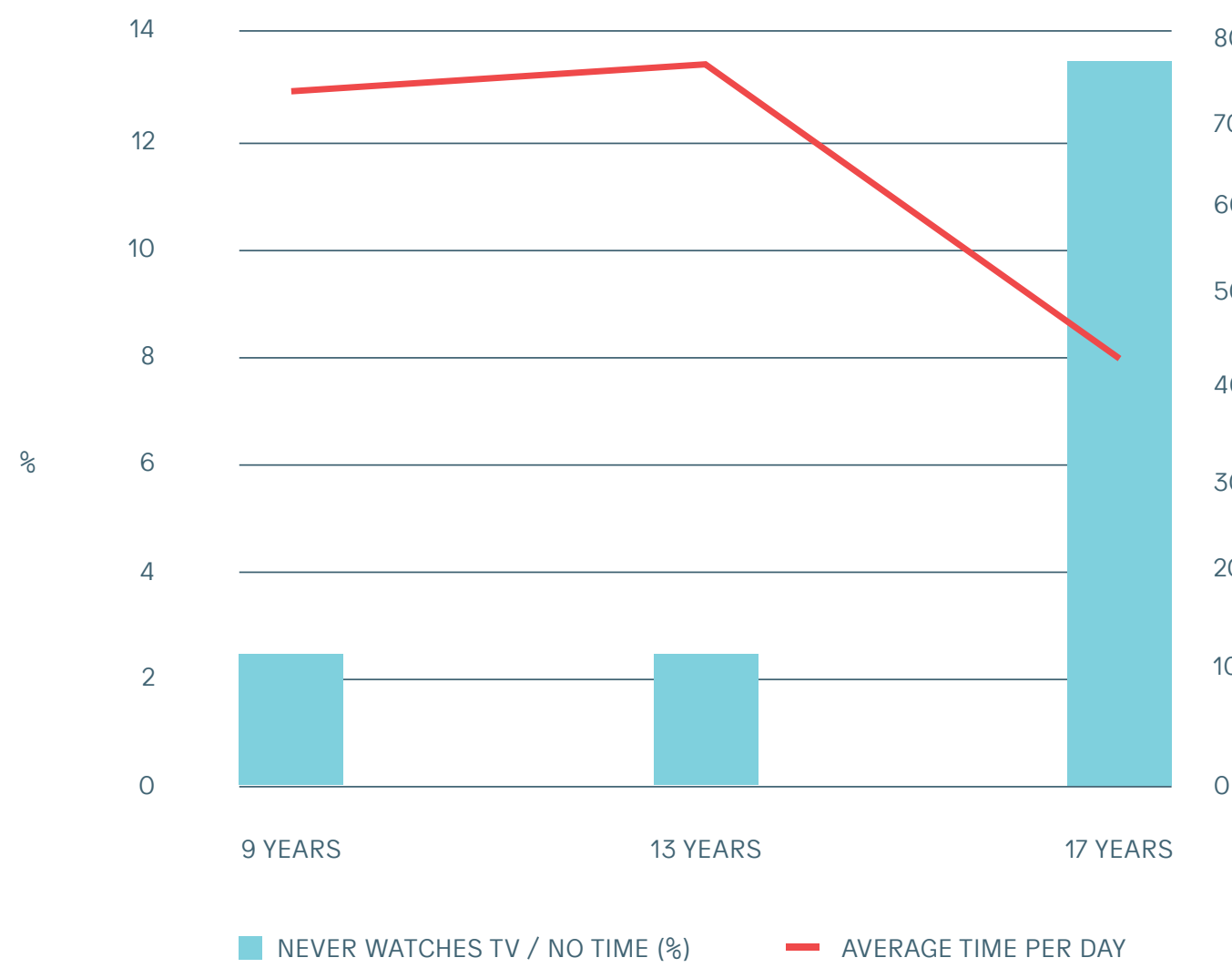

80

70

60

50

40

30

20

10

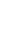


The proportion of young people who 'never' watch TV/video/film on a weekday evening is very small and relatively stable between nine and 13 years, though it increased markedly by 17 years (Figure 3.3). Similarly, the average amount of time spent watching TV is relatively stable between nine and 13 years, decreasing by almost half an hour by 17. Table 3.7 shows the relationship between high levels of weekday TV watching at 17 and earlier involvement in cultural and digital activities. Self-reported frequency of TV watching (on the basis of survey reports) at nine and 13 is associated with spending more time watching TV at the age of 17. Moderate levels of computer game usage at nine and 13 years are also associated with more time spent watching TV at 17. Those who spent more time reading at 13 are less likely to spend time watching TV four years later but earlier involvement in structured cultural activities has no significant effect. The pattern from the time-use diary is less clear-cut, though time spent reading at 13 reduces later TV watching, while TV watching at nine increases it. The lower levels of TV watching found among more advantaged groups (see Chapter 2) are still evident after taking account of earlier activities. Thus, more advantaged groups have a greater decline in time on TV as they grow older compared to those from other households. This most likely reflects differences in the amount of time devoted to homework and study, an issue that is discussed further below. 
Table 3.7 Relationship between High Levels of TV/Film Watching at 17 Years and Involvement in Cultural Activities at 9 and 13 Years (Logistic Regression Model Showing Odds Ratios)

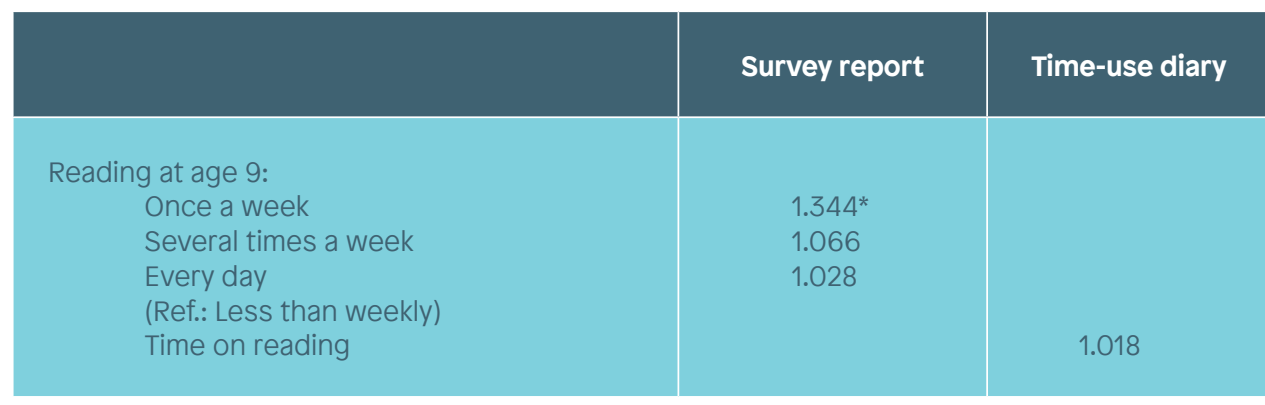

Involved in structured cultural activities at 9

0.938

\begin{tabular}{|c|c|c|}
\hline 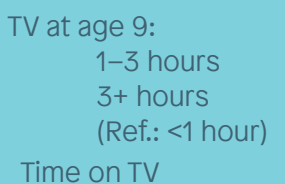 & $\begin{array}{l}1.231^{*} \\
1.348^{*}\end{array}$ & $1.025^{*}$ \\
\hline
\end{tabular}

Computer games at 9:

$\begin{array}{ll}1-3 \text { hours } & 1.204^{*} \\ 3+\text { hours } & 0.970 \\ \text { (Ref.: }<1 \text { hour) } & \end{array}$

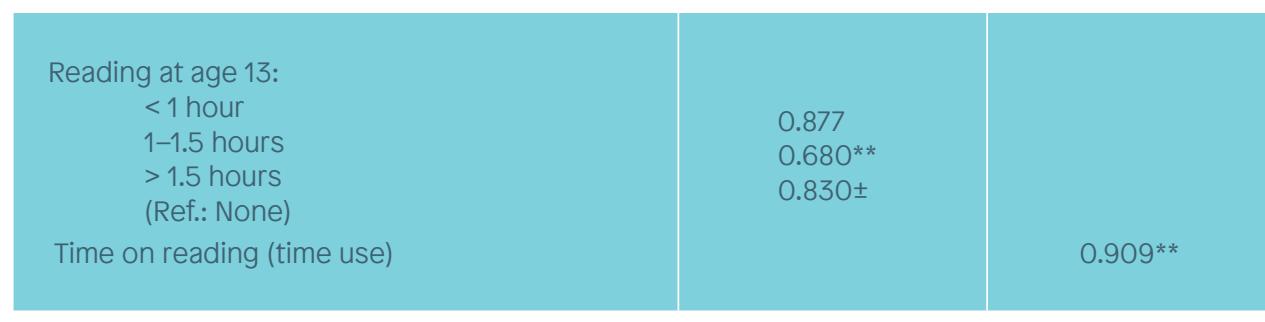

Involved in structured cultural activities at $13 \quad 1.032$

Time on cultural activities (time use)

0.964

Time spent listening to music (time use)

1.024

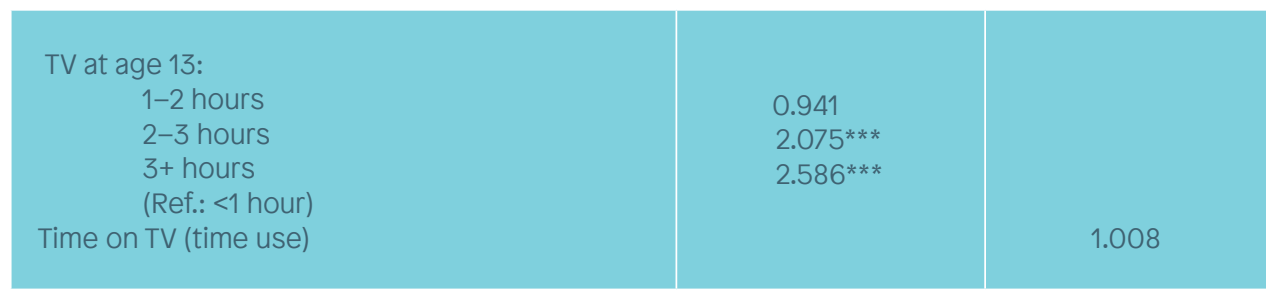

Computer games at 13:

$\begin{array}{ll}1-1.5 \text { hours } & 1.138 \\ 1.5-3 \text { hours } & 1.294^{* *} \\ 3+\text { hours } & 1.190 \\ \text { (Ref.: }<1 \text { hour) } & \end{array}$

Time on computer games (time use)

0.980

N 
Similarly, the proportion of young people who never play computer games is relatively stable (and very low) between nine and 13 years but increases to over one-quarter by the age of 17. In keeping with this trend, the average amount of time declines from 28 minutes at nine years, to 25 minutes at 13 years and 15 minutes at 17 years (Figure 3.4). Computer game playing at 17 is more prevalent among those who did this more often at both nine and 13 years (using either the survey or time-use reports). It is also more common among those who watched a lot of TV when they were nine (Table 3.7). Those who were involved in structured cultural activities at nine and 13 are less likely to play computer games when they are older (Table 3.8).

Figure 3.4 Proportion Reporting 'Never' Playing Computer Games and Average Time Spent Playing at nine, 13 and 17 Years (Weekday during Term-Time)

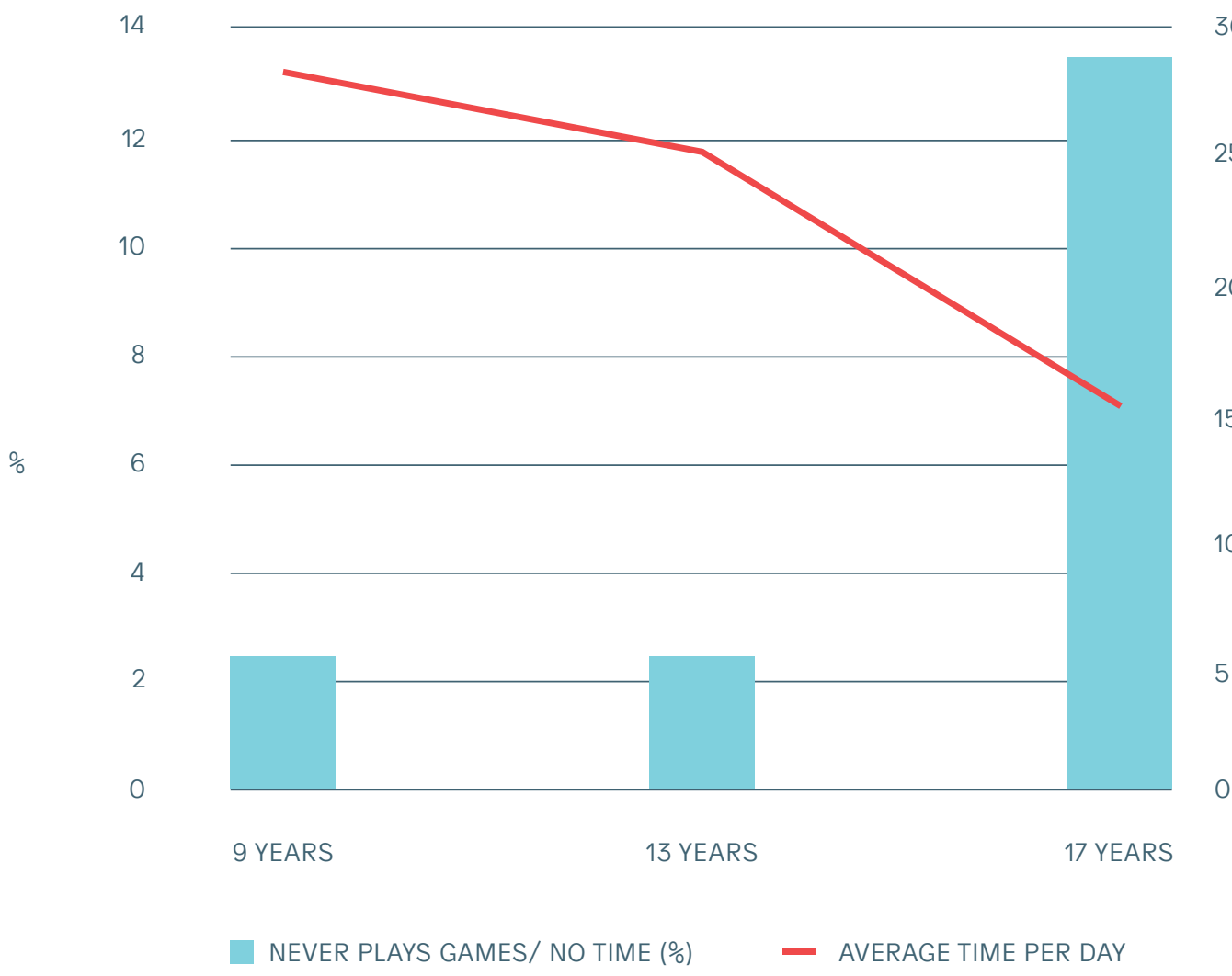


Chapter 2 showed lower rates of computer game playing among 17-year-olds from more advantaged families (in terms of maternal education and income). The difference by mother's education is accounted for by earlier involvement in cultural activities. Thus, young people from more highly educated families play computer games less often because they did not establish this pattern at a younger age. However, even controlling for earlier activities, income is significantly associated with computer gaming. In other words, young people from higher-income families spend less time playing computer games than might be expected given their activities in middle childhood and adolescence. Only part of the gender gap in computer gaming is explained by activities at nine and 13 , with very substantial differences between males and females with similar profiles of cultural activities at a younger age. 
Table 3.8 Relationship between High Levels of TV/Film Watching at 17 Years and Involvement in Cultural Activities at 9 and 13 Years (Logistic Regression Model Showing Odds Ratios)

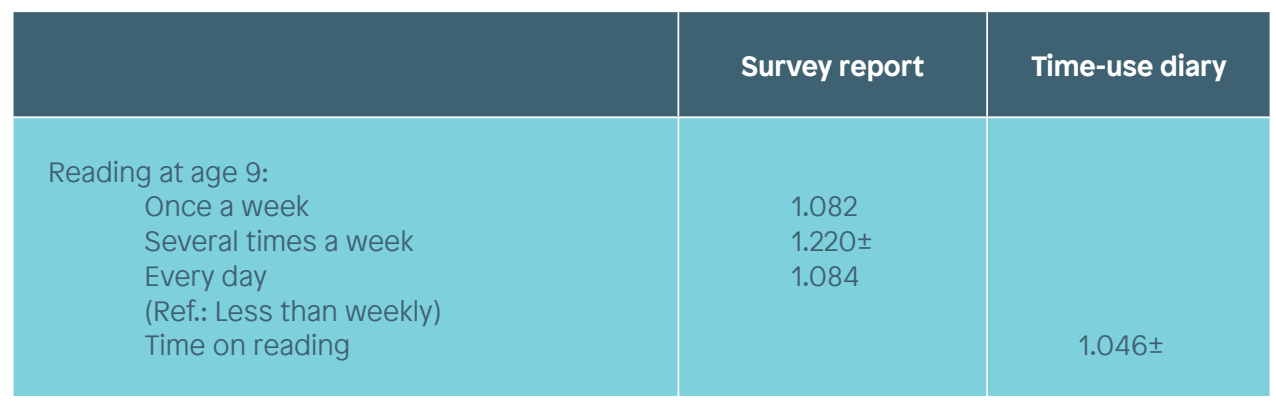

Involved in structured cultural activities at 9

$0.675^{* * *}$

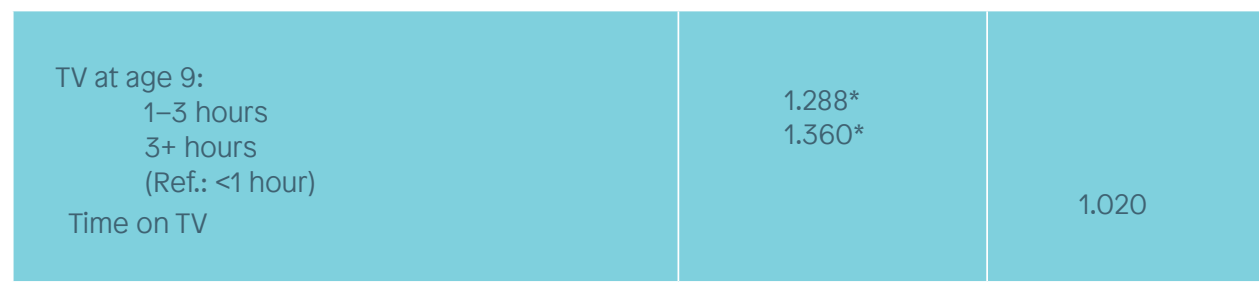

Computer games at 9:

$\begin{array}{ll}1-3 \text { hours } & 1.612^{* * *} \\ 3+\text { hours } & 1.550^{* * *} \\ \text { (Ref.: }<1 \text { hour) } & \end{array}$

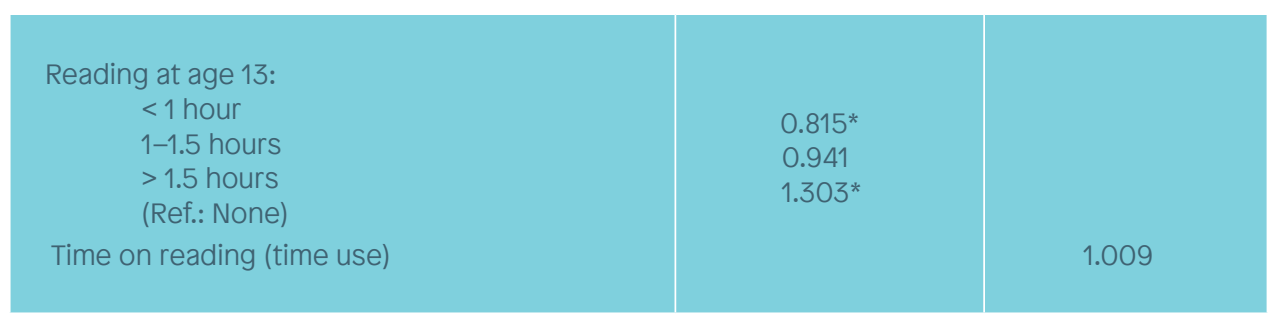

Involved in structured cultural activities at $13 \quad 0.843 \pm$

Time on cultural activities (time use)

$0.843 \pm \quad 0.970$

Time spent listening to music (time use)

$1.040^{*}$

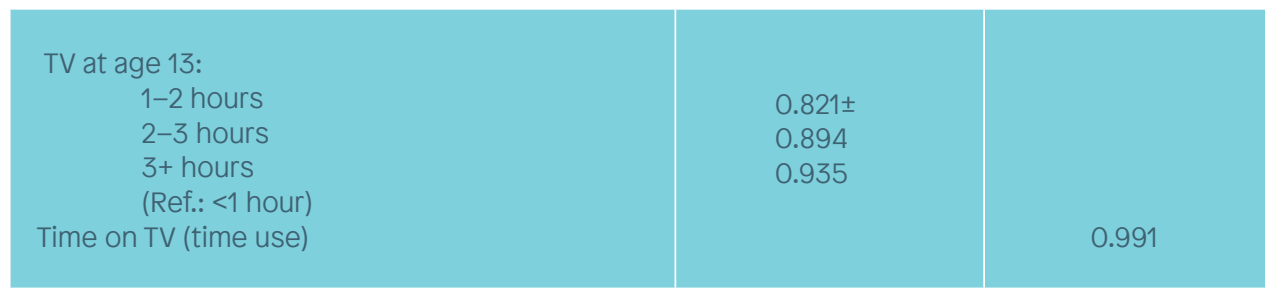

Computer games at 13 :

$\begin{array}{ll}1-1.5 \text { hours } & 1.198^{*} \\ 1.5-3 \text { hours } & 2.213^{* * *} \\ 3+\text { hours } & 3.001^{* * *}\end{array}$

(Ref.: $<1$ hour)

Time on computer games (time use)

$1.088^{* * *}$ 


\subsection{Conclusions}

This chapter has looked at longitudinal trends in involvement in cultural activities from the ages of nine to 17 years of age. Levels of engagement in all aspects of culture for which we have information at an earlier time point decline between 13 and 17 years. Thus, young people at 17 are less likely to read for pleasure, take part in music/drama classes or clubs, watch TV/films or play computer games (at least on weekdays) than they were at 13 (or nine) years of age. This decline is evident across groups in terms of gender, maternal education, migrant status and having a SEN. This pattern is consistent with earlier findings on sports participation, which showed a reduction in involvement over the course of second-level education (Lunn et al., 2013).

Despite this decline in participation, earlier involvement is found to be strongly predictive of later engagement. Thus, reading for pleasure at 17 was strongly associated with patterns at nine and 13 years of age. The gender and social gap in reading at 17 was entirely explained by patterns established in middle childhood and adolescence. Similarly, involvement in structured cultural activities at 17 is very strongly related to participation at nine and 13 but the social gradient in involvement is only partly explained by earlier patterns. Synergies are found between reading and some other forms of cultural participation, with structured cultural participation more prevalent among those who read for pleasure at an earlier age. Similarly, involvement in digital culture (TV/film watching and playing computer games) is greater among those involved in these activities when they were younger.

The next chapter looks at whether any of these patterns and trends reflect differences in the school experience of young people. 


\section{Chapter 4 \\ Schools and Cultural Participation}

\subsection{Introduction}

This chapter explores the extent to which the schools attended by young people influence their access to, and participation in, cultural activities. Section 4.2 examines school provision of art and culture on a curricular and extracurricular basis, while Section 4.3 examines the individual, family and school factors associated with taking art or music for the Leaving Certificate. Section 4.4 analyses whether participation in out-of-school cultural activities varies by the type of school attended and the factors that may account for young people feeling that their second-level education had enhanced their enjoyment of reading for pleasure or appreciation of art and culture.

\subsection{School Provision of Curricular and Extracurricular Art and Culture}

Figure 4.1 shows that the extent to which young people can choose art or music at Leaving Certificate level varies by the type of school they attend. The provision of these subjects is most prevalent in fee-paying schools and least prevalent in DEIS schools, with a larger gap between the two school types in relation to music than art. Girls' schools are more likely to offer these subjects than coeducational schools, while provision of music is lowest in boys' schools. Not surprisingly, subject provision varies by school size, with those attending larger schools more likely to have access to art or music. 
Figure 4.1 Proportion of Young People Attending a School that Offers Leaving Certificate Art or Music, by School Social Mix, Gender Mix and Size

90

80

70

60

50

40

30

20

10

0

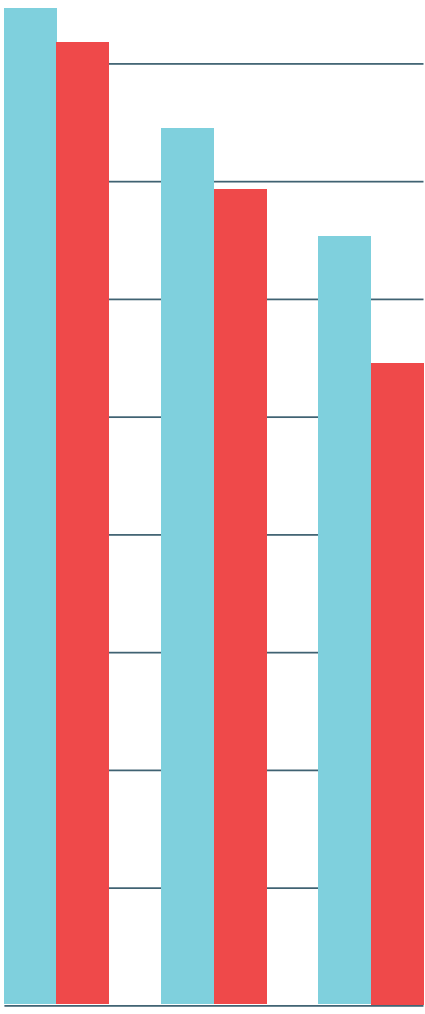

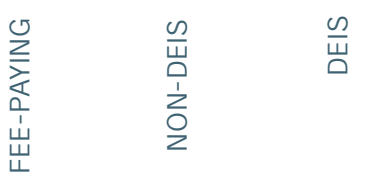

SCHOOL SOCIAL MIX
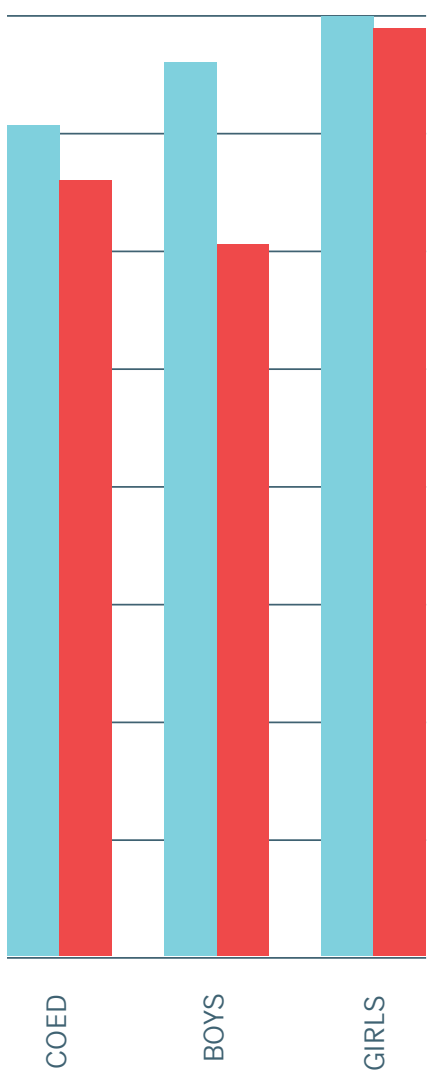

SCHOOL GENDER MIX
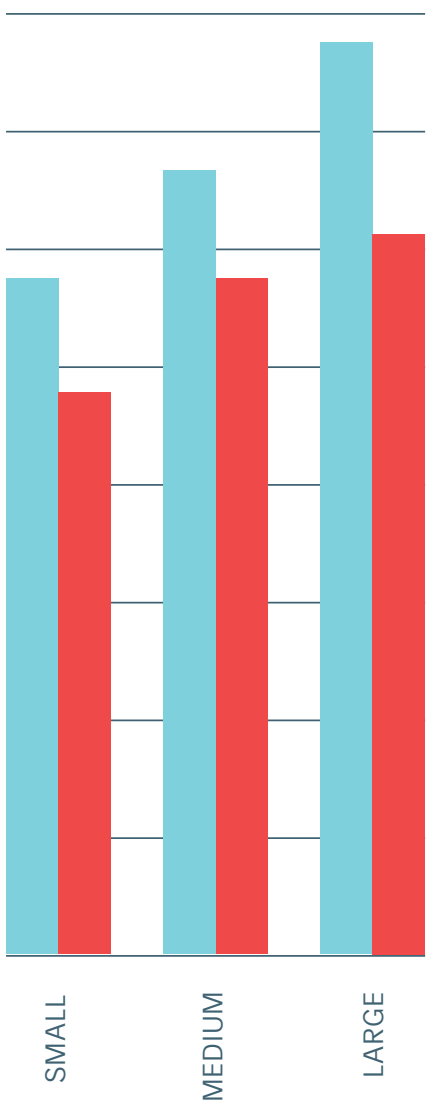

SCHOOL SIZE

As a result of these patterns, young people with more highly educated mothers or from professional/managerial households are more likely to attend a school that offers art or music. For example, 72 per cent of those with graduate mothers attend a school offering music, compared with 63 per cent of those whose mothers have Junior Certificate education or less. Young women are slightly more likely to attend a school offering art and much more likely to attend a school offering music. 
Figure 4.2 Proportion of Young People Attending a School that Offers Extracurricular Choir, Musical Instrument Tuition, Drama or Dance, by School Social Mix, Gender Mix and Size

100

90

80

70

60

50

40

30

20

10

0
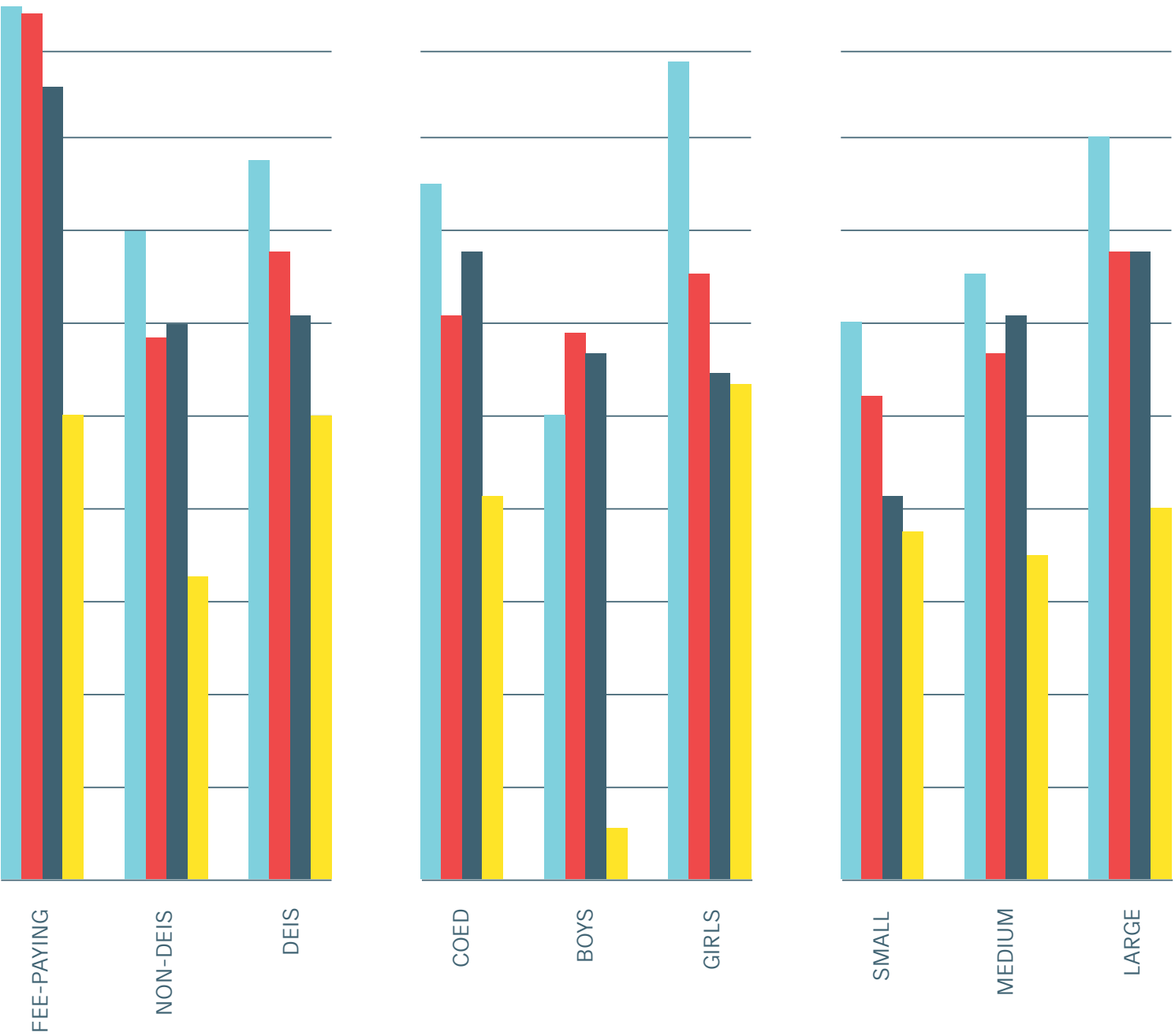

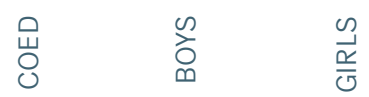

SCHOOL SOCIAL MIX

SCHOOL GENDER MIX

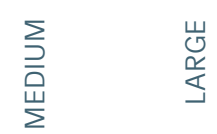

SCHOOL SIZE

CHOIR

MUSICAL INSTRUMENTS

DRAMA

DANCE

Access to extracurricular cultural provision also varies by the type of school young people attend (Figure 4.2). Levels of provision of choir, musical instrument tuition and drama are highest in fee-paying schools. Interestingly, provision is as common, or even slightly more prevalent, in DEIS schools as it is in non-DEIS schools, suggesting that DEIS schools actively try to promote cultural activities. Girls' schools are more likely to provide choir, instrument tuition and dance than coeducational 
or boys' schools, with hardly any boys' schools offering dance. In contrast, those in coeducational schools are more likely to have access to extracurricular drama than those in single-sex schools. As with curricular provision, extracurricular provision varies by school size, being most prevalent in larger schools. Reflecting these patterns, young women are more likely to attend schools that offer choir or dance, while those from more advantaged backgrounds (in terms of parental social class or education) are more likely to have access to drama and musical instrument tuition than their less advantaged peers.

\subsection{Take-Up of Leaving Certificate Art and Music}

One in six (15\%) of the 17-year-olds took or were taking art for the Leaving Certificate, while 12 per cent were taking Leaving Certificate music. Table 4.1 shows the influence of background and school factors on the take-up of these subjects. There is a clear gender gap in take-up of art, but little variation by social class background, mother's education or household income. In fact, the gender gap is even larger before takeup of Junior Certificate art is taken into consideration; thus, part of the gender gap regarding take-up of Leaving Certificate art reflects decisions about subject choice at junior cycle level. Those from lone-parent families are somewhat more likely to take art than those from two-parent families, while young people from immigrant families are much more likely to take it than those of similar characteristics from Irish backgrounds. In addition, young people with a special educational need (SEN) are much more likely to take the subject.

Art take-up is somewhat higher in DEIS schools than in non-DEIS schools but this is related to higher take-up of art at junior cycle level, with no significant difference evident when this is taken into account. Fee-paying schools do not differ from non-DEIS schools in the take-up of the subject. Art take-up is somewhat lower in girls' schools than might be expected given their profile; in other words, the large gender gap found in art take-up is slightly smaller in single-sex than in coeducational schools. Take-up is also somewhat higher in medium and large schools, most likely reflecting the greater likelihood of provision in these schools (see Section 4.2). Art take-up does not vary by the provision of extracurricular subjects or by whether or not the young person has taken Transition Year (TY). Not surprisingly, art take-up is much higher among young people who took the subject for their Junior Certificate. Interestingly, all else being equal, those who took Junior Certificate music were much less likely to take Leaving Certificate art than those who had not taken music at Junior Certificate level.

As a subject, music resembles art in the sense that its take-up is highly gendered, but take-up of music is higher than take-up of art among those with graduate mothers and those from middle- and higher-income groups (Table 4.1). Take-up of music does not vary by family structure or migrant status, though it is much lower among young people with SEN. 
Music take-up does not vary by school social mix, but it is lower in girls' schools than might be expected; in other words, and as with art, the gender gap in take-up is somewhat smaller in single-sex than in coeducational schools. Schools that provide extracurricular musical instrument tuition have higher take-up levels of music as a curricular subject. Those who have taken music at junior cycle level are much more likely to take it at senior cycle level; those who had taken art are less likely to take music for Leaving Certificate.

Further analysis (not shown here) indicates that music tends to attract those who had taken more higher-level subjects at junior cycle level, a pattern that explains at least part of the variation by SEN. Those who go on to take art tend to have taken fewer higher-level subjects for the Junior Certificate. 
Table 4.1 Individual and School Factors Associated with Take-Up of Leaving Certificate Art and Music (Logistic Regression Models Showing Odds Ratios)

\begin{tabular}{l|l|l} 
& Art & Music \\
\hline Constant & 0.012 & 0.024 \\
\hline Social group: & & $1.989^{* * *}$ \\
Professional - female & $2.368^{* * *}$ & $0.574^{* *}$ \\
Non-manual - male & 1.101 & $2.087^{* * *}$ \\
Non-manual - female & $3.357^{* * *}$ & 1.513 \\
Working-class - male & 1.347 & $2.736^{* * *}$ \\
Working-class - female & $2.717^{* * *}$ & 1.098 \\
Non-employed - male & 1.239 & $1.774^{*}$ \\
Non-employed - female & $2.661^{* * *}$ & \\
(Ref.: Professional - male) & & \\
\hline
\end{tabular}

\section{Mother's education:}

Leaving Certificate

Post-secondary

Degree or higher

$\begin{array}{ll}0.882 & 1.257 \pm \\ 0.932 & 1.197 \\ 1.102 & 1.689 * *\end{array}$

(Ref.: Junior Certificate or less)

Income quintile:
Second
Third
Fourth
Highest
(Ref.: Lowest quintile)

1.091
1.217
0.991
1.002

$1.432^{*}$
$1.684^{* *}$
$1.631^{* *}$
$1.537^{*}$

Lone parent family

$1.300^{*}$

0.864

Immigrant background

$1.656^{* * *}$

0.745

Has special educational need

$1.444^{* *}$

$0.539 * * *$

Lives in an urban area

$1.184 \pm$

1.007

\section{Year group:}

Leaving Certificate year

Left school

$1.274^{*}$

0.955

1.111

(Ref.: 5th year)

DEIS school
Fee-paying school
Gender mix:
Boys
Girls
(Ref.: Coed)
School size:
Medium
Large
(Ref.: Small)

1.189
$0.617^{*}$

\section{Extracurricular provision:}

Choir

$\begin{array}{ll}1.130 & 1.062 \\ 0.601^{* * *} & 0.681^{* *}\end{array}$

Musical instrument

Drama

$0.601 * * *$

$0.681 * *$

Dance

\begin{tabular}{|c|c|c|}
\hline $\begin{array}{l}\text { Prior school experience: } \\
\text { Took JC Art } \\
\text { Took JC Music } \\
\text { Took TY }\end{array}$ & $\begin{array}{c}10.055^{* * *} \\
0.736 * * * \\
1.123\end{array}$ & $\begin{array}{l}1.927 * * * \\
0.644 * * * \\
7.819 * * *\end{array}$ \\
\hline
\end{tabular}




\subsection{School Influences on Cultural Participation}

Chapter 2 considered the individual and family factors associated with participation in cultural activities outside of the school day. This section looks at whether the type of school attended by young people has any impact on these activities, over and above the effects of family background.

Because of differences in age at school start and whether young people had taken TY or not, the 17-year-olds in the study were at different stages in their school career: one-third were in fifth year, just over half were in their Leaving Certificate year and 17 per cent had already left school. Table 4.2 shows that cultural participation levels, with the exception of cinema attendance, are lower among those who have left school. This may reflect the way in which school promotes cultural engagement through, for example, extracurricular activities and the way in which young people's lives change as they make the transition to further/higher education or employment. However, it is also worth noting that those who have already left school tend to have been more disengaged from school, leaving school before the Leaving Certificate and/or not taking TY, so the patterns may reflect this profile. Those in their Leaving Certificate year have lower rates of involvement in singing/music, cinema and, particularly, structured cultural activities, suggesting a reduction in out-of-school activities in response to the impending exam.?

Frequency of reading for pleasure and singing/music is found to be lower among those in DEIS schools. Interestingly, however, involvement in structured cultural activities (such as drama and dance classes) is on a par with that found in nonDEIS and fee-paying schools, most likely reflecting the promotion of extracurricular cultural activities in DEIS schools (see Section 4.2). Young people in fee-paying schools are similar to those in non-DEIS schools except that those in fee-paying schools have lower levels of cinema attendance.

Young women in girls' schools have lower levels of reading and singing/music than might be expected given their profile. As with take-up of art and music, this means that the gender gap in these pursuits is slightly smaller in single-sex schools, though patterns of engagement are highly gendered overall. There is very little variation in cultural activities by school size, though cinema attendance is higher in larger schools. Although the model controls for urban/rural location, being in a larger school may reflect being in a larger city, accounting for this pattern.

\footnotetext{
${ }^{7}$ The questionnaire for young people did not include a question on the time they spent on homework or study. However, homework was recorded as a category in the time-use diary. The amount of time spent on homework during term-time among sixth years was twice the level found among fifth years (143 minutes compared with 72 minutes), which would suggest a curtailment of time for other activities.
} 


\section{Table 4.2 School Factors Associated with Out-Of-School Cultural Participation (Set of Logistic Regression Models Showing Odds Ratios)}

\begin{tabular}{|c|c|c|c|c|}
\hline & Reading & Singing/Music & Cinema & $\begin{array}{c}\text { Structured } \\
\text { Cultural } \\
\text { Activities }\end{array}$ \\
\hline $\begin{array}{l}\text { Year group: } \\
\text { Leaving Certificate year } \\
\text { Left school } \\
\text { (Ref.: } 5 \text { th year) }\end{array}$ & $\begin{array}{l}0.859 \\
0.580 * * *\end{array}$ & $\begin{array}{l}0.891 \pm \\
0.790^{*}\end{array}$ & $\begin{array}{l}0.803^{* * *} \\
1.020\end{array}$ & $\begin{array}{l}0.638^{* * *} \\
0.625^{* *}\end{array}$ \\
\hline $\begin{array}{l}\text { DEIS school } \\
\text { Fee-paying school }\end{array}$ & $\begin{array}{l}0.734^{* *} \\
0.860\end{array}$ & $\begin{array}{l}0.819^{*} \\
1.040\end{array}$ & $\begin{array}{l}1.128 \\
0.762 *\end{array}$ & $\begin{array}{l}1.038 \\
0.990\end{array}$ \\
\hline $\begin{array}{l}\text { Gender mix: } \\
\text { Boys } \\
\text { Girls } \\
\text { (Ref.: Coed) }\end{array}$ & $\begin{array}{l}0.842 \\
0.822^{*}\end{array}$ & $\begin{array}{l}1.007 \\
0.803^{* *}\end{array}$ & $\begin{array}{l}0.981 \\
1.092\end{array}$ & $\begin{array}{l}1.027 \\
1.113\end{array}$ \\
\hline $\begin{array}{l}\text { School size: } \\
\text { Medium } \\
\text { Large } \\
\text { (Ref.: Small) }\end{array}$ & $\begin{array}{l}1.053 \\
1.044\end{array}$ & $\begin{array}{l}0.969 \\
0.875\end{array}$ & $\begin{array}{l}1.028 \\
1.236^{*}\end{array}$ & $\begin{array}{l}0.983 \\
0.879\end{array}$ \\
\hline $\begin{array}{l}\text { Curricular provision: } \\
\text { Art } \\
\text { Music }\end{array}$ & $\begin{array}{l}1.114 \\
0.817 \pm\end{array}$ & $\begin{array}{l}0.948 \\
1.130\end{array}$ & $\begin{array}{l}1.211^{*} \\
0.897\end{array}$ & $\begin{array}{l}0.933 \\
1.139\end{array}$ \\
\hline $\begin{array}{l}\text { Extracurricular provision: } \\
\text { Choir } \\
\text { Musical instrument } \\
\text { Drama } \\
\text { Dance }\end{array}$ & $\begin{array}{l}1.241^{*} \\
0.879 \pm \\
0.959 \\
1.084\end{array}$ & $\begin{array}{l}1.001 \\
1.064 \\
1.092 \\
1.007\end{array}$ & $\begin{array}{l}0.896 \\
0.978 \\
0.951 \\
1.068\end{array}$ & $\begin{array}{l}0.824^{*} \\
1.048 \\
1.000 \\
1.174^{*}\end{array}$ \\
\hline $\begin{array}{l}\text { Prior school experience: } \\
\text { Took TY }\end{array}$ & 1.082 & $1.354^{* * *}$ & 1.050 & $1.572 * * *$ \\
\hline N & 5,972 & 5,972 & 5,972 & 5,972 \\
\hline
\end{tabular}

Note: $\quad{ }^{* * *} \mathrm{p}<.001 ;{ }^{* *} \mathrm{p}<.01 ;{ }^{*} \mathrm{p}<.05 ; \pm \mathrm{p}<.10$. These models control for the individual
and family background characteristics analysed in Chapter 2.

There is only slight variation in cultural activities by curricular and extracurricular provision. Those in schools offering music tend to have somewhat lower rates of reading for pleasure, while art provision is associated with higher cinema attendance levels. Reading for pleasure is more common where young people attend schools with a choir and slightly less common where they offer musical instrument tuition. Involvement in structured cultural activities is more prevalent in schools offering dance classes and less so in those offering choir. Interesting patterns emerge in relation to TY participation, with significantly higher rates of involvement in structured cultural activities and singing/music among those who had taken part in TY, when compared to their counterparts. 
Table 4.3 looks at the same set of school factors in relation to frequency of engagement in watching TV/films and playing computer games. Being in the exam year appears to constrain time spent playing computer games and watching TV/ films during the week (but not at the weekend). Those who have left school watch more TV during the week but spend less time on computer games at the weekend than those in fifth year. Even taking account of their more disadvantaged profile, those attending DEIS schools resemble those in non-DEIS schools in this regard, except for slightly higher rates of computer gaming during the week. Those in feepaying schools spend less time on TV and computer games during the week but have similar levels of weekend engagement.

There is little variation in digital cultural engagement by school size or gender mix, though, as with other activities, the gender gap is slightly reduced in singlesex schools. Students from schools that offer music as a curricular activity have lower levels of TV/film watching during the week. There is little systematic variation according to extracurricular provision, though there are slightly higher levels of weekend TV/film watching among those in schools offering drama. Levels of TV/film watching during the week are much lower among those who had taken part in TY as is, to some extent, time spent on computer games during the week. These patterns are likely to reflect the greater academic orientation of this group of students, rather than the direct impact of participation. 


\section{Table 4.3 School Factors Associated with High Levels of Participation in Digital Culture (Set of Logistic Regression Models Showing Odds Ratios)}

\begin{tabular}{|c|c|c|c|c|}
\hline & $\begin{array}{l}\text { TV/films } \\
\text { - Weekday }\end{array}$ & $\begin{array}{l}\text { TV/films } \\
\text { - Weekend }\end{array}$ & $\begin{array}{c}\text { Computer games } \\
\text { - Weekday }\end{array}$ & $\begin{array}{c}\text { Computer games } \\
\text { - Weekend }\end{array}$ \\
\hline $\begin{array}{l}\text { Year group: } \\
\text { Leaving Certificate year } \\
\text { Left school } \\
\text { (Ref.: } 5 \text { th year) }\end{array}$ & $\begin{array}{l}0.869 \pm \\
1.323^{* * *}\end{array}$ & $\begin{array}{l}0.954 \\
1.036\end{array}$ & $\begin{array}{l}0.667 * * * \\
1.076\end{array}$ & $\begin{array}{l}0.748 * * * \\
0.806 \pm\end{array}$ \\
\hline $\begin{array}{l}\text { School social mix: } \\
\text { DEIS school } \\
\text { Fee-paying school }\end{array}$ & $\begin{array}{l}1.149 \\
0.724 \pm\end{array}$ & $\begin{array}{l}1.012 \\
0.905\end{array}$ & $\begin{array}{l}1.203 \pm \\
0.652 *\end{array}$ & $\begin{array}{l}1.119 \\
0.842\end{array}$ \\
\hline $\begin{array}{l}\text { Gender mix: } \\
\text { Boys } \\
\text { Girls } \\
\text { (Ref.: Coed) }\end{array}$ & $\begin{array}{l}0.898 \\
1.215 \pm\end{array}$ & $\begin{array}{l}0.963 \\
1.047\end{array}$ & $\begin{array}{l}0.993 \\
0.798\end{array}$ & $\begin{array}{l}0.897 \\
0.936\end{array}$ \\
\hline $\begin{array}{l}\text { School size: } \\
\text { Medium } \\
\text { Large } \\
\text { (Ref.: Small) }\end{array}$ & $\begin{array}{l}1.036 \\
1.166\end{array}$ & $\begin{array}{l}0.992 \\
1.044\end{array}$ & $\begin{array}{l}1.087 \\
0.894\end{array}$ & $\begin{array}{l}0.979 \\
0.900\end{array}$ \\
\hline $\begin{array}{l}\text { Curricular provision: } \\
\text { Art } \\
\text { Music }\end{array}$ & $\begin{array}{l}1.173 \\
0.731 * *\end{array}$ & $\begin{array}{l}0.938 \\
1.023\end{array}$ & $\begin{array}{l}1.180 \\
0.860\end{array}$ & $\begin{array}{l}1.119 \\
0.948\end{array}$ \\
\hline $\begin{array}{l}\text { Extracurricular provision: } \\
\text { Choir } \\
\text { Musical instrument } \\
\text { Drama } \\
\text { Dance }\end{array}$ & $\begin{array}{l}1.002 \\
0.885 \\
1.082 \\
0.905\end{array}$ & $\begin{array}{l}0.945 \\
0.937 \\
1.138 * \\
0.909\end{array}$ & $\begin{array}{l}0.904 \\
1.163 \pm \\
0.920 \\
1.071\end{array}$ & $\begin{array}{l}0.982 \\
1.014 \\
0.921 \\
0.953\end{array}$ \\
\hline $\begin{array}{l}\text { Prior school experience: } \\
\text { Took TY }\end{array}$ & $0.773^{* *}$ & 1.007 & $0.836 \pm$ & 1.013 \\
\hline $\mathrm{N}$ & 5,972 & 5,972 & 5,972 & 5,972 \\
\hline
\end{tabular}

The 17-year-olds were asked about the benefits of their second-level education for a range of outcomes, including appreciating art/music and appreciating reading for pleasure. They were most positive about the benefits of their second-level education in terms of making new friends, helping them communicate well with others, their reading and writing skills, knowing how to find things out and thinking for themselves (Figure 4.3). However, young people are less positive about the extent to which school has prepared them to engage with, and appreciate, different skills and sets of knowledge (appreciating reading for pleasure or art/music, getting involved in sports and having computer skills). They are also less likely to report that their second-level education has been 'a lot' of help in preparing for the world of work or for adult life. 


\section{Figure 4.3 Perceived Benefits of Second-Level Education among 17-Year-Olds}

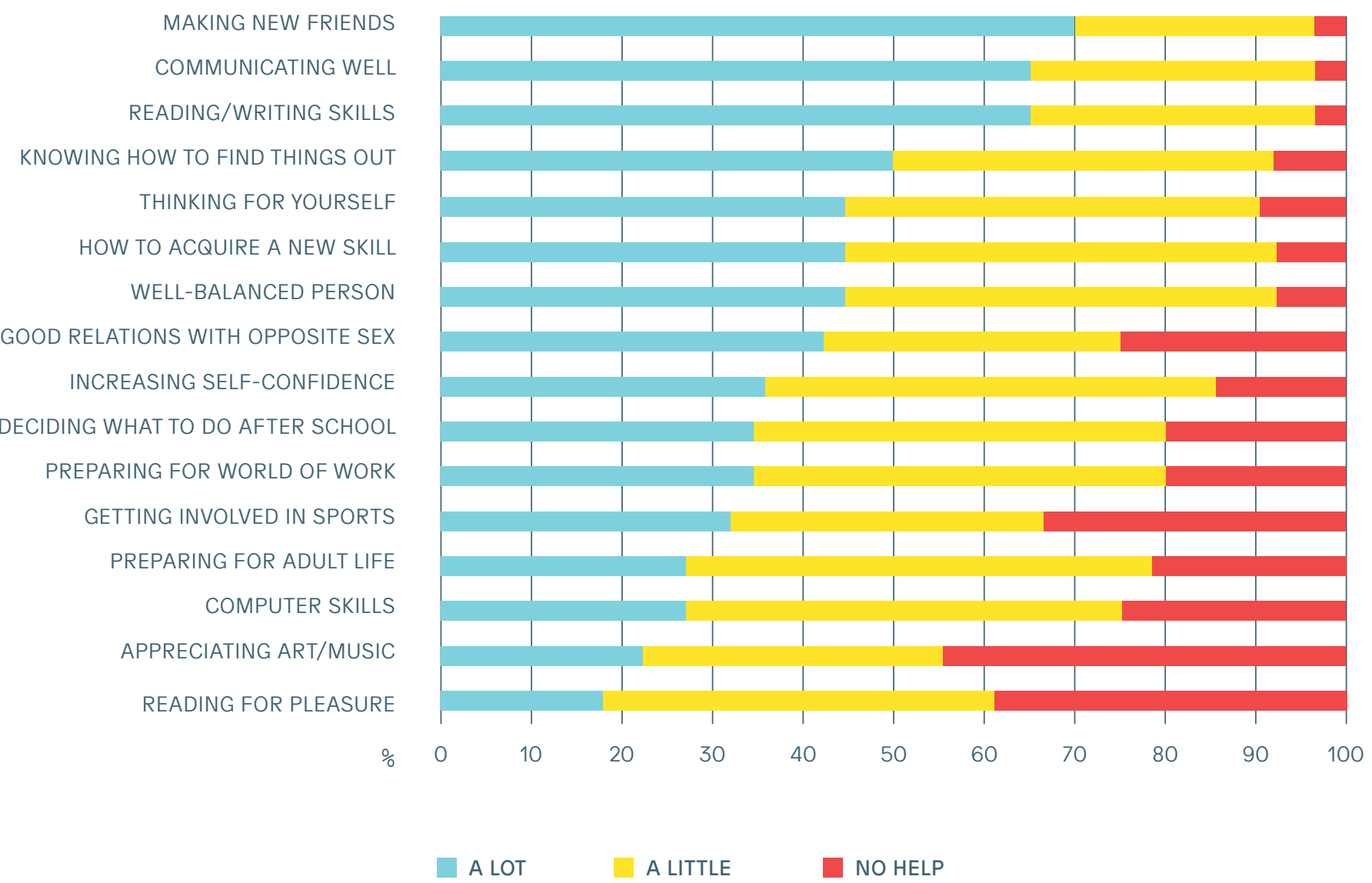

Young people's school characteristics and experiences are also reflected in the extent to which they feel that their second-level education has enhanced their enjoyment of reading for pleasure, or their appreciation of art and culture. There is variation in relation to stage in the schooling career, but this most likely reflects the differences in the profile of the groups discussed above. Those attending DEIS schools highlight the benefits of their schooling for their art and culture appreciation to a greater extent than might be expected given their more disadvantaged profile (Table 4.4). Responses are also somewhat more positive among those in feepaying schools. There is no variation by the gender mix of the school, school size or extracurricular provision. The exception is the greater appreciation of art and culture noted by those in schools offering musical instrument tuition. Those who had taken TY were more likely to say that their schooling had enhanced their enjoyment of reading and art and culture. Taking Leaving Certificate art or, more particularly, music, were associated with more positive perceptions of the value of their schooling to the appreciation of culture. However, taking Leaving Certificate art was negatively associated with seeing second-level education as having enhanced their reading for pleasure. This may reflect the less academically oriented profile of this group (see above) rather than the direct impact of subject take-up. 
Table 4.4 School Factors Associated with 17-Year-Olds Feeling their Second- Level Education Was 'A Lot' of Help in Appreciating Reading for Pleasure and Art and Culture (Logistic Regression Models Showing Odds Ratios)

\begin{tabular}{|c|c|c|}
\hline & Reading for Pleasure & Art \& Culture \\
\hline $\begin{array}{l}\text { Year group: } \\
\text { Leaving Certificate year } \\
\text { Left school } \\
\text { (Ref.: } 5 \text { th year) }\end{array}$ & $\begin{array}{l}1.001 \\
0.802 *\end{array}$ & $\begin{array}{l}0.825^{*} \\
0.734^{* *}\end{array}$ \\
\hline $\begin{array}{l}\text { Year group: } \\
\text { DEIS school } \\
\text { Fee-paying school }\end{array}$ & $\begin{array}{l}1.043 \\
1.188\end{array}$ & $\begin{array}{l}1.304^{* *} \\
1.215 \pm\end{array}$ \\
\hline $\begin{array}{l}\text { Gender mix: } \\
\text { Boys } \\
\text { Girls } \\
\text { (Ref.: Coed) }\end{array}$ & $\begin{array}{l}1.024 \\
1.027\end{array}$ & $\begin{array}{l}0.951 \\
0.923\end{array}$ \\
\hline $\begin{array}{l}\text { School size: } \\
\text { Medium } \\
\text { Large } \\
\text { (Ref.: Small) }\end{array}$ & $\begin{array}{l}1.083 \\
1.084\end{array}$ & $\begin{array}{l}1.171 \\
1.065\end{array}$ \\
\hline $\begin{array}{l}\text { Extracurricular provision: } \\
\text { Choir } \\
\text { Musical instrument } \\
\text { Drama } \\
\text { Dance }\end{array}$ & $\begin{array}{l}0.920 \\
0.976 \\
0.943 \\
1.023\end{array}$ & $\begin{array}{l}0.924 \\
1.197 * * \\
1.060 \\
0.904\end{array}$ \\
\hline $\begin{array}{l}\text { Prior school experience: } \\
\text { Took TY } \\
\text { Took JC Art } \\
\text { Took JC Music }\end{array}$ & $\begin{array}{l}1.240^{* *} \\
0.865^{*} \\
1.027\end{array}$ & $\begin{array}{l}1.163 \pm \\
1.668 * * * \\
2.002 * * *\end{array}$ \\
\hline $\mathrm{N}$ & 5,972 & 5,972 \\
\hline
\end{tabular}
Note: $\quad * * * p<.001 ; * * p<.01 ; * p<.05 ; \pm p<.10$. These models control for the individual
and family background characteristics analysed in Chapter 2.

Table 4.5 looks at the school factors associated with rating art and culture as a more important aspect of life in general, controlling for the same individual and family background factors considered in Chapter 2. Very few of the school characteristics were significantly associated with giving a higher rating to art and culture, though those attending single-sex schools gave a somewhat lower rating than might be expected, given their more advantaged profile. Similarly, responses did not vary significantly by a school's provision of extracurricular activities. However, those who had taken TY and those who had studied art or music at junior cycle level placed a significantly higher emphasis on art and culture than other 17-year-olds. 
Table 4.5 School Factors Associated with 17-Year-Olds' Rating of the Importance of Art and Culture for Life in General (OLS Regression Model)

\begin{tabular}{|c|c|}
\hline & Art \& Culture \\
\hline $\begin{array}{l}\text { Year group: } \\
\text { Leaving Certificate year } \\
\text { Left school } \\
\text { (Ref.: } 5 \text { th year) }\end{array}$ & $\begin{array}{r}0.018 \\
-0.031\end{array}$ \\
\hline $\begin{array}{l}\text { Year group: } \\
\text { DEIS school } \\
\text { Fee-paying school }\end{array}$ & $\begin{array}{l}-0.083 \\
0.018\end{array}$ \\
\hline $\begin{array}{l}\text { Gender mix: } \\
\text { Boys } \\
\text { Girls } \\
\text { (Ref.: Coed) }\end{array}$ & $\begin{array}{l}-0.108 \pm \\
-0.165^{* *}\end{array}$ \\
\hline $\begin{array}{l}\text { School size: } \\
\text { Medium } \\
\text { Large } \\
\text { (Ref.: Small) }\end{array}$ & $\begin{array}{r}-0.005 \\
0.003\end{array}$ \\
\hline $\begin{array}{l}\text { Extracurricular provision: } \\
\text { Choir } \\
\text { Musical instrument } \\
\text { Drama } \\
\text { Dance }\end{array}$ & $\begin{array}{l}-0.043 \\
0.006 \\
0.007 \\
0.017\end{array}$ \\
\hline $\begin{array}{l}\text { Prior school experience: } \\
\text { Took TY } \\
\text { Took JC Art } \\
\text { Took JC Music }\end{array}$ & $\begin{array}{l}0.187^{* *} \\
0.309^{* *} \\
0.308^{* * *}\end{array}$ \\
\hline $\mathrm{N}$ & 5,972 \\
\hline
\end{tabular}




\subsection{Conclusions}

This chapter has explored the extent to which young people's experience of cultural participation varies by the type of second-level school they attend. Access to artsrelated subjects as curricular or extracurricular activities varied across different types of school, with fee-paying and larger schools more likely to provide them. Patterns of provision also differed by gender mix, with girls' schools being more likely to provide Leaving Certificate art and music and cultural activities outside school (with the exception of drama). The interaction of school provision and individual subject choice meant that take-up of art and music at senior cycle level was highly gendered and, in the case of music, highly socially differentiated. Junior cycle exposure to these subjects, as well as taking part in TY, facilitated take-up at Leaving Certificate level.

Taking TY is also associated with out-of-school or after-school cultural activities, with higher levels of involvement in structured cultural activities and making music among those who had taken the programme. Stage of educational career made a difference too, with lower levels of participation found in reading, making music and structured activities among those who had left school. There also appeared to be a curtailment of involvement in the exam year, with lower levels of participation in all activities (except in relation to watching TV/films at the weekends).

Differences in cultural participation between fee-paying and other schools largely reflect the more advantaged profile of the students concerned, though levels of cinema attendance and involvement in digital culture (during the week) are lower among this group than among their peers in other school types. Those attending DEIS schools have lower levels of reading for pleasure and making music but the emphasis in DEIS schools on providing extracurricular cultural activities appears to have eliminated the gap in participation in structured activities; this also seems to have led to this group of young people having a more positive view of the value of their education in enhancing their appreciation of art and culture. 


\section{Chapter 5 \\ Cultural Participation and Outcomes among Young People}

\subsection{Introduction}

Previous research based on Growing Up in Ireland (GUI) data indicated that different types of cultural participation had implications for young people's outcomes at the age of 13. Reading and taking part in structured cultural activities outside school time contributed to cognitive development (in terms of both verbal and numeric skills) as well as to academic self-confidence (Smyth, 2016). Reading also contributed to socio-emotional wellbeing. Watching a lot of TV was found to promote verbal skills but at the expense of having greater socio-emotional difficulties. This chapter builds upon this analysis to look at young people's outcomes at 17 years of age. The chapter looks at a broad range of cognitive and non-cognitive outcomes and how they relate to earlier cultural participation.

\subsection{Cultural Participation and Cognitive Development}

The 17-year-olds were given cognitive tests at the time of the interview. The 'animal naming test' involved the participant naming as many animals as they could think of in one minute; this test reflects both general knowledge and executive function (Murphy et al., forthcoming). The young person's vocabulary was also tested using the same vocabulary measure given to participants of the British Cohort Study 1970 at age 42 and the Millennium Cohort Study sample when they were 14 in 2015. This test involved 20 multiple-choice questions, which required participants to match words that had the closest meaning to the target. ${ }^{8}$ As well as these cognitive tests, young people were asked to report their grades from their Junior Certificate exam. Each subject was assigned a grade point on the basis of the level taken and grade received (ranging from ten for a higher-level A grade to one for a foundation-level $D$ grade, with zero assigned to grades $E, F$ and $N G$ ). The grade points were then averaged over all exam subjects taken to give an average score. The same procedure was adopted to provide the grade points achieved in maths.

\footnotetext{
${ }^{8}$ The 17 -year-olds were also given a financial literacy test that consisted of three short questions aimed at testing the respondent's ability to work out relatively simple mathematical calculations. However, the small number of items makes the results difficult to analyse systematically. For that reason, Junior Certificate maths grades are used here as a measure of mathematical skills.
} 
The models presented in Table 5.1 control for reading and mathematics achievement test scores at nine years and verbal and numerical reasoning test scores at 13, as well as the individual and family background factors analysed in Chapter 2 and the school characteristics discussed in Chapter 4. The results can therefore be interpreted as indicating the impact of participation in cultural activities at nine and 13 years on changes in cognitive skills up to 17. Reading frequently in middle childhood and adolescence is significantly related to an improvement in verbal ability (naming test and vocabulary) by 17 years. Involvement in structured cultural activities has no significant relationship with changes in verbal ability over time. The findings for involvement in digital culture are complex. Those who watched more TV at 13 did better on the animal naming test (perhaps because of improved general knowledge) but did somewhat worse on the vocabulary test. Similar patterns were evident for very high levels of involvement in playing computer games at 13, with lower vocabulary and higher naming scores.

Performance in the Junior Certificate is likely to capture verbal and numerical skills, but will also reflect student motivation and the amount of time spent on homework and study. The frequency of reading for pleasure at 13 years is significantly related to both overall performance and maths grade. Those who read frequently at nine do better overall, but this effect is mediated through verbal and numerical test scores at 13. Involvement in structured cultural activities at nine is associated with higher grades overall, while maths grades are related to involvement at the age of 13. More time spent on TV and computer games at 13 is negatively related to overall performance and to maths grades (Table 5.1). 
Table 5.1 Relationship between Cultural Activities at 9 and 13 Years of Age and Cognitive Outcomes at 17 Years of Age (OLS Regression Models)
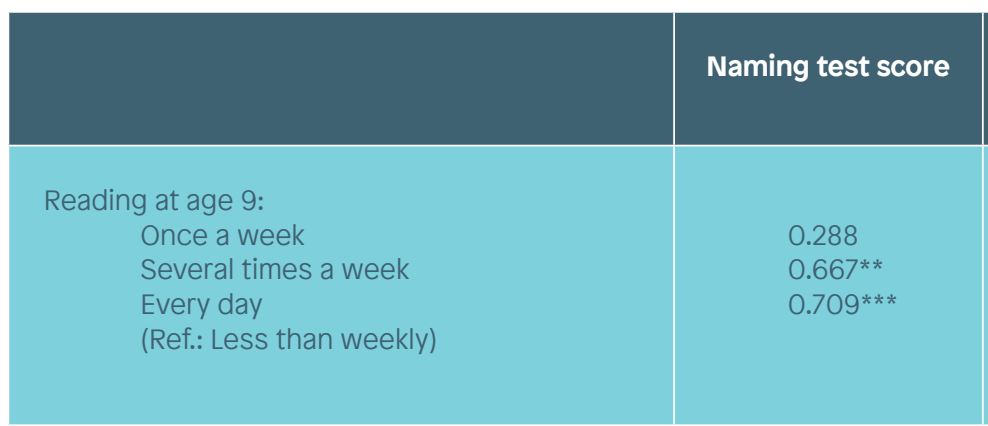

$\begin{gathered}\text { Vocabulary test } \\ \text { score }\end{gathered}$

-0.019
-0.109
$0.210 \pm$

\begin{tabular}{|c|c|}
\hline $\begin{array}{c}\text { JC grade point } \\
\text { average } \\
\text { (all subjects) }\end{array}$ & JC Maths grade \\
& \\
& \\
$-0.109^{*}$ & -0.031 \\
0.033 & 0.104 \\
0.054 & 0.089 \\
& \\
\hline
\end{tabular}

Involved in structured cultural activities at 9

0.202

$-0.031$

$0.092 * * *$

0.055

TV at age 9:
$\begin{aligned} & \text { 1-3 hours } \\ & 3+\text { hours } \\ & \text { (Ref.: }<1 \text { hour) }\end{aligned}$

\begin{tabular}{|l|l|}
\hline-0.240 & 0.096 \\
$-0.915^{* *}$ & 0.046 \\
& \\
\hline
\end{tabular}

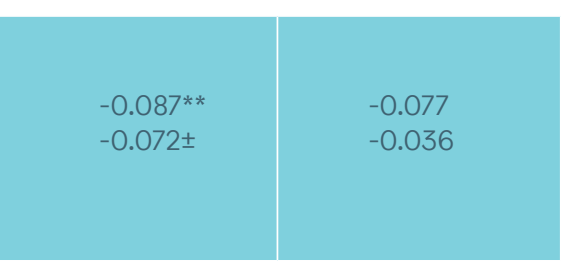

Computer games at 9:
$1-3$ hours
$3+$ hours
(Ref.: $<1$ hour)

$-0.103$

0.156

$-0.028$

0.002

0.028

0.011
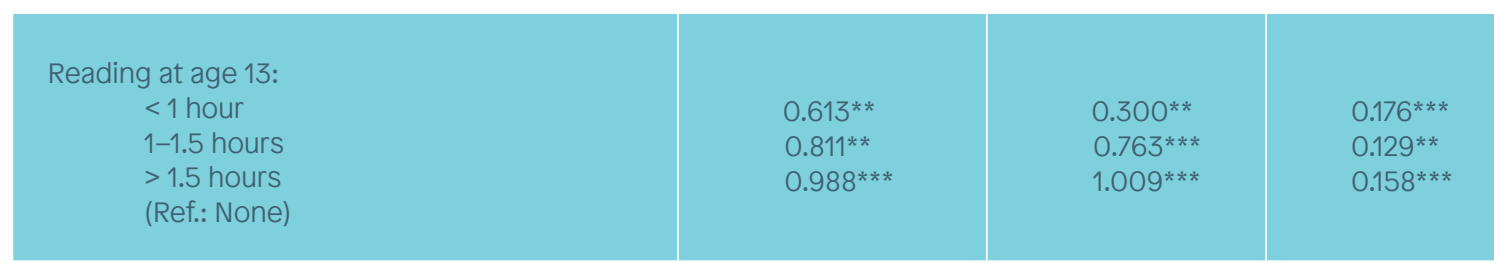

$-0.038$

Involved in structured cultural activities at 13

0.049

$-0.019$

0.038

$0.141^{* * *}$

TV at age 13:
1-2 hours
$2-3$ hours
$3+$ hours
(Ref.: $<1$ hour)

\section{Computer games at 13 :}

\begin{tabular}{|c|c|c|c|c|}
\hline $1-1.5$ hours & 0.013 & 0.059 & -0.028 & -0.065 \\
\hline $1.5-3$ hours & 0.090 & 0.053 & $-0.115^{* *}$ & $-0.223^{* * *}$ \\
\hline $\begin{array}{l}3+\text { hours } \\
\text { (Ref.: }<1 \text { hour) }\end{array}$ & $0.589 \pm$ & $-0.382^{*}$ & $-0.145^{* * *}$ & -0.145 \\
\hline
\end{tabular}

(Ref.: $<1$ hour)

\begin{tabular}{|l|l|l|l|} 
& & & \\
0.189 & $-0.228^{*}$ & $-0.066^{*}$ & $-0.099 \pm$ \\
$0.529^{*}$ & $-0.316^{* *}$ & -0.013 & -0.040 \\
$0.641^{* *}$ & $-0.180 \pm$ & $-0.131^{*}$ & $-0.156^{*}$ \\
& & & \\
\hline
\end{tabular}

\begin{tabular}{|l|r|r|r|}
\hline N & 5,968 & 5,929 & $5,889 \quad 5,881$ \\
\hline
\end{tabular}
Note: $\quad{ }^{* * *} p<.001 ; * * p<.01 ; * p<.05 ; \pm p<.10$. The models control for the individual, family background and school factors outlined in Chapters 2 and
4 as well as reading and maths achievement at nine and verbal and numeric aptitude test scores at 13. Except for the Junior Certificate models, the models also control for number of higher level Junior Certificate subjects taken. 
Table 5.2 shows the association between cognitive test scores and involvement in cultural activities at 17 years. Because they are measured at the same time-point, the results cannot be taken as evidence of impact; they only capture association. Those who read frequently at 17 tend to have significantly higher cognitive scores. Vocabulary test scores are higher among those who play a lot of computer games and, to some extent, sing or play an instrument. In contrast, vocabulary scores are somewhat lower among those who go to the cinema frequently.

\section{Table 5.2 Relationship between Cultural Activities and Cognitive Outcomes at 17 Years of Age (OLS Regression Models)}

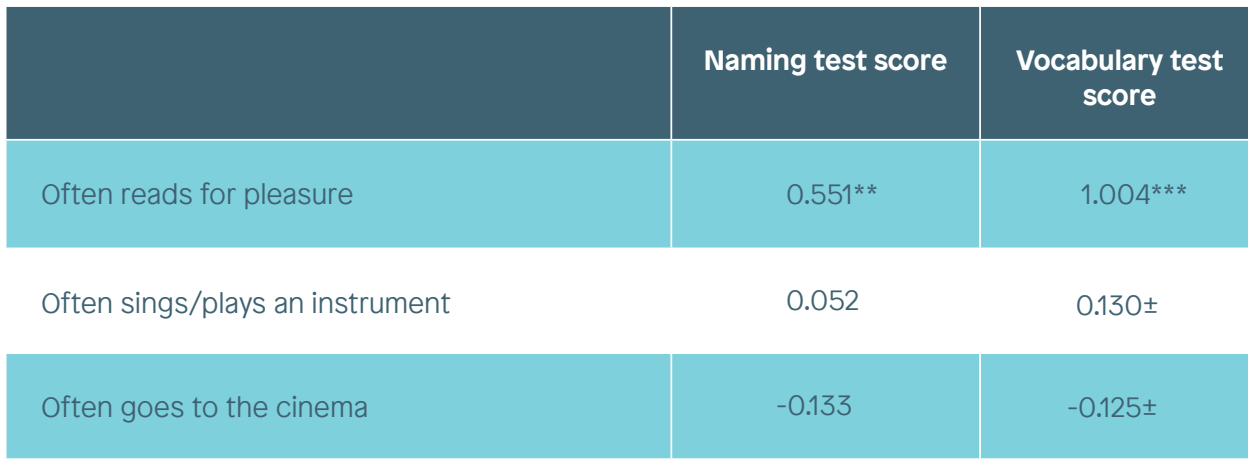

Involved in structured cultural activities

0.150

0.110

\begin{tabular}{|c|c|c|}
\hline Watches a lot of TV/film & 0.312 & -0.085 \\
\hline Plays a lot of computer games & 0.049 & $0.226 *$ \\
\hline $\mathrm{N}$ & 5,968 & 5,929 \\
\hline
\end{tabular}

Note: $\quad * * * p<.001 ; * * p<.01 ; * p<.05$. The models control for the individual, family background and school factors outlined in Chapters 2 and 4 . 


\subsection{Cultural Participation and Non-Cognitive Outcomes}

Chapter 1 highlighted a gap in research on the effects of cultural participation on non-cognitive outcomes. Because GUI collected information on a rich variety of noncognitive outcomes, it provides an opportunity to look at this relationship. However, the findings should be interpreted with some caution as many of the non-cognitive measures were collected for the first time in the third wave - when respondents were 17 years of age. The patterns therefore cannot be taken as measures of the impact of cultural participation but rather as associations.

Information on a number of different non-cognitive outcomes was collected from 17-year-olds (for further details, see Murphy et al., forthcoming). Firstly, young people were asked to rate their level of satisfaction with life from zero (extremely unsatisfied) to ten (extremely satisfied). Secondly, self-esteem (the value that a person places on him/herself) was measured using six of the ten items from the Rosenberg Self-Esteem Scale (including items such as "I am able to do things as well as most other people'). Thirdly, self-efficacy captures the extent to which people feel in control of their actions and outcomes and was measured using an adaptation of Sherer et al.'s (1982) instrument. It included items related to general self-efficacy ('If I can't do a job the first time I keep trying until I can') as well as social self-efficacy ('I find it easy to make new friends'), with four answer categories ranging from 'strongly agree' to 'strongly disagree'. Fourthly, people with an internal locus of control believe that they are in control of their own lives, while those with an external locus of control see control as being out of their hands. The scale included in the study was the Rotter locus of control scale (and included items such as 'Becoming a success is a matter of hard work. Lucky breaks have little or nothing to do with it').

The Strengths and Difficulties Questionnaire (SDQ) is a measure of socio-emotional difficulties, which was completed by the young people's parents when they were nine and 13 years of age. This was also administered when they were 17, where the total difficulties score was used as a measure of socio-emotional wellbeing.

The results shown in Table 5.3 show few consistent relationships between reading or participation in structured cultural activities and the non-cognitive outcomes considered here. Locus of control is somewhat higher among those who read daily at nine years, but no such effect is evident for reading patterns at 13. Involvement in structured cultural activities is associated with somewhat higher life satisfaction and self-efficacy but these effects are at the margins of significance. Slightly more consistent findings emerge in relation to involvement in digital culture. Spending three or more hours playing computer games at the age of 13 was associated with lower levels of life satisfaction, self-esteem, self-efficacy and locus of control four years later. Internal locus of control is significantly lower among those who played a lot of computer games at nine, even when gaming at 13 is taken into account. TV watching for three or more hours at 13 is associated with significantly lower selfesteem at 17 but the relationship with other outcomes is not significant. 
Because of the lack of systematic effects of earlier cultural participation (with the exception of computer gaming), the models presented in Table 5.4 are less complex, looking at the relationship between cultural activities at 17 and non-cognitive outcomes, controlling only for gender, mother's education, having a SEN and educational stage (fifth year, sixth year or having left school). Life satisfaction levels are higher where young people regularly make music, go to the cinema and (to some extent) are involved in music/drama clubs or lessons, but lower where they play computer games or watch TV/films regularly. Self-esteem is also significantly lower where young people play computer games regularly, though reading and making music are also associated with lower levels of self-esteem. On closer inspection, the latter relationships are significant only for males; they appear to relate to males who read frequently being less extravert and those who engage in singing/playing an instrument being more alienated from their peers. Research by Lehman and Dumais (2017) found that males involved in highbrow culture were more likely to be bullied by their peers. So the patterns found in GUI may reflect the fact that the strongly gendered nature of music involvement means that males who are involved are construed by their peers as 'different'.

Involvement in structured cultural activities and cinema attendance are associated with greater self-efficacy, while frequent computer gaming and TV watching are significantly related to lower levels of self-efficacy. Involvement in structured cultural activities is associated with a lower sense of internal locus of control. It is difficult to disentangle what is driving this pattern but it may be a reaction to having a fixed time commitment over which the young person has little control. Involvement in reading, music or other cultural activities is not significantly related to socio-emotional wellbeing. However, watching more TV/films and, particularly, playing computer games more frequently are associated with higher levels of socioemotional difficulties. Further analysis examined whether this pattern holds when earlier socio-emotional difficulties are taken into account (not shown here). It found that the size of the effect for computer games becomes smaller but that it is still large and significant, indicating that socio-emotional difficulties have increased between 13 and 17 years for those highly involved in computer gaming. 
Table 5.4 Relationship between Cultural Activities and Non-Cognitive Outcomes at 17 Years of Age (OLS Regression Models)

\begin{tabular}{|c|c|c|c|c|c|}
\hline & Life satisfaction & Self-esteem & Self-efficacy & Locus of control & $\begin{array}{l}\text { Socio-emotional } \\
\text { difficulties } \\
\text { (parent report) }\end{array}$ \\
\hline Often reads for pleasure & $-0.122 \pm$ & $-0.268^{*}$ & 0.003 & 0.157 & 0.081 \\
\hline Often sings/plays an instrument & $0.173^{* *}$ & $-0.225^{*}$ & 0.007 & $-0.206 \pm$ & -0.167 \\
\hline Often goes to the cinema & $0.126^{*}$ & 0.144 & $0.170 *$ & 0.067 & -0.189 \\
\hline Involved in structured cultural activities & $0.130 \pm$ & 0.071 & $0.377^{* * *}$ & $-0.317^{* *}$ & 0.141 \\
\hline Watches a lot of TV/film & $-0.185^{* *}$ & $-0.214 \pm$ & $-0.210^{*}$ & -0.092 & $0.477^{* *}$ \\
\hline Plays a lot of computer games & $-0.390 * * *$ & $-0.484^{* *}$ & $-0.462 * * *$ & -0.133 & $1.331 * * *$ \\
\hline N & 5,915 & 5,915 & 5,915 & 5,915 & 5,915 \\
\hline
\end{tabular}

Note: $\quad{ }^{* * *} p<.001 ;{ }^{* *} p<.01 ;{ }^{*} p<.05 ; \pm p<.10$. The models control for gender, mother's education and SEN.

\subsection{Conclusions}

This chapter has looked at the relationship between participation in cultural activities and a range of cognitive and non-cognitive outcomes at 17 years of age. As might be expected, frequent reading for pleasure at a younger age is associated with the greater development of vocabulary levels and academic performance. Involvement in structured cultural activities (such as music or drama lessons/ clubs) is also associated with higher Junior Certificate performance. However, these kinds of cultural participation have little systematic relationship with non-cognitive outcomes such as self-esteem or socio-emotional wellbeing. In contrast, involvement in digital culture, especially computer gaming, has a stronger relationship with non-cognitive outcomes than with cognitive ones. Although linked to better scores on the animal naming test (reflecting general knowledge), watching three or more hours of TV at 13 years is associated with lower vocabulary scores, lower Junior Certificate grades and poorer self-esteem four years later. Those who spent three or more hours playing computer games at 13 are found to have consistently poorer outcomes than their peers in the form of lower vocabulary scores and lower grades, poorer life satisfaction, self-esteem, self-efficacy and locus of control, and higher levels of socio-emotional difficulties. 


\section{Chapter 6 \\ Conclusions}

\subsection{Introduction}

This report has used Growing Up in Ireland (GUI) data on 6,216 17-year-olds to look at their engagement in cultural activities and the individual, family and school characteristics associated with such involvement. This period is an interesting time in their lives as they prepare for leaving school (with some already having left school) and their activities are likely to reflect their growing independence from their families. The study builds upon earlier analyses of GUI (Smyth, 2016) to document the experiences of Cohort ' 98 at 17 years of age, relating their participation at this stage to the kinds of activities in which they were involved at nine and 13 years of age. As in the earlier study, a broad definition of cultural participation is adopted, encompassing reading, music, structured lessons/clubs, cinema, TV/film viewing and playing computer games. ${ }^{9}$ This chapter presents a brief overview of the main findings of the study and highlights some of the implications for policy development.

\subsection{Main Findings}

One of the most striking findings relates to the highly gendered nature of involvement in cultural activities. Young women are much more likely than young men to read for pleasure, to sing or play an instrument and to be involved in structured cultural activities (such as taking music or drama lessons). In contrast, young men are much more engaged in some aspects of digital culture, namely playing computer games. In fact, gender differences were so marked that young women from disadvantaged backgrounds had almost the same level of involvement in more highbrow cultural activities as young men from more advantaged backgrounds.

A marked social gradient was also evident: young people from professional/ managerial or graduate families were found to be more likely to read, make music and attend music/drama lessons and less likely to play computer games or watch TV/films (at least during the week). In contrast with analyses on this group of young people at younger ages, household income was not directly related to participation in cultural activities (once parental education and social class were taken into account).

\footnotetext{
${ }^{9}$ Some aspects of cultural participation, such as drawing/painting or going 
Looking at trends in cultural participation from middle childhood to early adulthood, two main features are evident. Firstly, there is an overall decline in the frequency of engagement in all types of cultural activities, with a very marked increase in the proportion who report never reading for pleasure. Some of this decline reflects the stage of young people's lives (for example, preparing for the Leaving Certificate) but it is also part of a longer-term fall-off in participation in more structured social activities (see Lunn et al., 2013, for similar findings on sports participation). Secondly, patterns of cultural engagement are established relatively early and those who are more involved in activities like reading or playing computer games at nine and 13 years are much more likely to be involved at the age of 17 . At the same time, given the decline in participation between 13 and 17, early involvement appears to be a necessary but not a sufficient condition for later involvement.

For most 17-year-olds, school remains an important domain for access to, and experience of, arts and culture. However, a significant minority of young people were critical of the extent to which their second-level education had enhanced their experience of reading for pleasure or contributed to their appreciation of art and culture. Access to Leaving Certificate art or music was found to vary by school type, with fee-paying, larger and girls' schools more likely to provide these subjects. Only 15 per cent of 17-year-olds were taking (or had taken) art for the Leaving Certificate, while 12 per cent were taking music. Art take-up was highly gendered but not very socially differentiated; take-up rates were also higher for migrant young people and those with a special educational need (SEN). In contrast, music take-up was highly socially differentiated, with higher take-up among those from graduate and higherincome families. In fact, this was the only aspect of cultural engagement at 17 years that varied significantly by income (over and above the effects of social class and mother's education).

Extracurricular provision also varied by school type, with larger schools more likely to provide after-school cultural activities. Fee-paying schools were more likely to provide music (choir, instrument tuition) or drama, but rates of provision were as high in DEIS schools as in non-DEIS schools. As with curricular culture, girls' schools were more likely than other school types to offer these extracurricular activities (with the exception of drama).

The school experience made a difference to young people's cultural engagement outside school. Levels of reading and making music were significantly lower in DEIS schools, all else being equal, though rates of involvement in structured cultural activities were on a par with other schools, most likely reflecting the relatively high levels of extracurricular cultural provision. Young people who attended DEIS schools also placed a stronger emphasis on the contribution of their schooling to their appreciation of art and culture than might be expected given their more disadvantaged profile. 
Having taken part in the Transition Year (TY) programme was significantly related to higher levels of involvement in singing/playing an instrument and in structured cultural activities, as well as lower levels of engagement in digital culture (at least on weekdays). This group of young people was also more positive about the contribution of their schooling to reading for pleasure and appreciation of art and culture, and placed a greater emphasis than others on the role of art and culture in their lives in general. Stage of education also made a difference, with reduced involvement in structured cultural activities during the Leaving Certificate year and after leaving school, as well as lower levels of reading and making music among those who have left school.

Cultural engagement was found to have longer-term benefits for young people, with frequent reading for pleasure and involvement in structured cultural activities at younger ages enhancing later cognitive development (as reflected in vocabulary test scores and Junior Certificate performance). Cultural engagement was not found to be closely related to non-cognitive skills, but clear evidence emerged on poor outcomes (such as lower levels of life satisfaction and greater socio-emotional difficulties) among those who spent a considerable amount of time playing computer games.

\subsection{Implications For Policy Development}

The importance of cultural engagement among children and young people has been given renewed policy emphasis with the Creative Ireland programme, one strand of which focuses on children and young people. As part of the programme, the pilot Creative Schools initiative has provided support for more than 450 schools to plan creative activities for their students. Other aspects include the piloting of Creative Schools clusters, the provision of professional development for teachers and the extension of Music Generation, which provides musical instrument tuition within and outside schools. These measures build upon a key aim in the broader current children's strategy, Better Outcomes, Brighter Futures, that 'children and young people are ... enjoying play, recreation, sports, arts, culture and nature' (DCYA, 2014, p. 4). GUI provides an important evidence base to inform policy development. In particular, the fact that patterns of engagement are found to be established in middle childhood and adolescence highlights the importance of early intervention to support young people's involvement in the arts and culture, broadly defined. At the same time, the significant decline in arts involvement between 13 and 17 years suggests a need to focus attention on bolstering engagement during this crucial phase. 
The very marked gender differences in engagement are established early and persist into adolescence and early adulthood. Indeed, previous research indicates that such gender differences in cultural activities are already apparent in early childhood (Smyth, 2016). Similarly, differences in cultural activities by family background emerge early and are relatively stable into adolescence. The findings point to the importance of challenging the construction of 'high' culture as the preserve of girls and those from more advantaged families. This is all the more important given the benefits of reading and involvement in structured cultural activities for cognitive development. Existing patterns of cultural engagement are likely to serve to reinforce social inequalities in educational outcomes.

School emerges as an important domain for access and exposure to the arts and culture. While it is understandable that schools seek to cater to their student population, there is a risk that the pattern of curricular and extracurricular provision across different types of school will serve to reinforce gender and social variation in access. Challenges are evident for smaller schools in providing access to the full range of cultural curricular and extracurricular experiences, suggesting the potential for cross-school cooperation in provision and/or for an enhanced role for community-based provision in some contexts. The findings point to much lower levels of take-up of Leaving Certificate music among the lowest-income groups (even taking account of social class and mother's education). This would appear to support the results of earlier research (for example, Moore, 2014), which points to the way in which doing well in music at Leaving Certificate and higher education level is highly dependent on access to (largely paid-for) out-of-school musical instrument tuition.

Taking part in the TY programme serves to promote cultural engagement and enhance the recognition of the value of art and culture among participants. This pattern undoubtedly reflects the way in which young people are afforded access to a range of cultural learning experiences during TY. However, given lower levels of participation in TY among more disadvantaged groups, there is potential to further reinforce social differentiation in engagement. At the time of writing, a review of senior cycle education is being conducted by the National Council for Curriculum and Assessment. Findings of the consultation process highlight the potential for greater flexibility to combine traditional subjects with short courses and/or modules (NCCA, 2019; Smyth et al., 2019). Short courses of this kind may provide a way to increase exposure to arts and culture for a broader variety of young people than those who wish to study art or music as a Leaving Certificate subject. In the consultation process, students, parents and teachers suggested the need to move away from exam-based assessment and to reduce the content of some subjects. Such changes may help to reduce the practice of young people curtailing their involvement in social (including cultural) activities in preparation for the Leaving Certificate exam, thus facilitating a better balance between formal and informal learning. 
The emphasis on extracurricular cultural provision in DEIS schools appears to have reduced the gap in involvement in structured activities and to have led to young people being more positive about the role of their schooling in their appreciation of art and culture than is the case for similar 17-year-olds attending other schools. In keeping with other research on the use of free time more generally (Smyth et al., 2011; Smyth et al., 2019), young people appear to constrain their involvement in cultural activities in the lead-up to the Leaving Certificate exams. Levels of cultural engagement are also lower among those who have left school. This may reflect the absence of access to school-based activities, but it should also be noted that this group of young people in the sample are more disadvantaged in other respects.

The timing of data collection sees young people on the brink of the transition to further/higher education and the labour market. Given the study findings on the importance of earlier cultural involvement, it is likely that, without appropriate policy supports, the pattern established by 17 years of age will set the tone for cultural engagement in adult life, reinforcing the notion of 'high' culture as an arena for more advantaged groups. 


\section{References}

Arts Council (2018). Attendance, participation and engagement with the arts in Ireland 2018: A national survey, Dublin: Arts Council.

Bodovski, K. and G. Farkas (2008). '“Concerted cultivation” and unequal achievement in elementary school', Social Science Research, Vol. 37, No. 3, pp. 903-919.

Broh, B.A. (2002). 'Linking extracurricular programming to academic achievement: Who benefits and why?', Sociology of Education, Vol. 75, pp. 69-96.

Chan, T.W. and J.H. Goldthorpe (2005). 'The social stratification of theatre, dance and cinema attendance', Cultural Trends, Vol. 14, No. 3, pp.193-212.

Cheadle, J.E and P.R. Amato (2010). 'A quantitative assessment of Lareau's qualitative conclusions about class, race and parenting', Journal of Family Issues, Vol. 32, No. 5, pp. 679-706.

Christin, A. (2012). 'Gender and highbrow cultural participation in the United States', Poetics, Vol. 40, No. 5, 423-443.

Covay, E. and W. Carbonaro (2010). 'After the bell: Participation in extracurricular activities, classroom behavior, and academic achievement', Sociology of Education, 83, No.1, pp. 20-45.

Department of Children and Youth Affairs (2014). Better outcomes, brighter futures, Dublin: DCYA.

Department of Children and Youth Affairs (2018). LGBTI+ national youth strategy, Dublin: DCYA.

Department of Education and Skills (2013). Arts in education charter, Dublin: DES.

Dumais, S.A. (2019). 'The cultural practices of first-generation college graduates: The role of childhood cultural exposure', Poetics, Vol. 77, in press.

Dumais, S.A. and A. Ward (2010). 'Cultural capital and first-generation college success' Poetics, Vol. 38, No. 3, pp. 245-265.

Edwards, S. (2014). 'Towards contemporary play: Sociocultural theory and the digitalconsumerist context', Journal of Early Childhood Research, Vol.12, No. 3, pp. 219-233. 
Erikson, R. (1984). 'Social class of men, women and families', Sociology, Vol. 18, No. 4, pp. 500-514.

Fredericks, J.A. and J.S. Eccles (1996). 'Is extracurricular participation associated with beneficial outcomes? Concurrent and longitudinal relations', Developmental Psychology, Vol. 42, No. 4, pp. 698-713.

Hallam, S. (2010). 'The power of music: Its impact on the intellectual, social and personal development of children and young people', International Journal of Music Education, Vol. 28, No. 3, pp. 269-289.

Harland, J., K. Kinder and K. Hartley (1995). Arts in their view: A study of youth participation in the arts, Slough: NFER.

Johnsson-Smaragdi, U. and A. Jönsson (2006). 'Book reading in leisure time: Longterm changes in young peoples' book reading habits', Scandinavian Journal of Educational Research, Vol. 50, No. 5, pp. 519-540.

Kloosterman, R., N. Notten, J. Tolsma and G. Kraaykamp (2011). 'The effects of parental reading socialization and early school involvement on children's academic performance: A panel study of primary school pupils in the Netherlands', European Sociological Review, Vol. 27, No. 3, pp. 291-306.

Kraaykamp, G. and K. Van Eijck (2010). 'The intergenerational reproduction of cultural capital: A threefold perspective', Social Forces, Vol. 89, No.1, pp. 209-231.

Lagaert, S., M. van Houtte and H. Roose (2017). 'Engendering culture: The relationship of gender identity and pressure for gender conformity with adolescents' interests in the arts and literature', Sex Roles, Vol. 77, No. 7-8, pp. 482-495.

Lareau, A. 2003. Unequal childhoods: Class, race and family life, Berkeley: University of California Press.

Lehman, B. and S.A. Dumais (2017). 'Feminization of arts participation and extracurricular activities? Gender differences in cultural capital and bullying victimization', Poetics, Vol. 61, pp. 26-38.

Lunn, P. and E. Kelly (2008). In the frame or out of the picture. A statistical analysis of public involvement in the arts, Dublin: NESF.

Lunn, P., E. Kelly and N. Fitzpatrick (2013). Keeping them in the game: Taking up and dropping out of sport and exercise in Ireland, Dublin: ESRI. 
Mak, H.W. and D. Fancourt (2019a). 'Longitudinal associations between ability in arts activities, behavioural difficulties and self-esteem: Analyses from the 1970 British Cohort Study', Scientific Reports, No. 9 (available online).

Mak, H.W. and D. Fancourt (2019b). 'Arts engagement and self-esteem in children: Results from a propensity score matching analysis', Annals of the New York Academy of Sciences, No. 1-10 (available online).

Marsh, J., G. Brooks, J. Hughes, L. Ritchie, S. Roberts and K. Wright (2005). Digital beginnings: Young children's use of popular culture, media and new technologies, Sheffield: University of Sheffield.

Martin, A.J., M. Mansour, M. Anderson, R. Gibson, G.A. Liem and D. Sudmalis (2013). 'The role of arts participation in students' academic and nonacademic outcomes: A longitudinal study of school, home, and community factors', Journal of Educational Psychology, Vol. 105, No. 3, pp. 709.

Metsäpelto, R.L. and L. Pulkkinen (2012). ‘Socioemotional behavior and school achievement in relation to extracurricular activity participation in middle childhood; Scandinavian Journal of Educational Research, Vol. 56, No. 2, pp.167-182.

Moore, G. (2014). 'Mind the gap: Privileging epistemic access to knowledge in the transition from Leaving Certificate music to higher education', Irish Educational Studies, Vol. 33, No. 3, pp. 249-268.

Murphy, D., J. Williams, A. Murray and E. Smyth (forthcoming). Growing Up in Ireland: Design, instrumentation and procedures for Cohort ' 98 (Child Cohort) at 17/18 years of age, Dublin: DCYA.

Nagel, I. (2010). 'Cultural participation between the ages of 14 and 24: intergenerational transmission or cultural mobility?', European Sociological Review, Vol. 26, No. 5, pp. 541-556.

Nagel, I. and M. Verboord (2012). 'Reading behaviour from adolescence to early adulthood: A panel study of the impact of family and education on reading fiction books', Acta Sociologica, Vol. 55, No. 4, pp. 351-365.

National Council for Curriculum and Assessment (2019). Senior cycle review: Consultation document, Dublin: NCCA.

Robinson, K. (1999). All our futures: creativity, culture and education, London: National Advisory Committee on Creative and Cultural Education. 
Schmutz, V., E Stearns and E.J. Glennie (2016). 'Cultural capital formation in adolescence: High schools and the gender gap in arts activity participation', Poetics, Vol. 57, pp. 27-39.

See, B.H. and D. Kokotsaki (2015). Impact of arts education on the cognitive and non-cognitive outcomes of school-aged children. A review of evidence, Durham: Education Endowment Foundation.

Sherer, M., J.E. Maddux, B. Mercandante, S. Prentice-Dunn, B. Jacobs and R.W. Rogers (1982). 'The self-efficacy scale: Construction and validation', Psychological Reports, Vol. 51, No. 2, pp. 663-671.

Smyth, E. (2016). Arts and cultural participation among children and young people: Insights from the Growing Up in Ireland study, Dublin: ESRI/Arts Council.

Smyth, E., J. Banks, E. Calvert (2011). From Leaving Certificate to leaving school: A longitudinal study of sixth year students, Dublin: Liffey Press.

Smyth, E., S. McCoy and J. Banks (2019). Student, teacher and parent perspectives on senior cycle education, Dublin: ESRI.

Sullivan, A. and M. Brown (2013). Social inequalities in cognitive scores at age 16: The role of reading, London: Institute of Education.

van Schooten, E., K. de Glopper and R.D. Stoel (2004). 'Development of attitude toward reading adolescent literature and literary reading behavior', Poetics, Vol. 32, No. 5, pp. 343-386.

Warner, C.H. and M.A. Milkie (2015). 'Cultivating gendered talents? The intersection of race, class, and gender in the concerted cultivation of U.S. elementary students. Notions of family: Intersectional perspectives', Advances in Gender Research, Vol. 17, pp. 1-27. 
